Portland State University

PDXScholar

1981

\title{
Work personality as a factor in evaluating the work potential of the mentally retarded
}

Janet L. Scally

Portland State University

Follow this and additional works at: https://pdxscholar.library.pdx.edu/open_access_etds

Part of the Cognitive Psychology Commons, and the Mental and Social Health Commons Let us know how access to this document benefits you.

\section{Recommended Citation}

Scally, Janet L., "Work personality as a factor in evaluating the work potential of the mentally retarded" (1981). Dissertations and Theses. Paper 3162.

https://doi.org/10.15760/etd.3154

This Thesis is brought to you for free and open access. It has been accepted for inclusion in Dissertations and Theses by an authorized administrator of PDXScholar. Please contact us if we can make this document more accessible: pdxscholar@pdx.edu. 
AN ABSTRACT OF THE THESIS OF Janet L. Scally for the Master of Science in Psychology presented July 21, 1981.

Title: Work Personality as a Factor in Evaluating the Work Potential of the Mentally Retarded.

APPROVED BY MEMBERS OF THE THESIS COMMITTEE:

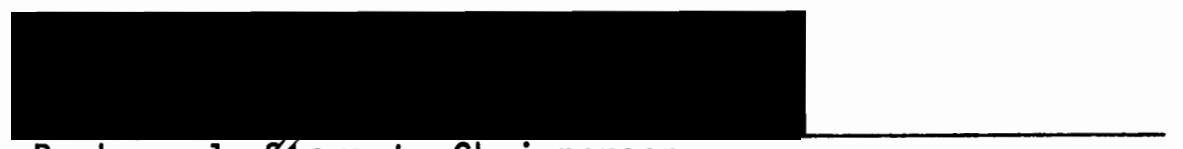

Barbara J. Stewart, Chairperson
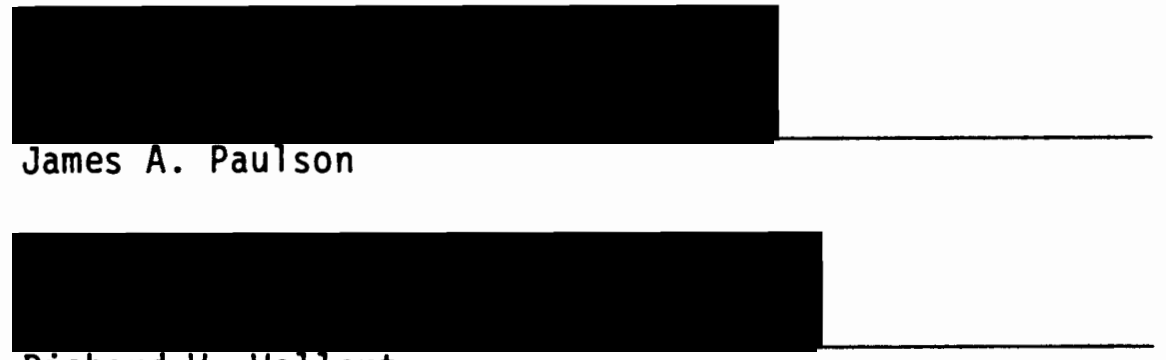

Richard W. Wollert

This thesis focused on the development of a Work Personality Scale and the systematic study of how this aspect of the mentally retarded person is related to his or her intelligence and dexterity skill level.

The rationale for the proposed study was based upon the following three premises which have evolved from an examination of previous research.

1. Work behavior is an important variables in assessing the work potential of the mentally retarded.

2. Presently, the instruments available for assessing work potential have not been adequately standardized with the noninstitutionalized 
mentally retarded population or validated for the purpose of predicting vocational potential.

3. It remains unclear how work personality, dexterity, and IQ are related and to what degree each influences the level of vocational adjustment attained by the mentally retarded individual.

\section{Phase One}

Rater reliability of the 44 items in the research version of the Work Personality Scale was determined. Of these 44 items, 27 items had acceptable rater reliability. These 27 items were then factor analyzed using a sample size of 75 . The results of the factor analysis were used in the construction of four Work Personality Subscales. Rater reliability, test-retest reliability, and internal consistency reliability of the subscales were also examined. The following hypothesis was tested.

Hypothesis I. The common factors underlying the Work Personality Scale items are: (1) motivation, (2) work habits, (3) work relationships, and (4) presence of maladaptive behaviors. The items within each subscale were examined to determine their conceptual relationship and the following subscale titles were devised: Subscale 1: Independence and appropriate work habits; Subscale 2: Absence of attentiongetting behaviors; Subscale 3: Responsibility regarding attendance; and Subscale 4: Appropriateness of interpersonal skills. Regarding Hypothesis I, it appears that Subscale 1 reflects both motivation and work habits, Subscale 2 measures work relationships and presence of interfering behaviors, Subscale 3 measures work habits, and Subscale 4 reflects both work relationships and presence of maladaptive behaviors. 
Rater reliabilities of the subscales ranged from .46 to .85 , testretest reliabilities of the subscales ranged from .77 to .95 and internal consistency reliabilities of the subscales ranged from .61 to .94 .

\section{Phase Two}

The interrelationships among work personality, IQ, and dexterity were analyzed using correlational procedures. Data on 44 subjects were collected. The variables investigated included the WAIS full scale IQ, Purdue Pegboard (right hand, left hand, both hands, and assembly), and Work Personality factor-based scores (Subscales 1-4) and single items $(3,19,24,25$, and 41). The following hypotheses were tested.

Hypothesis II. The correlations between Work Personality factorbased subscale scores and the remaining variables (WAIS full scale IQ, and Purdue subscale scores) are low and positive.

The results indicate that WAIS and Purdue scores are uncorrelated with Work Personality scores with the exception of Work Personality Subscale 1. The average correlation of the Work Personality Subscales with the WAIS is .18 and with the Purdue subtests is .06 .

Hypothesis III. The correlations between WAIS full scale IQ and the Purdue subscale scores are positive and greater than the correlations of the Work Personality Subscales with either the WAIS or Purdue.

It appears that although the average correlation between the WAIS and Purdue is positive, it is not significantly greater than the average correlations of either the WAIS or Purdue with the Work Personality Subscales. 
WORK PERSONALITY AS A FACTOR IN EVALUATING THE WORK POTENTIAL OF THE MENTALLY RETARDED

by

JANET L. SCALLY

A thesis submitted in partial fulfillment of the requirements for the degree of

\author{
MASTER OF SCIENCE \\ in \\ PSYCHOLOGY
}

Portland State University 


\section{TO THE OFFICE OF GRADUATE STUDIES AND RESEARCH:}

The members of the Committee approve the thes is of Janet $L$. Scally presented July $21,1981$.
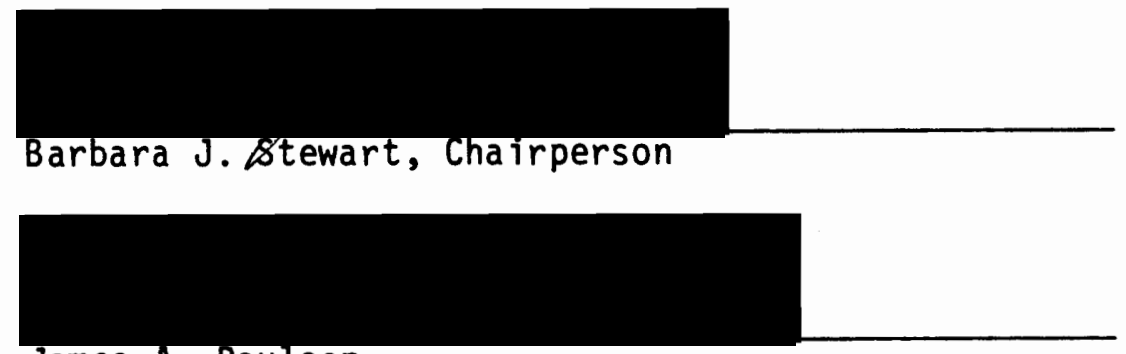

James A. Paulson

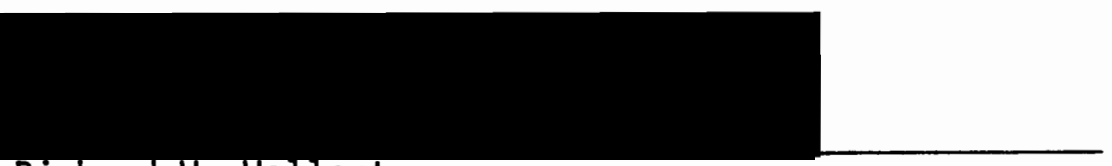

Richard W. Wollert

APPROVED :

Robert E. Johes, Head, Departiment of P'sychology

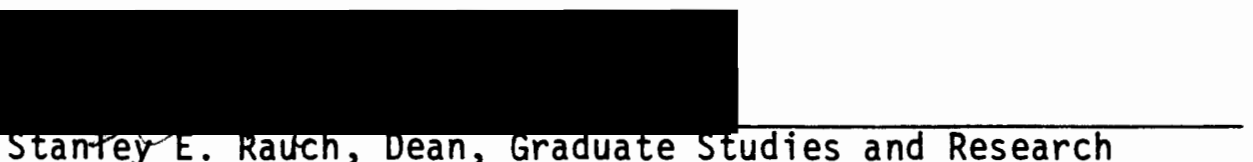

StanteyE. Rauch, Dean, Graduate Studies and Research 
TABLE OF CONTENTS

PAGE

LIST OF TABLES ............................... v

LIST OF FIGURES. ............................. vi

CHAPTER

I PROBLEM ............................. 1

II REVIEW OF THE LITERATURE. ............ 7

Work Personality. . . . . . . . . 7

Manual Dexterity. ............ 14

Intelligence. . . . . . . . . . 18

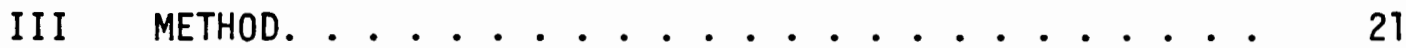

Subjects............... . . 21

Instruments ............. . . 21

Procedure for Development of the Research Version of Work Personality Scale......... 23

Statistical Analys is in Scale Development. . . 40

IV RESULTS ....................... 45

Rater Reliability of the Work Personality

Scale Items ............. 45

Factor Analyses and Formation of Subscales. . . 45

Rater, Test-Retest, and Internal Consistency

Reliability for the Work Personality Subscales. .

Frequency Distributions and Descriptive

Statistics for the Work Personality Subscales. . 
CHAPTER

Correlation of the Work Personality Scale with WAIS and Purdue..............

$\checkmark$ DISCUSSION. . . . . . . . . . . . . . .

BIBLIOGRAPHY . . . . . . . . . . . . . . . . . . . .

APPENDICES

I Behavioral Sketch ................

II Instructions Provided to Raters for Scoring Scale Items ... . . . . . . . . . 69

III Operational Definttions of Interfering Behaviors. . . 72

IV Tables.................... . . . 76 


\section{LIST OF TABLES}

TABLE

PAGE

I Rater Reliability, Test-Retest Reliability, and

Internal Consistency Reliability for Final

Subscales and Items. . . . . . . . . . . . . 46

II Factor Loadings for Each Item Using 5- and

9-Point Formats. . . . . . . . . . . . .

II List of Final Subscales with Factor Loadings and

of Items to be Used as Single-Item Measures. . . . 


\section{LIST OF FIGURES}

FIGURE

PAGE

1. Original Work Personality Scale Items. . . . . . 25

2. Work Personality Scale............ 26 
CHAPTER I

\section{PROBLEM}

This study is an outgrowth of my experience in working with mentally retarded adults, both in an institutional setting and in a vocational rehabilitation center. As an instructor of institutionalized profoundly and severely retarded adults, my primary task was to eliminate those behaviors which made learning difficult, if not impossible, (i.e., hitting, biting, rocking), and to develop in their place new behaviors which are conducive to learning (i.e., sitting, attending, awareness of surroundings). I found that for those individuals who did learn to control their behavior and attend to outside stimuli, the rate of learning and level of skill attained increased significantly. Many began to learn skills not thought possible for a profoundly retarded adult, such as carrying out a three-step command, and a few of these individuals later became involved in workshop training conducted away from their home unit. This experience served to shift my attention away from absolute values of IQ and toward actual behavior when attempting to assess the success of the mentally retarded in learning a skill and adapting to new situations and demands.

In addition, through my observations of the hospital workshop, I became aware of what the mentally retarded were able to accomplish when adequate training was provided. Profoundly and severely retarded 
adults had been trained to perform simple assembly and sorting tasks in a structured work setting for periods of up to four hours. However, these same individuals, when back on their home units, continued to need assistance in their daily living activities. Expectations in terms of performance and intensity of training seemed to be the primary factors which differentiated between the home and work environment.

My experience in a community based vocational rehabilitation agency further supported my previous observations and provided the final impetus which led to the present study. With the needs of the mentally retarded in mind, I was asked at this agency to assess the Work Evaluation Program. The observations I made and the concerns which resulted from my assessment of the program were as follows:

1. Work potential was being assessed using a standard battery of tests, the same battery used to evaluate clients of average and above average intellect.

2. Evaluation, using standardized tests, took approximately six hours to complete but little of the resulting data was helpful in developing programs or determining eventual success. For example, the Geist Interest Inventory was used to assess the interests of the mentally retarded. However, many of the interest areas identified by this inventory require higher verbal and/or performance skills than the mentally retarded typically possess. Consequently, following through on these interest areas is frequently not feasible in terms of eventual job placement.

3. Work habits, work attitudes, and work behaviors were not systematically assessed. Instead, specific behavior problems were 
noted and included as part of each trainee's program. In addition, the observation and evaluation of behavior was subjective and open to observer bias and prejudice.

4. For the mentally retarded, determining vocational potential was often a matter of intuition, largely based upon the individual's behavior or self-presentation.

5. Work evaluation theoretically was a five-week program but many times a final determination of placement for the mentaliy retarded was extended by placing the individual in a Work Adjustment Program. Once placed into this setting without definite directives, such persons frequently ceased to be attended to with the intensity that would have been required to insure higher placement. Instead, these individuals often continued on in the sheltered workshop environment, not reaching the potential they may have been capable of.

Influenced by these prior experiences and prompted by a desire to develop a more effective means for evaluating the work potential of the mentally retarded, I began an investigation of the available resources for evaluating the potential of the mentaliy retarded and examined the findings of related research. This investigation led to the development of the research study presented here.

Assessing vocational potential pertains to determining what type of work can maximally be expected from an individual. For the mentally retarded, vocational potential refers to establishing the optimum level of employment that he/she will be capable of attaining. Presently, there are three basic levels of employment which are available to the mentally retarded: (1) competitive employment, 
(2) employment within a workshop environment, and (3) employment in a Work Activities Center. Each of these levels, in general terms, reflects the amount of supervision and treatment provided to the person. In a competitive situation, the trainee is expected to function independently, requiring a minimum of supervision or guidance. The trainee placed in a workshop requires a moderate amount of supervision, but can be expected to work for the duration of a six hour day. Finally, the trainee who is placed in a Work Activities Center is considered capable of functioning in a work environment for short periods of time (30-45 minute periods) with a maximum amount of supervision. The Work Activities Program extends beyond work skills instruction and encompasses home-living and perceptual-motor skill development.

Virtually all mentally handicapped individuals who are seeking employment are referred by the State Department of Vocational Rehabilitation to a private rehabilitation agency for training. Approximately 15 percent of those who are referred to these agencies are mentally retarded, the level of retardation ranging from an IQ of 49 to an IQ of 79. Prior to being placed in one of the three above mentioned settings, each person enters into an evaluation program which normally lasts for five weeks. The vocational evaluator assesses each incoming client to recommend which of the three placement levels would be most appropriate and then makes suggestions, specifying the necessary training or treatment needs.

Once evaluation has been completed the mentally retarded client ordinarily is not directly placed into the setting which has been identified as the most appropriate. Instead, this person is normally 
referred to Work Adjustment Training where he/she receives supplemental training. Work Adjustment Training, a six-month program, uses work, the work environment, work relationships, and supportive services to help the trainee develop more effective work habits, attitudes and behaviors. Upon completion of this training, the mentally retarded client is placed in one of the three work environments which best suits his needs and capabilities at that time.

As a general rule, the procedures and instruments utilized in the evaluation of the mentally retarded have essentially been the same as those used in evaluating the intellectually normal. It has generally been assumed that the problems and factors affecting the mentally retarded were similar to those of the non-handicapped population. However, the merit of such a generalization appears to be questionable for two basic reasons. First, the utility of standardized dexterity and ability tests is limited because of the problems produced by the restricted range of scores. This narrow range of scores does not allow one to make discriminations among scores that would be of practical value. Secondly, the majority of jobs secured by the mentally retarded demand a minimum of intellectual abilities, depending to a great extent on simple repetitive motor movement; hence, the practicality of identifying the minimum intelligence or dexterity levels is of limited value. Studies attempting to relate dexterity and IQ to workshop productivity have failed to isolate a measure that could reliably be used in predicting future vocational success. This is not to say that evaluation of the mentally retarded is pointless but what it does suggest is that another aspect of the person should be considered. 
It is proposed in this thesis that what needs to be considered is not only the intellectual level or dexterity skill but also the individual's ability to adapt to the work environment. Adaptation to the work environment is reflected in the individual's "work personality" and is comprised of his/her: (1) work attitudes, (2) habits, (3) motivation, and (4) the absence of maladaptive behaviors. Possession of these behaviors is necessary to insure effective adaptation to the work environment. The relationship between this aspect and vocational potential is an issue which has been widely discussed but has only recently become the focus of empirical research. While numerous articles have stressed the importance of work personality characteristics (Cohen, 1960; Hartzler, 1951; Michael-Smith, 1960; Windle, 1962), few have attempted to develop and validate a device which would permit systematic assessment of this aspect. 
CHAPTER II

\section{REVIEW OF THE LITERATURE}

A review of the literature reveals that research concerning evaluation of the mentally retarded has passed through three stages. During each of these stages, research focused upon the identification and validation of the aspect which was believed to be the best index for evaluating the vocational potential of the retarded individual. Initially, intelligence level was thought to be the most important variable in determining placement potential and research concentrated on relating specific job tasks with the necessary minimum IQ. Then, as placement of the mentally retarded in the community and workshops increased, it became clear that the majority of the jobs secured by this population involved repetitive visual-motor movements. Consequently, the focus of research shifted to measures of manual dexterity. Finally, and most recently, the adaptive level and personal adjustment of the mentally retarded has come into focus. Research in this area has attempted to demonstrate that work potential of the mentally retarded can best be predicted on the basis of work attitudes, behavior, and overall adjustment to daily demands and expectations.

\section{Work Personality}

The adaptive, or adjustment level of the mentally retarded has recefved relatively little attention in empirical studies. In spite of this, it is generally agreed by those writing in the field of vocational 
evaluation that, given a person with the minimum acceptable mental ability for performing simple work tasks (IQ between 25-40), factors such as place of employment (competitive vs. workshop), amount of wages, and length of employment seem to be more dependent on effective personality adjustment rather than on higher intelligence or dexterity levels (Cohen, 1963; Patterson, 1964; and Gellman, 1968).

The few studies that have attempted to relate specific personality measures to work characteristics of the mentally retarded have focused primarily on the American Association of Mental Deficiency (AAMD) Adaptive Behavior Scale. Following is a review of the Adaptive Behavior Scale, including an examination of the studies which have attempted to apply it in a workshop setting.

The AAMD Adaptive Behavior Scale (Nihira, Foster, Shellhaas, \& Leland, 1975) was developed in 1969 for the purpose of identifying deficiencies and subsequent program needs for the institutionalized mentally retarded. The scale is designed to provide objective descriptions and evaluations of an individual's adaptive behavior.

The scale consists of two parts. Part I is organized along developmental lines and is designed to evaluate an individual's skills and habits in ten behavioral domains. A sample of the areas covered in this part are: (1) independent functioning, (2) physical development, (3) economic activity, and (4) language and development. Part II of the scale consists of 14 domains and is designed to provide measures of maladaptive behavior related to personality and behavior disorders. Included in this part are: (1) violent and destructive behaviors, (2) self-abusive behaviors, and ( 3 ) sexually aberrant behaviors. 
The scale data are based on behaviors which can be observed and it is advised in the instruction Manual (Fogelman, 1975) that scale information be obtained from the person who spends the "greatest number of waking hours" (Fogelman, 1975, p. 9) with the individual who is being assessed. The manual further specifies that it will be necessary to acquire information from those who live with the person being rated. Once the form is completed the raw scores can be interpreted by comparing the scores with a normative sample of institutionalized residents of similar age. The resulting percentile ranks can then be plotted on a summary profile sheet, providing the rater with a visual profile of an individual in relation to the norm of retarded people in institutions. Reported interrater reliabilities for Part I range from .71 to .92 with a mean reliability of .86 . Part II reliabilities, however, are not as impressive and range from .37 to .69 with a mean reliability of .57. No validity information is available in the 1975 manual revision, but the authors do mention two studies which they believe provide evidence as to the scale's discriminant validity. Both of these studies focused upon the scale's value in discriminating between groups within an institution (Leland, Shellhaas, Nihira, \& Foster, 1967; Greenwood \& Perry, 1968).

The Adaptive Behavior Scale is generally accepted as a valid assessment device within an institutional setting, but as of yet, its utility has not been demonstrated outside this domain. One of the premises of this study is that the utility of the scale in noninstitutional settings will always be limited for several reasons. First, the scale is designed to assess the behavior of institutionalized 
residents and, consequently, many of the scale items are simply not suited for the population encountered in a rehabilitation center. For example, "making loud noises while others are reading" or "running away from hospital grounds" are behaviors which would not likely be observed. Secondly, the scale cannot reliably be completed through observations made at a workshop center and very often there is no one available who could provide accurate information concerning the trainee's home or daily living skills. Guarnacia (1976) reported interrater reliabilities as low as .42 for Part I domain scores, when clients were rated by their counselors.

A third limitation is that the scale is not sensitive enough to reflect monthly change as a result of training. In the Adaptive Behavior Scale, vocational activity is assessed through three dichotomous items which are scored on the basis of whether or not the desired behavior is present. The use of these dichotomous (yes-no) items rather than a several point response continuum (e.g., always, usually, sometimes, rarely, never) essentially precludes the detection of change in the trainee's behavior.

Finally, the relationship between the possession of the necessary daily living skills as measured by the Adaptive Behavior Scale and vocational potential has not been documented. Because the workshop setting is a stable one with expectations and demands that vary little from day to day, mentally retarded individuals often have less difficulty in this situation than they do when they encounter the ever changing demands beyond their work world. Therefore, it is possible that a retarded person may not be able to "read a book," "order food in a restaurant" or "buy his/her own clothes" and yet, if provided with 
adequate training, may function quite well in a competitive work situation.

Since the AAMD Adaptive Behavior Scale is the only adjustmentlike measure which has been empirically studied, those studies focusing on the instrument have been reviewed. In the earliest published study, Nihira (1969) examined the factor structure of both Part I and II of the scale using 919 institutionalized retarded adults. His analysis found that the scale factored out into three major dimensions: personal independence, (2) social maladaptation, and (3) personal maladaptation. However, the fact that his subjects were institutionalized, limits the applicability of his findings to the population presently being considered.

In another study which partially replicates Nihira's, 40 noninstitutionalized adults were selected. In this study, Guarnaccia (1976) analyzed the ten domains of Part I of the scale and an independent measure of productivity. His factor analys is yielded four main factors, one of which was also identified by Nihira. These factors were: (1) personal independence, (2) personal responsibility, (3) productivity, and (4) social responsibility. Guarnaccia also examined the relative contribution of the four predictor variables--age, sex, verbal IQ and maternal trust--to the four factors of adaptive function. The most noteworthy aspect of this analysis was the failure of the predictor IQ to contribute to the variance of factor 3, productivity. A primary weakness of Guarnaccia's conclusions was in the size of the sample used. Because the factor analysis was based on a sample size of 40 , the results must be interpreted and applied to the present study with caution. 
A third study designed to examine the Adaptive Behavior Scale within a workshop setting was conducted by Cunningham and Presnall (1978). Using a sample of 217 retarded adults, a factor analys is was performed on the 24 domains of both Part I and Part II. The seven dimensions that were found were than analyzed to determine how well they could predict productivity in a workshop setting. A stepwise regression analysis yielded a significant regression effect in which the factors of personal independence and social maladaptation accounted for $25 \%$ of the variance in salary.

The sample size used in the Cunningham and Presnall (1978) study was adequate; however, the application of the findings to the present study is 1 imited for the following reasons. First, the authors identified a major flaw in their design which seriously confound the results of the regression analysis. The work-area supervisors who were influential in determining salary also had the responsibility of rating the subjects. The possibility of rater bias affecting the outcome is quite likely, and as suggested by the authors, the study needs to be replicated.

A second weakness is one which is common to most studies designed to determine the factors which predict vocational potential. The problem is in regard to the selection of the criterion to represent potential. The position of the present study is that neither workshop wages nor productivity are realistic indices of work potential. In research studies, these criterion measures are typically obtained under close supervision with an inordinate amount of structure and surrounded with an aura of importance normally lacking in the real-life 
situation; the resulting measures usually grossiy overestimate the trainee's overall work productivity. Wages received in the workshop are directly related to rate of productivity and most mentally retarded clients quickly learn to work at their maximum level when productivity counts are taken, only to revert back to old habits and levels of activity when the stopwatch clicks off. It is proposed that research should utilize a criterion measure which more suitably will reflect how successful the mentally retarded client has been. A possible alternative criterion is the level of placement that the client attains upon completion of training rather that the client's productivity measured under the conditions specified above.

A final weakness of Cunningham and Presnall's (1978) study lies in what appears to be a contradiction between the stated purpose and the study design. The authors' desire, as stated in their introduction, was to examine how well the Adaptive Behavior Scale could predict vocational success using workshop productivity as the criterion. The design of the study dictates the selection of Work Activities clients. This specification severely restricts the scope of the examination as Work Activities is generally considered the lowest placement for the retarded population and is generally non-transitory in terms of work placement .

More recently, Spreat (1980) has continued in the effort to validate the Adaptive Behavior Scale. Spreat compared the work behavior of two groups, one group of institutionalized retarded adults and one group of formerly institutionalized retarded adults, and found that prediction of group membership could be made on the basis of Adaptive 
Behavior Scale scores. Although his findings may help provide additional support for the discriminant validity of the Adaptive Behavior Scale, they are of little significance in terms of providing meaningfur information regarding the work performance of mentally retarded in a workshop setting. The present study focused on the development of a scale that will allow for the assessment of each trainee's work personality.

Primarily due to the lack of an adequate measuring device, the significance of work personality in assessing the work potential of the mentally retarded remains uncertain. The AAMD Adaptive Behavior Scale does not appear to be applicable for this purpose and, consequently, the primary intent of the present study is to develop a scale that will allow for the quantitative analysis of work personality. With the aid of this scale, the first objective of the current study is to determine the extent to which work personality describes an aspect of the retarded person which is distinct both from dexterity skill and intelligence.

Work personality is presently viewed as the most promising predictor of work potential for the mentally retarded. However, the relative value of dexterity skill and IQ in predicting this same potential has clearly not been fully determined. Because the three factors of work personality, dexterity, and IQ are potentially useful in predicting placement level, an exploratory analysis of their interrelationship is included in this study. A number of studies thought pertinent to this analysis have been reviewed.

\section{Manual Dexterity}

Prior to the identification of personal adjustment as an 
influential factor in assessing the work potential of the mentally retarded, dexterity skill had been viewed as the best predictor of vocational success. As previously noted, reliance on standardized dexterity tests logically ensued from the general recognition that the greatest job opportunities for this population were in fields which involved the use of the hands. However, a number of concerns regarding the use of such tests to determine the work potential of the mentally retarded have been expressed. Patterson, in a 1964 critique of the major assessment techniques in use with the mentally retarded population, enumerated the four major concerns as follows:

1. The apparatus or materials used in these tests have not been adequately standardized; thus, it cannot be fully determined how much one's results are influenced by a particular piece of apparatus.

2. These tests have been standardized and validated without exception on adults of average intelligence and to date this remains true.

3. The majority of tests have only face validity. The Minnesota Rate of Manipulation and the Crawford's Small Parts Test, two tests commonly used with the retarded population, have not been empirically validated and, consequently, their predictive value with this population remains unanswered.

4. These tests may be misleading and limiting as indicated by data which suggest that when practice is taken into account, the mentally retarded person is capable of producing at a level which far exceeds that which would be expected on the basis of dexterity tests alone (Gold, 1973; Tate, 1967). 
A wealth of both criticism and support exists in regard to the use of dexterity tests with the mentally retarded but again very little data concerned with determining their predictive value can be found in the literature. Two studies which have examined the predictive validity of a number of standardized dexterity tests will be presented here. Elkin (1968), in the first of two experiments, attempted to validate 21 variables in predicting the performance of 59 educable retardates on an experimental job in a workshop setting. The predictor variables included four aptitude ratings, ten dexterity ratings, and two observational ratings assessing behavior and work habits. Significant correlations with performance were found for 16 predictors for males and 19 predictors for females. The better workers (better in terms of productivity) were characterized by higher intelligence, better psychomotor skills, and superior performance on work samples.

In the second of Elkin's experiments, eight measures which demonstrated predictive significance in Experiment One, were reassessed to determine their relationship with performance in a community setting. Only one measure, the $0^{\prime}$ Connor Finger Dexterity test, was found to be significantly related to performance on domestic jobs, a result which failed to confirm the usefulness of the 16 predictors identified in Experiment One.

Elkin proposed that the discrepancy between the results of the two experiments was a function of poor selection techniques and inadequacies of the scales used to assess performance on the domestic job. However, a possible alternate explanation may be that the disparity was a function of the criterion employed in the two experiments. In 
Experiment One, productivity (number of units completed in the allotted time) served as the criterion while job evaluation and work assessment (behavioral ratings) were the criterion measures in Experiment Two. If the results are analyzed with the above distinction in mind then in actuality the results are not contradictory. Instead, it may be postulated that standardized tests are of value in predicting at least one aspect of work performance, productivity, but do not appear to be sufficient in assessing the mentally retarded's overall work performance in non-workshop settings. It is asserted in the present study that overall work performance can best be predicted by directly examining and rating the criterion characteristics identified by Elkin in a simulated work environment.

An examination of the Purdue Pegboard in predicting productivity of the mentally retarded was conducted by Tobias and Gorelick in 1960. The Purdue Pegboard scores were found to be related to a variety of production tasks, including ballpoint pen assembly $(\underline{r}=.79)$ and wire clamp assembly $(\underline{r}=.75)$. The authors also found the Purdue Pegboard to be a valid predictor of performance on a variety of standardized work samples $(\underline{r}=.71)$.

These results demonstrate that the Purdue Pegboard appears to be useful in predicting the productivity of the retarded but again the question is raised as to the generalizability of such a prediction. Afterall, what is the value of knowing the retarded individual's dexterity level in determining overall performance in a community placement? Before this question can be answered research will need to be directed towards identifying the relative contribution of dexterity 
skill in the work success of the mentally retarded.

\section{Intelligence}

In the early 1900's intelligence was thought to be the best index for predicting the vocational aptitude of the mentally retarded. The dependence on this single aspect appears to have resulted primarily because so little was known about the mentally retarded individual other than he was of inferior intelligence. Unfortunately, there is little information regarding the relevance of this measure in predicting the vocational success of the mentally retarded and what does exist in the literature suggests that intelligence is at best of limited value in the evaluation of this population.

As early as 1917, research directed toward determining the relationship between IQ and work success suggested that IQ was not as important as previously believed (Anderson, 1917; Ordahl, 1919). In 1922, Cowdery examined the relationship between IQ and 22 different trade occupations using a sample of 578 boys with IQ's ranging from 45 to 129. On the basis of degree of correlation between IQ and performance, he classified the trades into the following three divisions: (1) the positive type, (2) the neutral type, and (3) the negative type. The negative type classification was comprised of those trades which were best performed by the mentally retarded. Cowdery suggested that for persons of low intelligence there is a need for the careful study and analysis of other factors which will influence work success.

More recently, research designed to examine this relationship has produced conflicting results. Gold (1973), Elkin (1968), and Patterson (1964) failed to find significant correlation between IQ and work 
performance in a workshop setting while Tobias and Gorelick (1960) and Thomas, Sprangler and Izutsu (1961) found moderately high correlations (.46 and .70 , respectively). A closer examination of these studies reveals that the disparity may largely be a result of procedural differences, the most weighty of these differences being the discrepancies between the amount of practice allotted prior to measuring productivity. In Gold's 1973 study, 20 mentally retarded subjects with IQ's ranging from 25 to 55 were intensively trained on an individual basis prior to measuring their level of productivity. Under these conditions, intelligence no longer appeared to be a contributing factor in productivity. However, in the Tobias and Gorelick study, productivity was measured following a relatively short practice period during which the individual's potential was not focused upon as it was in Gold's study. Here, differential rate of learning was not taken into account and, consequently, some subjects (those with lower IQ's) may not have adequately learned the task in the allotted practice time. Not surprisingly, differences in IQ were reflected in the rate of productivity.

For the purpose of evaluating the mentally retarded's work potential, it would seem more efficacious to de-emphasize IQ and concentrate on devising training procedures to enable these individuals to overcome learning deficiencies. However, determining how IQ relates to their overall ability to adapt to actual work expectations still remains to be answered.

Initially, the present study was designed to include an exploratory examination of the scales predictive validity regarding work placement levels. However, as the study progressed into the twelfth month, 
it became evident that the necessary sample size could not be obtained within the allotted time. Consequently, the present study has focused on the other three aspects: (1) scale development, (2) determination of reliability, and (3) comparison of the scale with IQ and dexterity. Subsequent validation studies will be necessary before such a scale can be deemed "valid" for the mentally retarded population. 


\section{CHAPTER III}

\section{METHOD}

\section{Subjects}

All subjects were active clients at St. Vincent dePaul Rehabilitation Center. St. Vincent dePaul Rehabilitation Center is similar to a large number of rehabilitation agencies in terms of the population and the services provided. Selection of subjects for the study was based solely on IQ, including all clients at the Center whose IQ ranged from approximately 49 to 79. An approximate total of 100 subjects was selected, although not all subjects were involved in all aspects of the study.

For the $\mathrm{N}=75$ sample used in the factor analysis, 38 subjects were female and 37 were male. Their ages ranged from 17 to 78 with an average age of 28 . IQ was determined for 44 of the subjects. Eight of these 44 subjects were moderately retarded (IQ: 40-54), 17 were mildly retarded (IQ: 55-69), and 17 were borderline retarded (IQ: 70-84). The average IQ for this sample was 62 . Twenty subjects from the 75 were used to obtain rater-reliability statistics and 15 subjects from the 75 were used to determine test-retest reliability.

\section{Instruments}

Purdue Pegboard. The Purdue Pegboard, developed for employment purposes, was used in this study to assess motor dexterity skills (Tiffin, 1968). This instrument is a time-limit test and takes 
approximately five minutes to complete. It consists of four parts: (1) insertion of pegs with right hand, (2) insertion with left hand, (3) insertion with both hands, and (4) assembly which requires the placement of a washer, collar, and another washer over each peg. The scores on all parts are based on the number of pegs inserted or assemblages completed in the time allotted. The raw scores for each of the four parts provided the data for analysis. Test-retest reliability for this test ranges from .82 to .91 .

Using the standardized method of administration, the researcher tested each subject individually and allowed the subject two practice trials on each part prior to the final scored trial.

Wechsler Adult Intelligence Scale (WAIS). The WAIS was selected for use in this study to obtain a measure of each subject's intelligence. This scale consists of six verbal subtests (information, comprehension, arithmetic, similarities, vocabulary and digit span) and five performance subtests, (picture arrangement, picture completion, block design, object assembly, and digit symbol). When scored, the scale provides a total IQ, Verbal IQ, Performance IQ, and eleven WAIS subscores. Reliability estimates for the three overall scores range from .93 to .97 and for the eleven subscales from .60 to .96 .

The scale was administered by the researcher in accordance with the WAIS Manual (Wechsler, 1955) in a quiet room free from interference and noise.

Work Personality Scale. The Work Personality Scale was used to allow for the systematic observation of subject behavior in a workshop setting. The scale consisted of 44 items, assessing the subject's: 
(1) interactions with supervisor, (2) interactions with peers, (3) work habits, and (4) work skills. Interrater and test-retest reliability were determined during the course of the study.

The scale was completed by the floor supervisors who were trained in its use. All ratings were to be completed at the end of the day, after client work hours, so as to discourage ratings based on immediate observations and to encourage the rater to consider each client's general performance over the past month. Each rating took approximately ten minutes to complete.

Procedure for Development of the Research Version of Work Personality Scale.

Introduction. The research version of the scale employed in the collection of data was developed from an original 1 ist of 49 items which were converted to a graphic format and then examined in a trial field study. A number of modifications were made in the first draft of the scale as a result of the trial field study and the training sessions which followed. These changes are reflected in the final draft of the 44-item research version of the Work Personality Scale.

Selection of Items. An initial list of 29 behavioral characteristics, believed to be related to placement potential, was generated from observations made by the researcher over a period of one year. This 1 ist was then reviewed by the job placement counselors at the Center, who suggested the addition of two items. Finally, a number of current scales (Krantz, 1971; Bitter \& Bolanovich, 1974) were consulted in an effort to uncover any additional items, previously identified as predicting job performance. Three new items were discovered bringing 
the total scale items to 34 (see Items 1-34, Figure 1).

One of these 34 items, interfering behaviors (i.e., autistic behaviors, rocking) had been found by the researcher to be especially critical in determining the potential for community placement. However, this rating would not have elaborated on the specific behavior comprising this characteristic. Consequently, a separate list of 15 specific interfering behaviors was compiled and attached to the original list of 34 items, bringing the total number of items to 49 (see Figure 1 for Items 35-49).

Conversion of Items to Graphic Format. The next phase of development involved converting the items into a graphic format. A combination 9-point, 5-1etter graphic scale devised by Sushan (1972), was employed (see Figure 2). Each item was headed by a brief definition of the variable which provided the rater with a point of reference. In addition, the two anchor points and midpoint of the continuum were cued with a description and examples of the qualifying behavior.

This rating procedure required the observer to rate each client in terms of his/her relative work performance by selecting the letter $A, B$, $C, D$, or $F(A$, positive/F, negative). If the $c l$ ient was performing at a "B" (good), "C" (fair), or "D" (poor) level, the rater then made a further discrimination by selecting the numerical value which best represented the client's performance. This particular format was selected because it was felt that the letter grade system would be more meaningful to the raters and, consequently, would result in the least amount of resistance. In addition, if it appeared that the raters were unable to make the finer discriminations required by the 9-point 

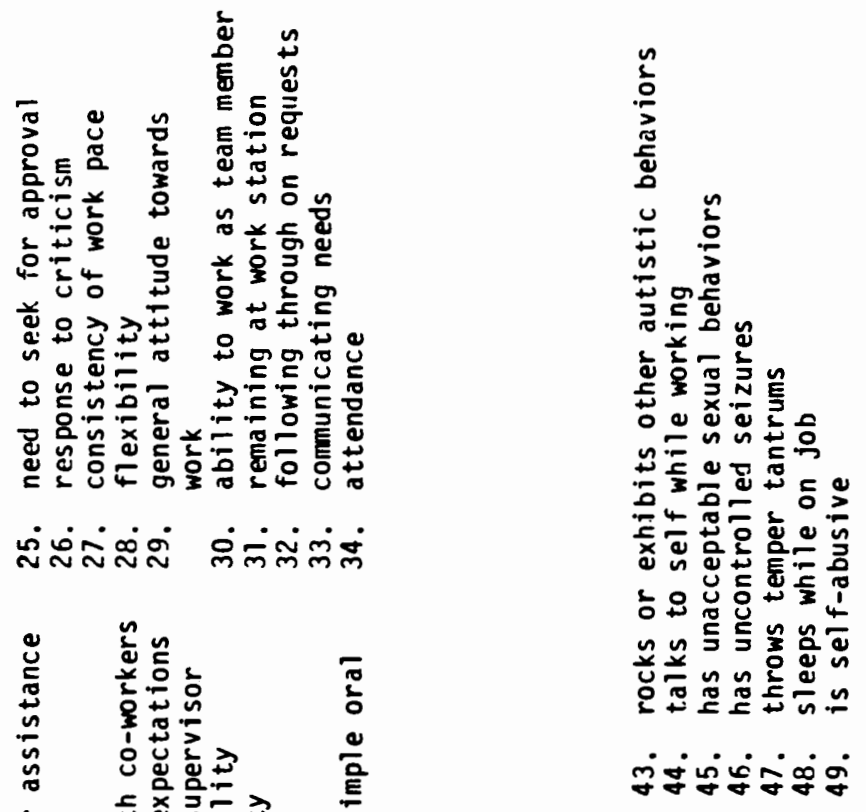

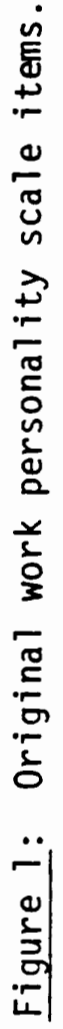
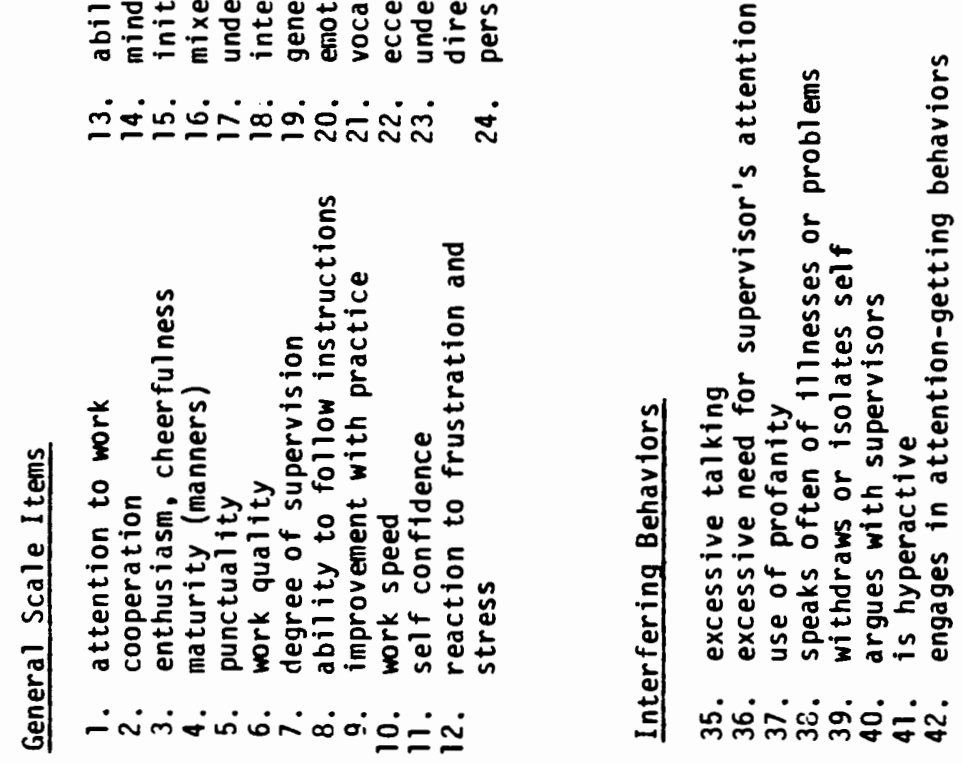
DIRECTIONS: For each item, rate the client's relative work performance as defined under the item heading, by first selecting the letter (A), (B), (C), (D), or (F). The following scoring guide will assist you in making this selection

Scoring

(A) Excellent--performance meets usual competitive standards in unskilled employed. This grade has a numerical value of 9.

(B) Good--above average work adjustment performance but does not fully meet competitive standards in unskilled employment. The numerical value which applys to this letter score is 7 or 8 .

(c) Fair--falls in average performance range of work adjustment trainees. Although within acceptable limits of the workshop, considerable improvement is required to attain competitive standards. A letter score of " $C$ " represents a numerical score of 4,5 , or 6

(D) Poor--below average work adjustment performance. Improvement is needed to meet workshop standards. The numerical values related to this letter score are 2 or 3 .

(F) Extremely inappropriate--behavior requires special supervisory or professional staff attention. May require services beyond the scope of workshop training such as medical treatment or mental health services. A letter score of "F" has a numerical value of 1 .

Next, if you have identified the letter area (B), (C), or (D) as best reflecting the client's performance, you will need to make a finer assessment by selecting one of the corresponding numerical values as explained below:

If you chose (D), poor, you will need to decide if the client's performance reflects a 2 or a 3 value; 2 , indicating that his/her performance is comparatively less adequate than others rated in the same letter category and 3 , indicating a comparatively better performance. Use the cue descriptors located below each item scale to help you make this decision.

If you chose (C), fair, you will need to select a numerical value of $\underline{4}, \underline{5}$, or $\underline{6}$; 5 , reflecting work performance which falls midway between the lower thir $\bar{d}-\overline{4}$, and the upper third--6, of those rated in the (C) category. Again, the cue descriptors will help you make this selection.

Finally, if you chose $(\underline{B})$, good, you will need to select either a $\underline{7}$ or $\underline{8}$ numerical value; 7 , reflecting performance comparatively less adequate than others rated in this letter category or 8 , reflecting comparatively better performance. Use the cue descriptors to help you make this selection.

Once you have selected the letter and numerical value which best reflects the client's performance, place an "X" directly over the corresponding number. For example, see below:

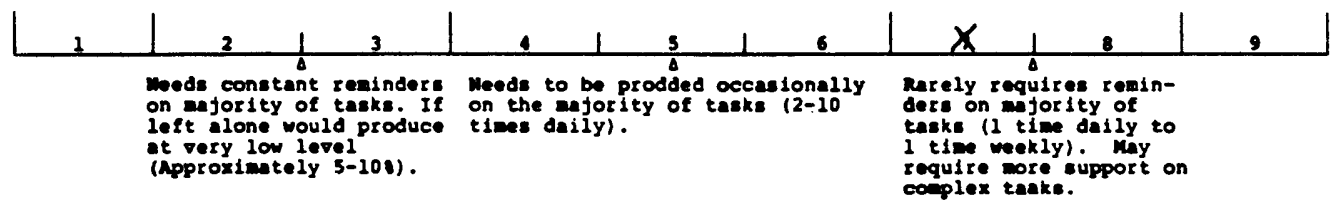

Respond to all scale items and please record the client's name, your name, the date and time the scale is completed, and the period of time the rating covers.

CLIENT'S NAME RATER' S NAME

DATE RATING COMPIETED: TIME : PERIOD COVERED: FTOM to 
1. Attention to Work: Once a task is learned, how capable is the trainee of attending to the work task, without the need to be reminded, prodded, or encouraged by supervisor.

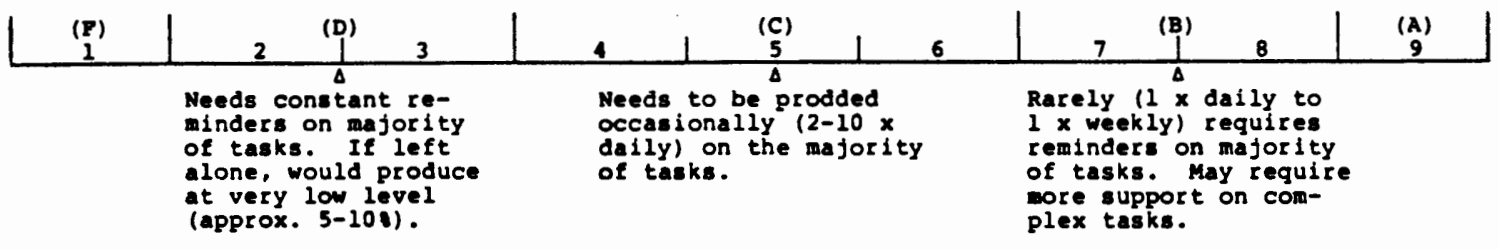

2. Cooperation: How capable and willing is the trainee of working together with supervisor, following through on requests and meeting supervisor expectations.

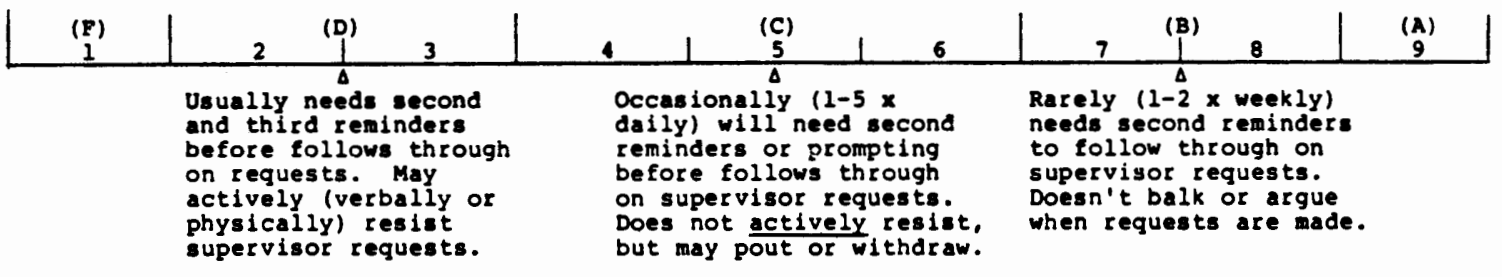

3. Enthusiasm, Cheerfulness: To what degree does the trainee approach his work and others with an attitude of enthusiasm and cheerfulness.

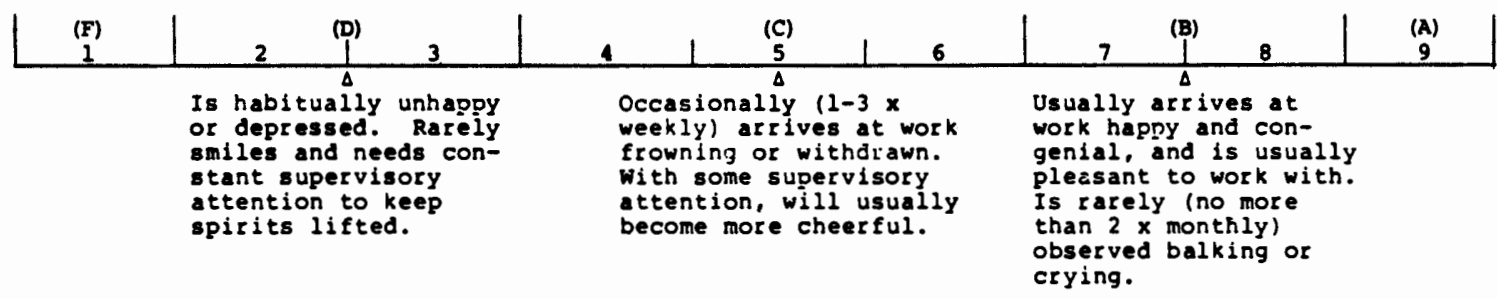

4. Maturity: How capable is the trainee of responding to situations and others in a mature adult-like manner.

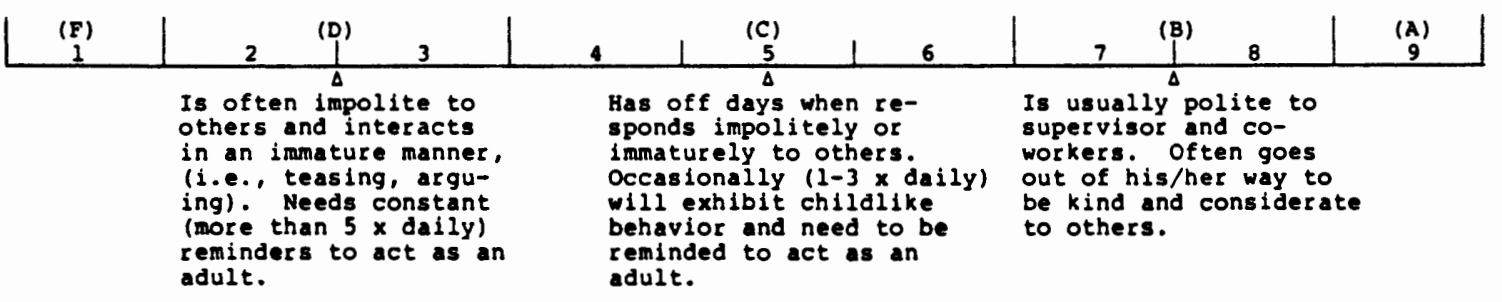

Figure 2. Continued. 
5. Punctuality: To what degree does the trainee understand expectation and arrive at work and return from breaks and lunch at the expected time without supervisor reminders or proddings.

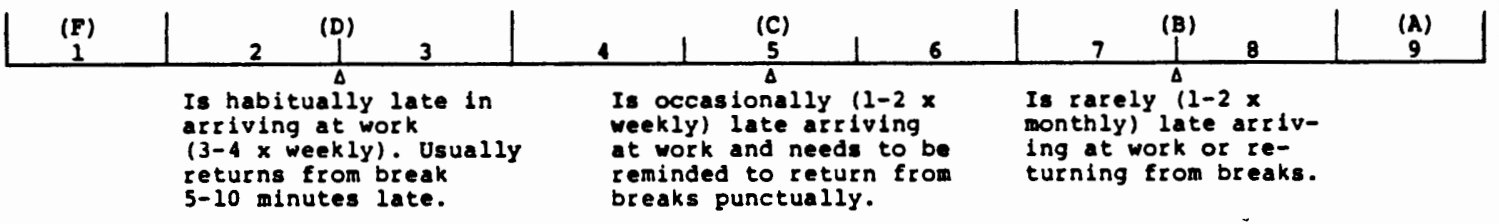

6. Work quality: Once a task is learned, what quality (percentage of errors) of work is the trainee able to maintain without the need to be reminded, prodded, or encouraged by supervisor.

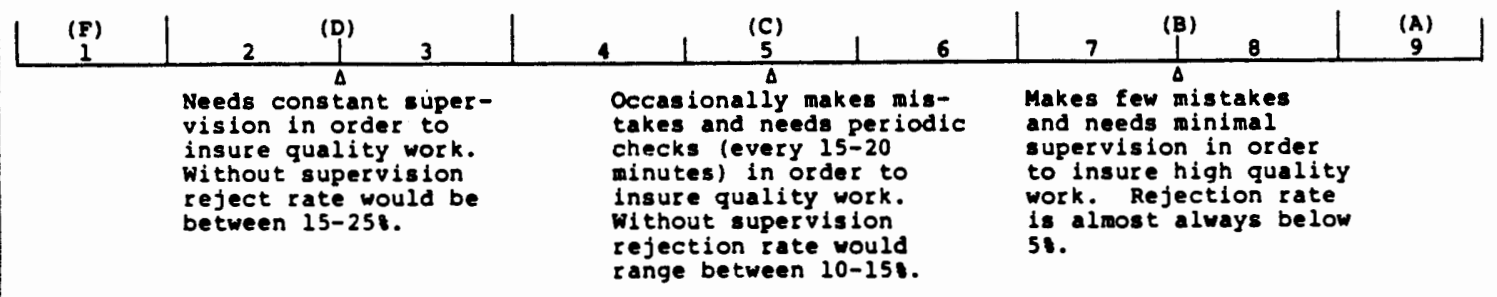

7. Degree of Supervision Needed: Considering all aspects of work, what degree of supervision is needed to insure that the trainee is following through on all work expectations (i.e., following through on requests, refilling work station when necessary and working on task steadily and with a minimum of errors).

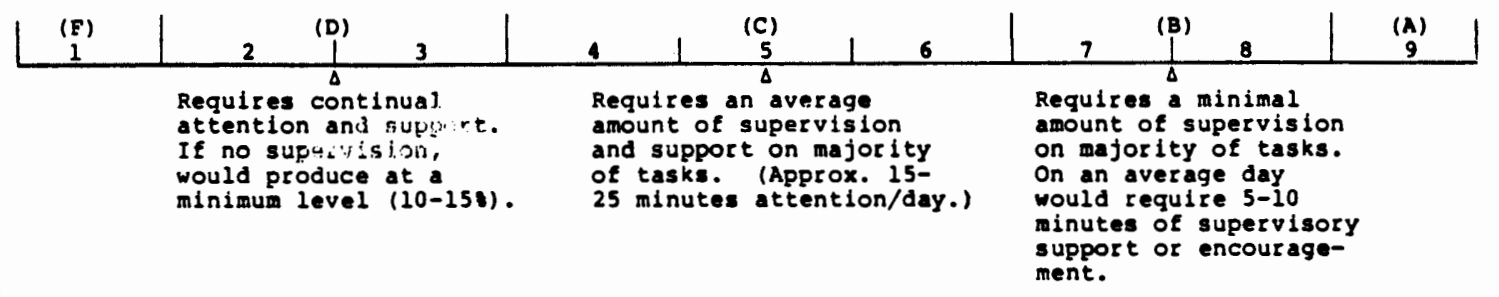

8. Ability to Follow Instructions: When learning a new task, what degree and type of instructions is necessary to teach new task.

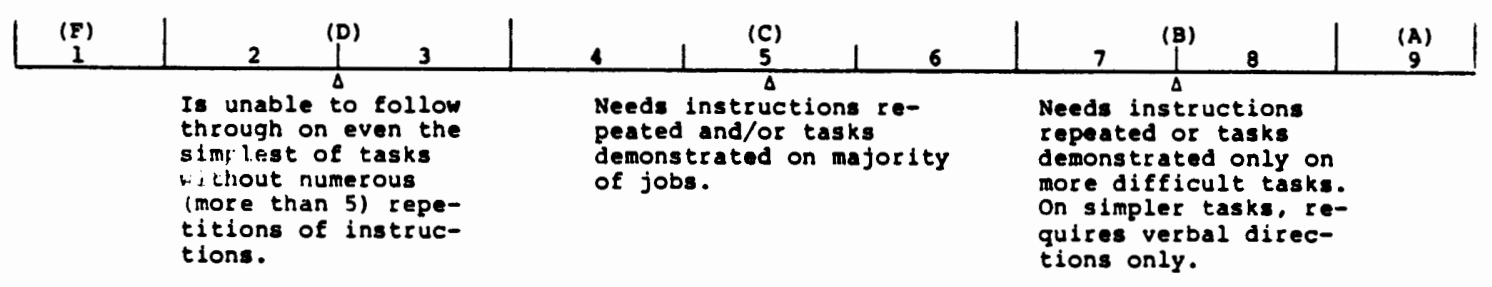

Figure 2. Continued. 
9. Improvement with Practice: Once the trainee learns the operations of a new task, to what degree does his/her work speed and work quality improve with practice.

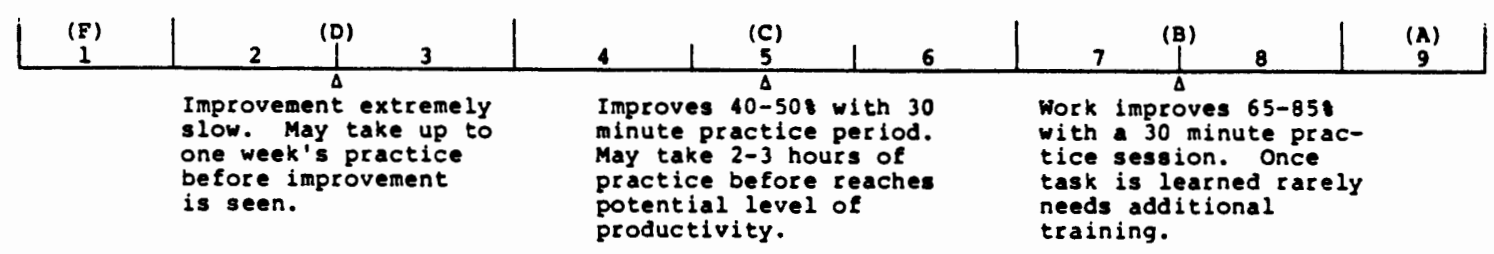

10. Work Speed: Once a task is learned, at what average speed would the client produce at without the need to be prodded or encouraged by supervisor.

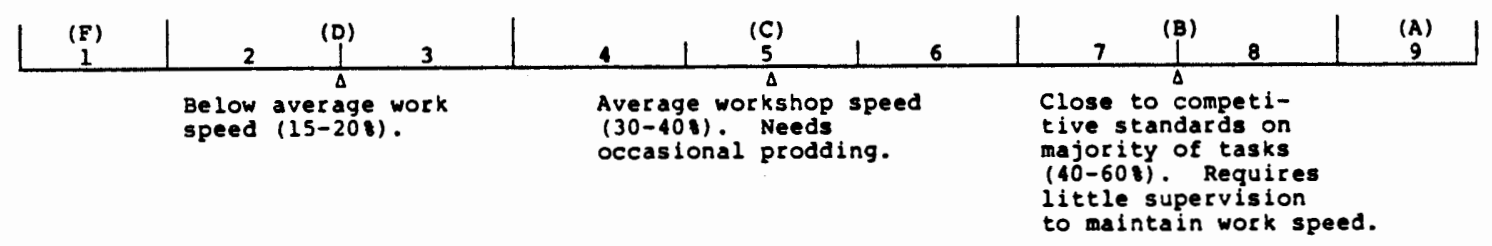

11. Self-Confidence: To what extent does the trainee perform and express confidence in his/her abilities and power to effectively control own environment.

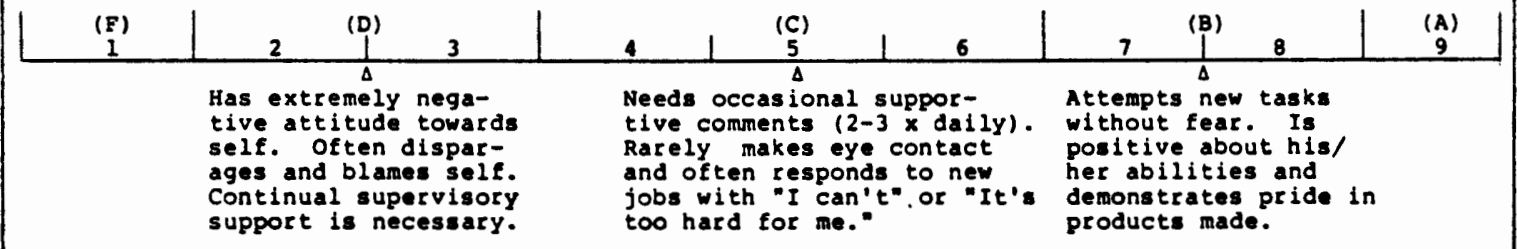

12. Reaction to Frustration and Stress: In stressful or frustrating situations, how capable is trainee of reacting calmly and rationally without supervisor intervention.

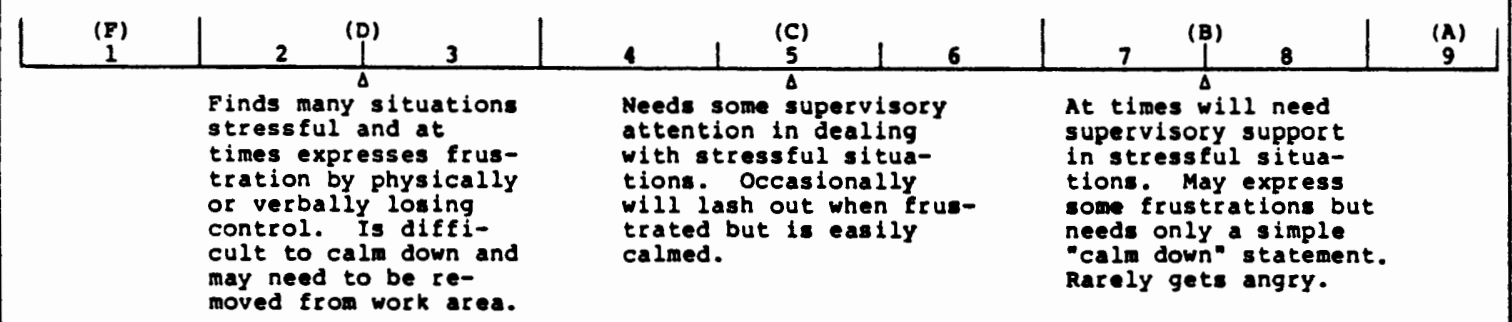

Figure 2. Continued. 
13. Ability to Ask for Assistance: On those occasions when supervisory assistance is legitimately needed, how capable, willing, and/or promptly will the trainee seek help from supervisor.

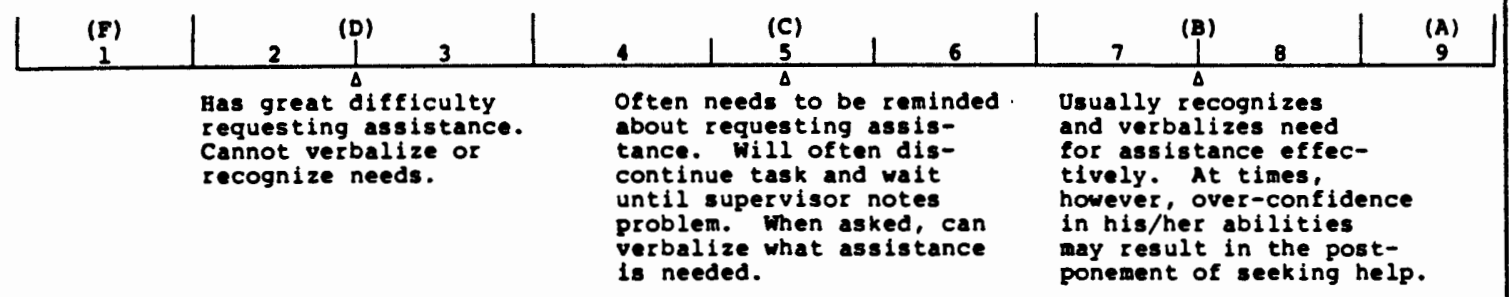

14. Minds own Business: To what extent does trainee attend to his/her own task without becoming needlessly involved in co-worker's or supervisor's business.

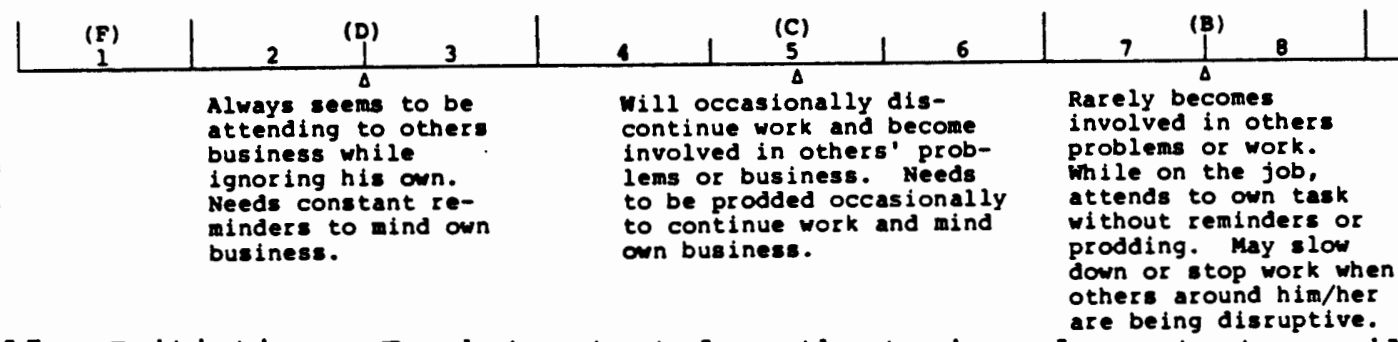

15. Initiative: To what extent does the trainee demonstrate a willingness and ability to begin a task without prompting and appropriately introduce an action beyond what is minimally expected.

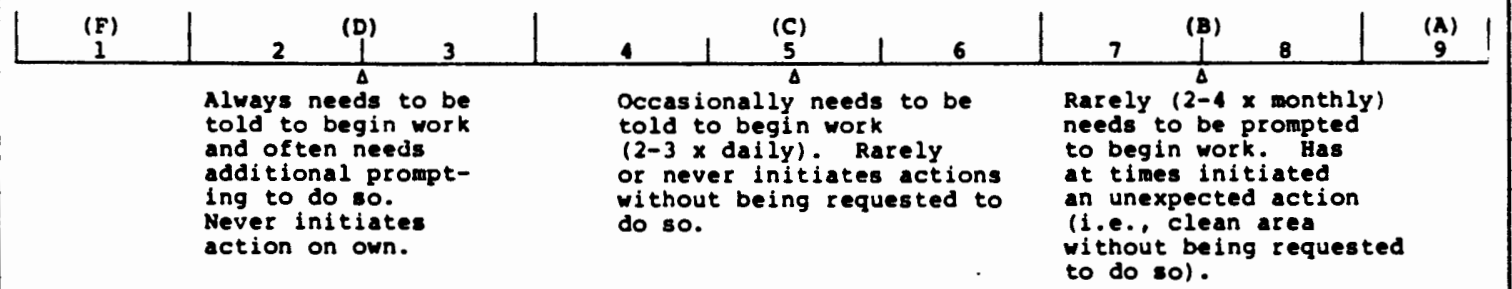

16. Mixes Socially with Co-Workers: During off-times, (i.e., breaks, lunches, before or after work) how capable is the trainee of interacting appropriately with co-workers.

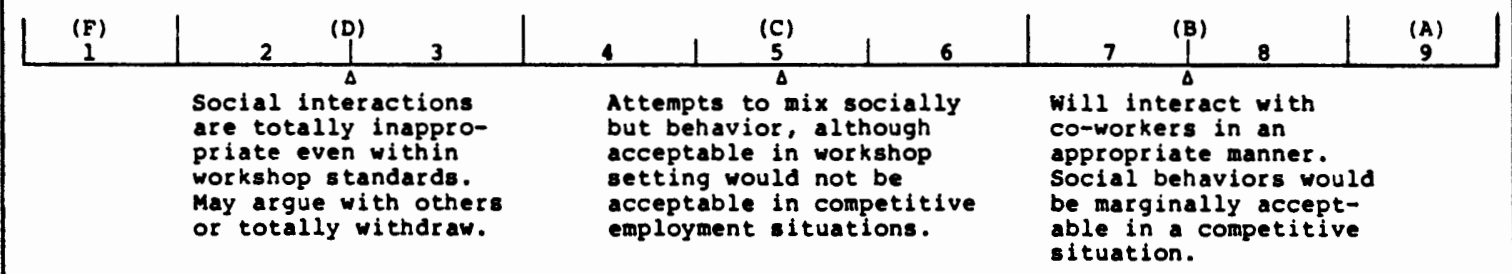


17. General Presentability: When arriving at work, how presentable is the trainee, taking into consideration grooming and clothing practices.

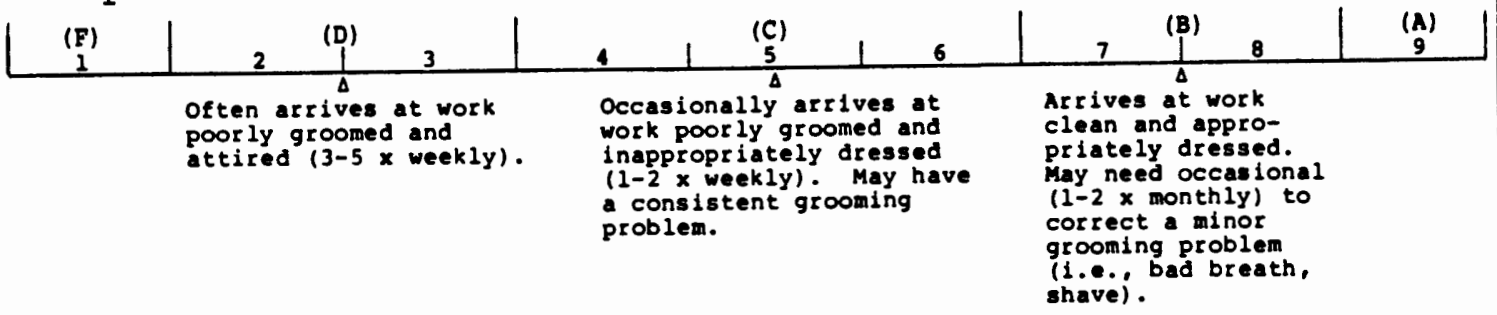

18. Emotional Stability: To what extent does the trainee maintain stable and appropriate emotional attitudes and behaviors. How

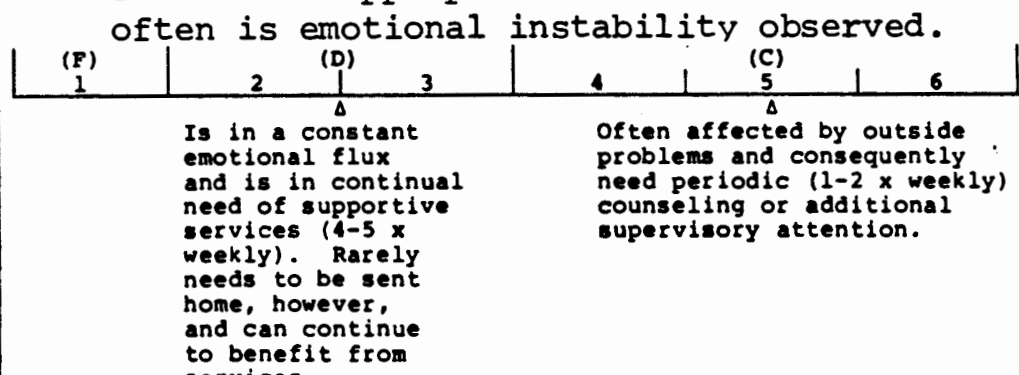

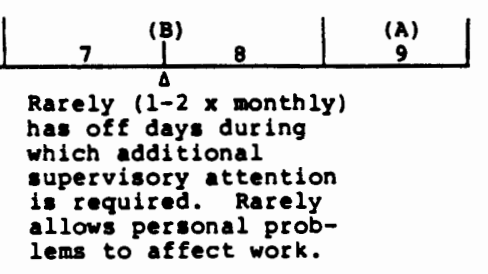

19. Vocal Habits: What are the trainees vocal habits taking into consideration the ease with which he/she makes him/herself understand and the tone and tempo of his/her speech.

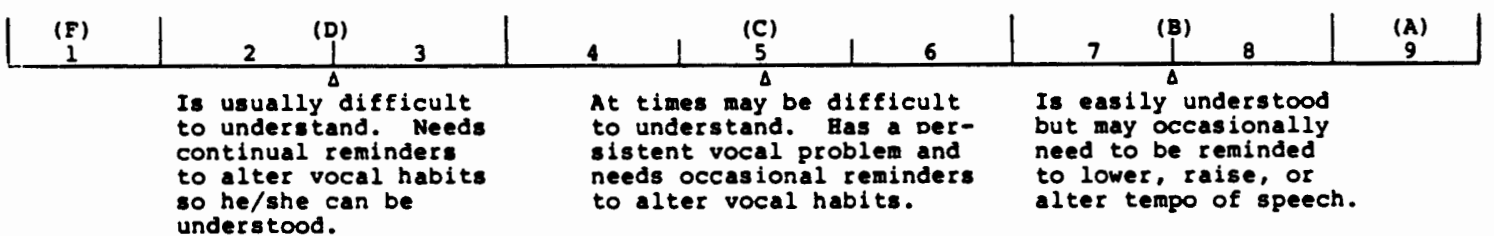

20. Need to seek for Approval: To what extent does the trainee seek out supervisory approval.

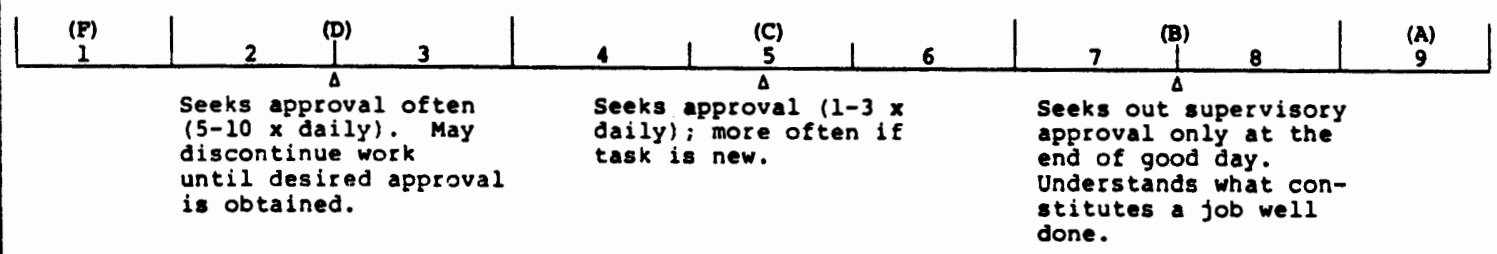


21. Response to Criticism: How likely is the trainee to respond to constructive criticism with acceptance and consequent resolution of the problem.

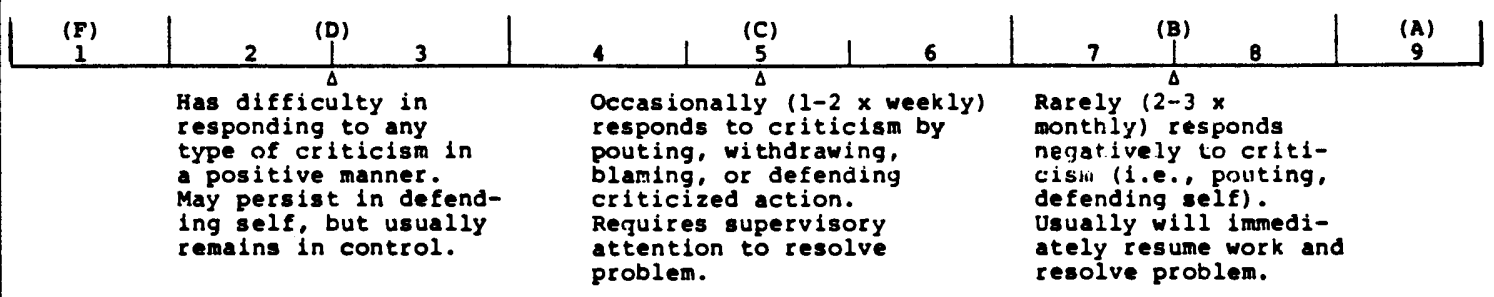

22. Consistency of Work Pace: Once a task learned, to what extent do extraneous events and stimuli affect the work pace of the trainee.

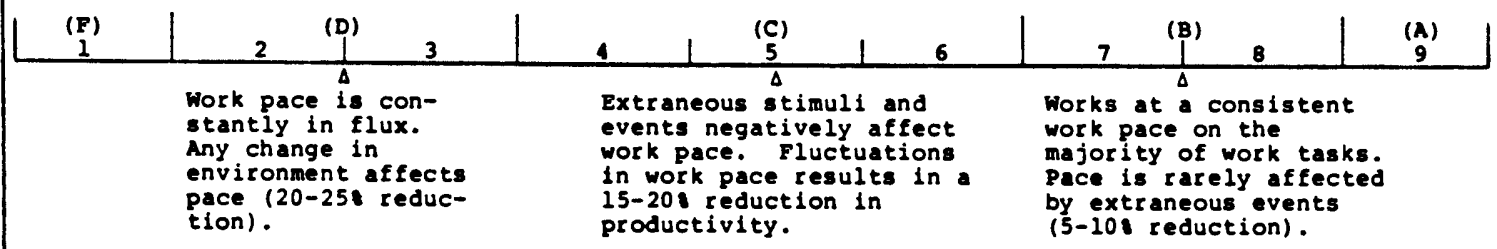

23. Flexibility: How capable is the trainee of adapting to changes in job or work environment without the need for supervisory attention and support.

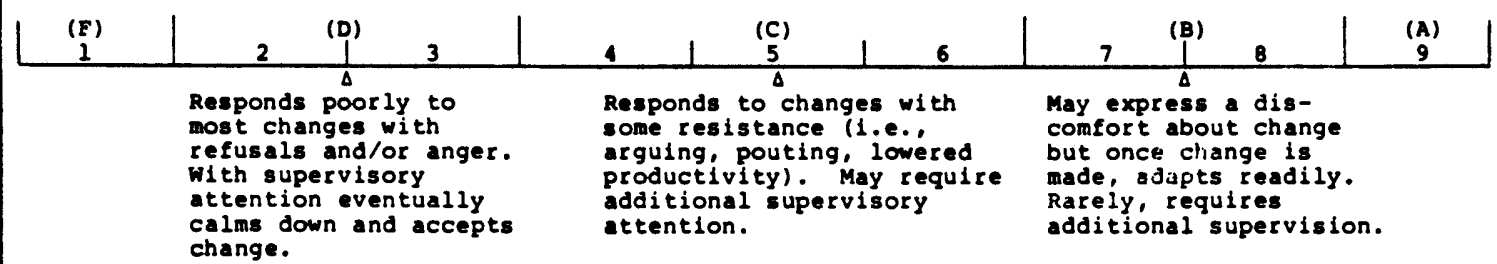

24. General Attitudes Towards Work: What is trainee's general attitude and approach to his/her work and others in this environment.

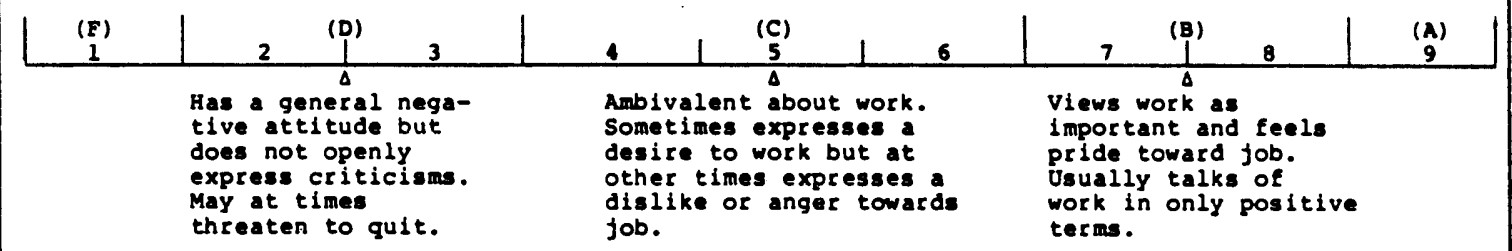


25. Ability to Work as Team Member: Once a task is learned, how capable is the trainee of keeping pace and cooperating with team members in an assembly line situation without the need for supervisory prompting and support.

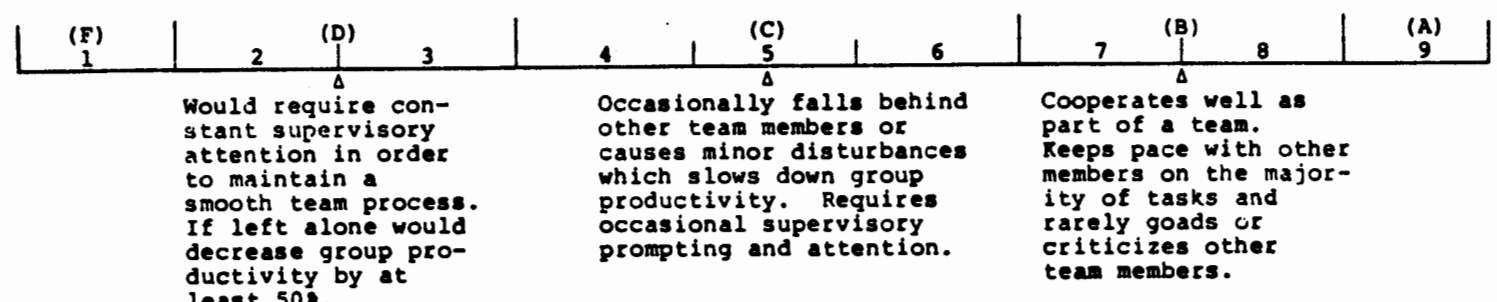

26. Informing Supervisor of Time Away From Work Station: How capable is trainee of informing supervisor of time away from work station.

\begin{tabular}{|c|c|c|c|c|}
\hline $\begin{array}{c}(\mathbf{F}) \\
1\end{array}$ & $\left(D_{1}\right)$ & $\begin{array}{c}\text { (C) } \\
5\end{array}$ & (B) & $\begin{array}{c}\text { (A) } \\
9 \\
\end{array}$ \\
\hline & $\begin{array}{l}\text { aften leaves work } \\
\text { oftions without } \\
\text { stations } \\
\text { permission and often } \\
\text { without good reason. }\end{array}$ & $\begin{array}{l}\text { occasionally leaves work } \\
\text { stations without permission; } \\
\text { however, if does so usually } \\
\text { has a good reason for doing } \\
\text { so. }\end{array}$ & $\begin{array}{l}\text { Rarely leaves work } \\
\text { station without } \\
\text { permission ( } x \\
\text { monthly). Will } \\
\text { prompty return to } \\
\text { work station after } \\
\text { errands are finished. }\end{array}$ & \\
\hline
\end{tabular}

27. Attendance: How likely is trainee to attend work on a regular basis, barring legitimate absences, without the need for supervisory reminders.

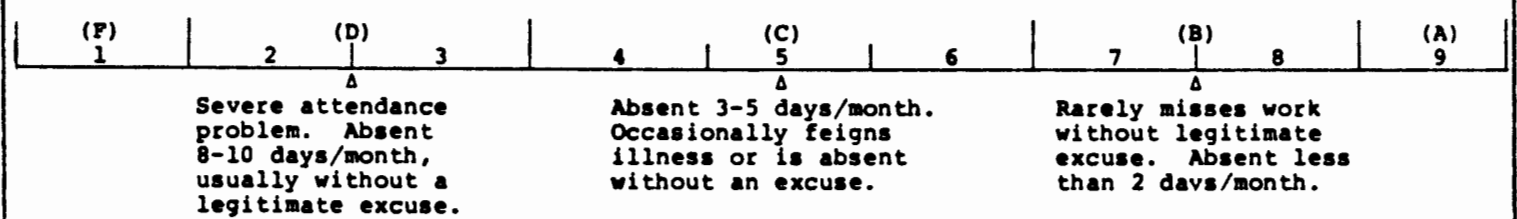

28. Informing Supervisor of Time Away From Work: How capable is trainee of informing supervisor of extended time away from work (1 hour or longer) for reasons including doctor's appointments or vacation days.

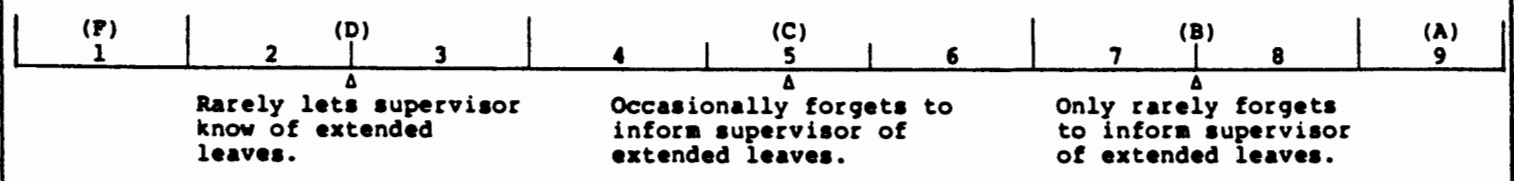

Figure 2. Continued. 


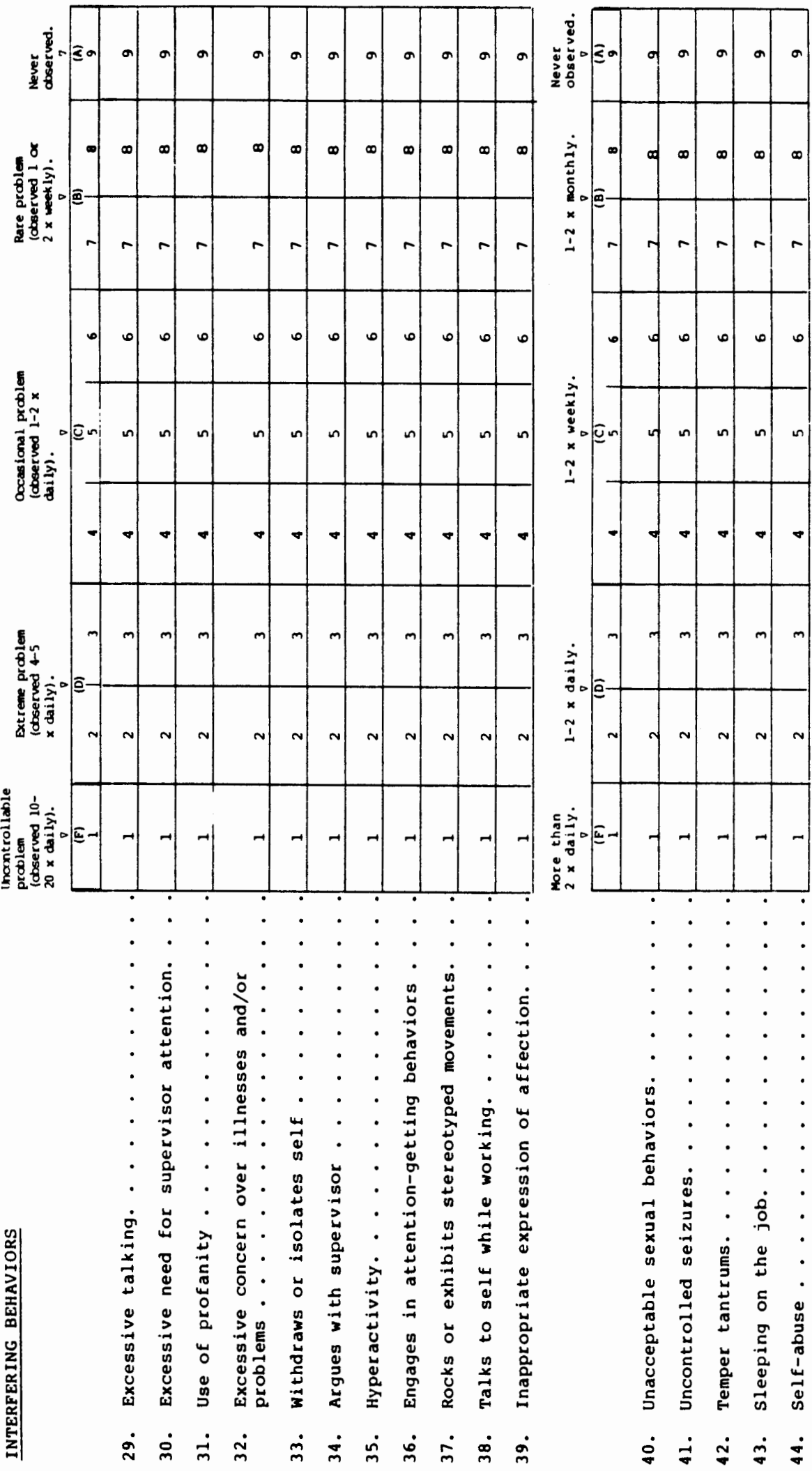

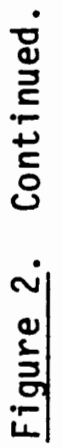


numerical system, the format could easily be transformed into a 5-point scale.

Trial Field Study. One supervisor randomly chose ten subjects from the general assembly area of the workshop. These subjects were observed for one month and then rated at the end of this period. The purpose of this initial trial rating was to identify and resolve any scoring difficulties that occurred when the scale was applied in an actual field setting. Items which were difficult to rate or seemed ambiguous were rewritten or el iminated from the scale. In addition, the researcher examined the range of scores on individual items and overall scores in order to determine the discriminant value of the scale and its items.

Analysis and discussion of the trial field study resulted in the identification of seven items that were thought to be redundant. These items were eliminated and the specific reasons for their exclusion are as follows:

(17) Understands work expectations

This aspect could be evaluated adequately by items $1,2,5,6$, $10,13,14,27,30$, and 31 .

(18) Interaction with superior

This aspect could be evaluated adequately by items $2,4,12$, 13 , and 25 .

(22) Eccentric habits

This aspect could be evaluated in detail with the 15 interfering items. 
(23) Understanding of simple oral directions

(32) Following through on requests

(33) Communicates needs

(34) Perseverance
These aspects could be evaluated adequately by items 8,13 , and 21 .

This aspect could be evaluated adequately by items 1 and 27 .

Items 16, "mixes socially with co-workers" and 30, "ability to work as a team member" were identified as potential problems due to the possibility that these behaviors may not be observed with enough consistency to allow adequate evaluation and acceptable reliability. However, the researcher decided to retain these items and evaluate them further as the study progressed.

Finally, the analysis of items and overall scores revealed that all item scores over the ten subjects encompassed the full range of values (1-9) with average overall scores ranging from 3.9 to 8.01 .

In summary, of the original 49 items used in the field study, seven were eliminated. The remaining 42 items were included in the initial draft of the research version of the Work Personality Scale.

Training of Raters. When the training sessions began, the 42 items being used were earlier versions of items 1-27, 29-38, and 40-44 (see Figure 2).

Initially, three primary sessions were set up, each to last 45 minutes. However, as training progressed it became clear that additional training time would be necessary to insure rater confidence. Two additional sessions were required and each of the five sessions lasted one hour and 15 minutes. Although nine supervisors participated 
in the initial sessions, training continued throughout the course of the study to accommodate staff changes. A total of eight raters were eventually involved in collecting data. An outline of the areas covered during the training sessions is presented below.

Training Session One: General Introduction

1. Statement of the general purpose of the scale was presented, taking care not to sensitize the raters to this study's desired outcome of predicting work placement level. Instead the focus was on the need to develop a valid device for assessing work personality for the purpose of evaluating client progress and program effectiveness.

2. Theoretical background supporting the need to assess work personality of the mentally retarded in addition to intelligence and dexterity were discussed.

3. Role of the rater was explained including frequency of the ratings, rater time involvement, and rater perspective.

4. The researcher gave a brief explanation of the scale format and brief overview of scale items.

5. Open discussion and questions closed the first session.

Training Session Two: Item Examination (Items 1-20)

1. Discussion of each item was provided with a detailed, concrete definition of each variable to be rated.

2. Identification of behaviors that fit and did not fit each rated point for each item was discussed.

Training Session Three: Item Examination (Items 21-42) and Trial Rating.

1. Discussion of remaining items as in session two was provided. 
2. Types of error often found in rating procedures and ways to overcome biases were discussed.

3. Trial Rating--Providing each rater with a behavioral sketch of a potential client (see Appendix I), each was asked to individually rate the confederate trainee.

Prior to leaving this session, each rater was asked to choose one trainee in their work area to observe for two weeks and then rate at the end of this period. Individual meetings were set up with each rater to discuss any scoring difficulties they may have experienced.

Training Session Four: Results of Trial Rating.

1. The researcher presented the preliminary rater reliability data resulting from the above trial rating. The percentage of agreement between raters obtained and the desired criterion level are stated below.

Percentage of agreement obtained:

$81 \%$ of the items were rated within 2 numerical and 1 letter point. $19 \%$ of the items were rated within 3 numerical and 2 letter points. Desired percentage of agreement:

$75 \%$ of items rated within 2 numerical or 1 letter point.

$15 \%$ of items rated within 3 numerical or 2 letter points.

$10 \%$ of items rated within 4 numerical or 3 letter points. The percentage of agreement obtained exceeded the desired criterion.

2. Discussion of items with a greater than two numerical or one letter point disagreement.

3. Open discussion--A number of changes were made in the scale and a manual was developed to improve the clarity of those items where 
disagreement or confusion was apparent. The changes made are discussed below and a list of the comments and definitions provided to the raters are located in Appendices II and III.

In the first of these changes, the descriptor phrases for items 14 and 15 were altered to more realistically reflect the average range of behavior normally observed. For each of these items, the word "occasionally" was substituted for the word "usually." Next, two additional items which the raters collectively agreed were important were included, bringing the total number of items for the research version of the Work Personality Scale to 44 . Item 26 was changed and items 28 and 39 added as follows: Item 26 was broken down into two separate items, item 26 and 28 . In the final form of the research version of the scale, item 26 focuses on "informing supervisors of short absences from the work station" and item 28 focuses on "informing supervisor of extended leaves (greater than one hour)." Item 39, "inappropriate expression of affection," was added with the justification that the behavior was commonly observed in the workshop environment. The final change made was in regard to items 40-44. Because these behaviors were observed less frequently than the remaining interfering behaviors, the criterion descriptors were altered to insure a greater range of response (Figure 2 reflects these changes).

Training Session Five: Individual Meetings with Raters.

1. Scoring difficulties and problems regarding interpretation of behaviors observed were discussed.

2 . The general attitude of the rater in regard to their involvement in the study was discussed. 
Summary of Research Version of the Work Personality Scale. The research version of the scale consisted of 44 items, 28 general items and 16 interfering behaviors (see Figure 2). The elimination of seven of the original 49 items (see Figure 1) and the addition of two items resulted from information obtained during the trial field study and training of the raters. This version of the scale was employed for data collection and the subsequent development of the final version of the Work Personality Scale.

\section{Statistical Analysis in Scale Development}

Data gathered from the research version of the Work Personality Scale were first analyzed to provide documentation regarding rater reliability of the items. Items with adequate rater reliability were then factor analyzed to aid in the selection of items for Work Personality Subscales. Subscales were constructed and examined regarding rater reliability, test-retest reliability, and internal consistency rellability. Finally, the Work Personality Subscales were correlated with WAIS and Purdue Pegboard scores to determine their interrelationships.

Rater Reliability of the Work Personality Scale. Rater reliability indicates how well the ratings of two or more independent raters agree. In the development of a scale, the measure of reliability is of extreme importance not only because it reflects the generalizability of the measurement but because subsequent validation of an instrument is dependent on its reliability. For this reason, the development of the present scale began with identification of the reliably rated items. 
Four raters were involved in gathering the rater reliability data. Twenty subjects were each rated independently by two of these four raters. The correlation between "Rater 1" and "Rater 2" scores for each of the 44 work personality items was computed using the Pearson productmoment correlation coefficient. It must be pointed out that the same two raters were not available to rate all 20 subjects. Consequently, "Rater $1 "$ and "Rater 2" for any subject may actually be Rater A and B, $A$ and $C, A$ and $D, B$ and $C$, etc. Such an arrangement results in rater reliabilities that only approximate the reliabilities that would have been obtained if the same two raters had been available for all 20 subjects. Only those items with rater reliability coefficients of .30 or greater were retained for subsequent factor analysis.

Factor Analysis. Factor analysis has been defined in the simplest of terms by Rummell (1967, p. 445) as "a means by which regularity and order in phenomena can be discerned." Although it has many appications, factor analysis was used in the study primarily as an exploratory tool-a tool which served as a heuristic device in reducing a large number of items into a smaller number of common factors.

The technique of factor analysis was applied to determine if the scale items with acceptable rater reliability could be reduced to a smaller number of common factors. Ratings of clients who were in training at the onset of the study in addition to new clients who entered into the program during the course of the study constituted the data for this analysis.

The scores of 75 subjects on the Work Personality Scale items were factor analyzed using the Statistical Package for the Social 
Sciences (SPSS) (Nie, Hall, Jenkins, Steinbrenner, \& Brent, 1975). The procedure selected for the factor analysis used squared multiple correlations between each item and all remaining items as the communality estimates on the main diagonal of the correlation matrix. The extraction of factors was followed by a Kaiser Varimax rotation. The factor analysis results were then used to develop subscales of work personality as described in the next section, Formation of Subscales.

A secondary purpose of the factor analys is was the preliminary identification of the structural components of work personality. The expected outcome of the factor analysis was as follows:

Hypothesis I. The common factors underlying the Work Personality Scale items include: (1) motivation, (2) work habits, (3) work relationships, and (4) presence of maladaptive behaviors. Due to the small sample size, the factor analysis results are considered exploratory and should be interpreted cautiously.

Formation of Subscales. For the purpose of identifying items in the formation of the subscales, the following guidelines were used.

1. No item was to be included in a subscale unless it had a factor loading of .40 or larger, with a loading of greater than .50 preferable.

2. For each item included in a subscale, the factor loading should meet the above requirement on both the 5-point and 9-point analyses.

3. No item was to be included on more than one subscale.

4. Each subscale should preferably have three or more items.

5. The items included in each subscale should be conceptually connected. 
After items were selected for inclusion in the various subscales, subscale scores were computed by averaging the standardized scores for those items belonging to a given subscale.

Rater, Test-Retest, and Internal Consistency Reliability. Three types of reliability were determined for the Work Personality Subscales: rater reliability, test-retest reliability, and internal consistency reliability.

As described earlier, a total of 20 subjects were involved in the analysis of rater reliability. Pearson product-moment correlation coefficients were calculated for items and subscales in both 5-point and 9point formats to determine how well the scores of the independent raters agreed.

For the analysis of test-retest reliability, 15 subjects were rated twice by the same rater. The second rating followed the first after an interim of 7-10 days. A one-week interim between ratings was chosen because it was believed long enough to be reasonably assured that raters would not recall how they had previously rated each item, and short enough so that changes in behavior due to training or treatment intervention would not be expected. The Pearson correlation was again used to determine test-retest reliability for items and subscales on both 5-point and 9-point formats.

Internal consistency (coefficient alpha) reliability indicates the degree of measurement error due to measurement inconsistencies of the scale items. Coefficient alpha was calculated for each subscale on both the 5- and 9-point formats. The data for all 75 subjects used in the factor analysis were also employed in computing coefficient alpha. 
Interrelationship Between IQ, Dexterity, and Work Personality Subscales. Forty-four subjects participating in the Work Evaluation Program were administered the WAIS and the Purdue Pegboard on their first day in the program. Once these tests were completed, each subject was then introduced to one of seven supervisors and situated at a work station. After five days of attendance on the work floor, each subject was then rated by his supervisor using the Work Personality Scale. These scores were analyzed using correlational procedures to determine if these three sets of variables (intelligence, manual dexterity, and work personality) are related and to what degree.

The hypotheses tested during this phase of the study were:

Hypothes is II. The correlations between total ivork personality' scores and the two remaining aspects, total WAIS and total Purdue scores are low and positive.

Hypothesis III. The correlations between total I!AIS and total Purdue scores are positive and greater than the correlations of either total WAIS or total Purdue scores with work personality. 


\section{CHAPTER IV}

\section{RESULTS}

\section{Rater Reliability of the Work Personality Scale Items}

Using a general minimum cutoff of .30 correlation, 17 of the original 44 items from the research revision of the Work Personality Scale were eliminated from further consideration in scale development. All items which did not meet this .30 criterion on both the 5 -point and 9-point formats were dropped with the exception of item 19, "vocal habits" which had a 5-point rater reliability of .24 and a 9-point rater reliability of .19 . This borderline item was retained because it was considered as being conceptually important in the evaluation of the mentally retarded in the workshop situation.

Table I contains the rater reliability coefficients for both the 5-point and 9-point formats for those 27 items retained for further analyses.

\section{Factor Analyses and Formation of Subscales}

In the factor analysis, only the ratings of the 27 items having satisfactory rater reliability were used. A complete list of the items contained within each factor and the factor loadings after rotation can be found in Table II.

The first step in the development of the subscales was to examine the factor loadings of each item for both the 5-point and 9-point format. Al1 factor loadings of .40 or greater were identified and each 


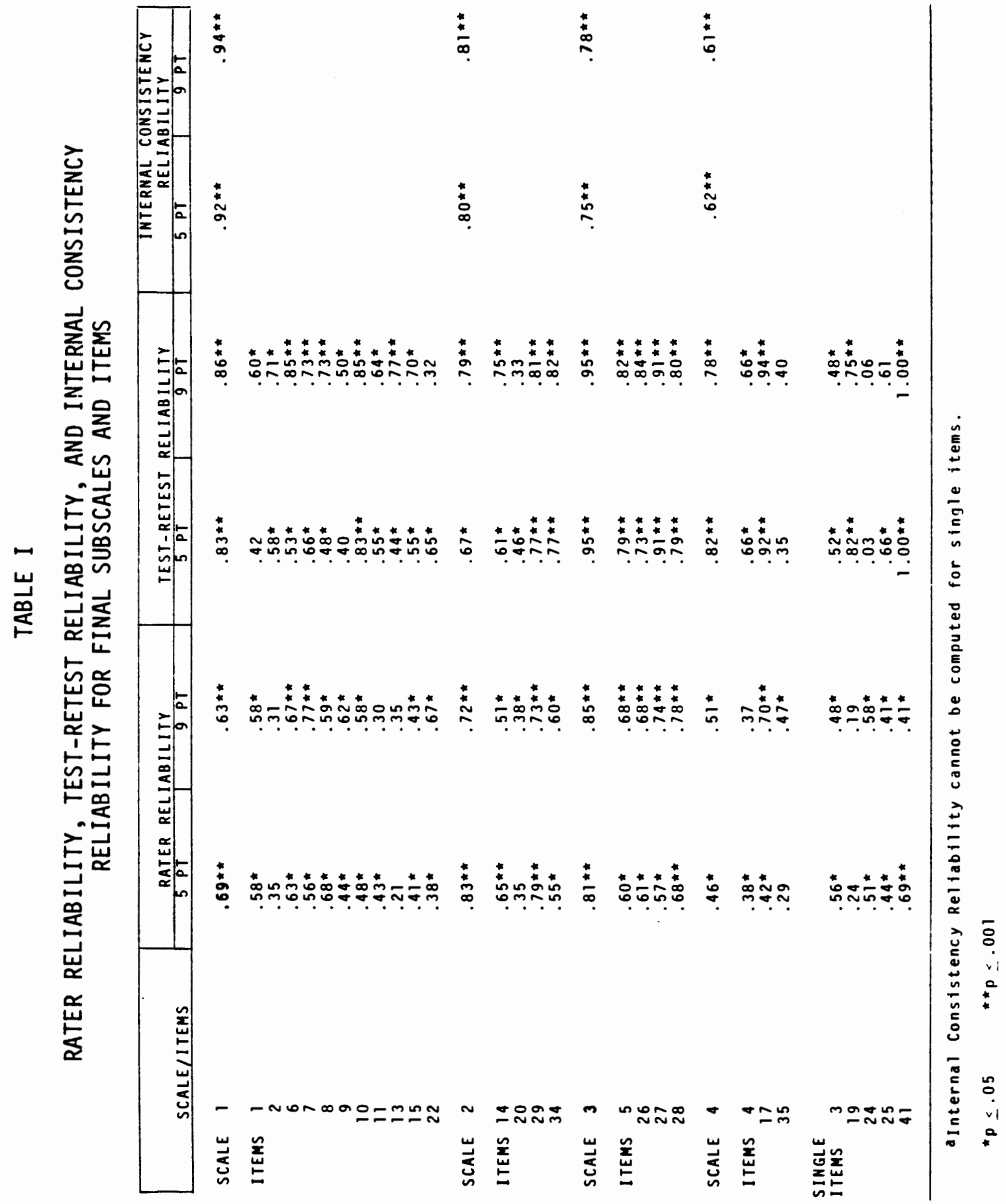




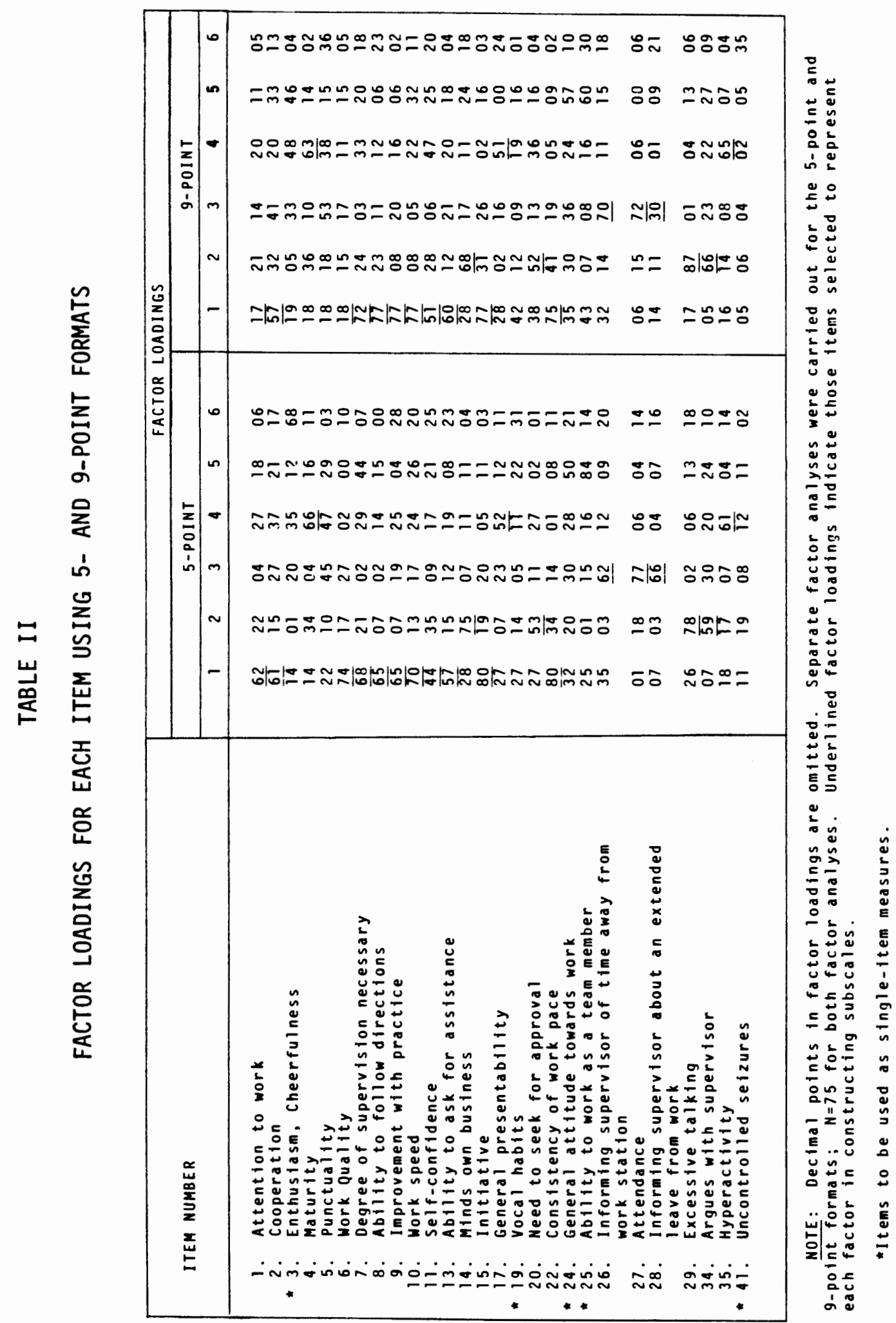


item was examined to determine which one factor the item was best represented by using the guidelines presented in the Methods section. For many of the items the determination was rather obvious as only the significant factor loadings were located on the same factors for both the 5-point and 9-point formats. Table II was used to facilitate the above examination of factor loadings.

The next step in the procedure was to examine the factors in terms of their conceptual clarity. For this purpose, those items which could clearly be placed on one factor were grouped and the item descriptions within each factor were evaluated. The first four factors each contained more than two items and all were comprised of items which appeared to be conceptually related. Factor five, however, included two items with high loadings (item 24, "general attitude towards work" and item 25, "ability to work as a team member") that could not be conceptually combined under a common heading. Consequently, the decision was made to retain these two items as separate items.

The remaining three items: item 3, "presence of an attitude of cheerfulness and enthusiasm," item 9, "vocal habits," and item 41 , "absence of uncontrolled seizures," either did not have high factor loadings on the same factors or did not reveal high factor loadings on any factor. In order to determine the status of these items, each was evaluated in terms of its relative value in contributing to the assessment of work personality. Using this criterion, the decision was made to include all three as separate items.

The final step in the process was to examine the items within each subscale and devise a descriptive title for each. In doing so, 
the items with the higher factor loadings were stressed and, consequently, were reflected to a greater extent in the assigned title than the items with lower factor loadings. The following subscale titles were assigned.

Subscale 1 - Independence and appropriateness of work habits.

Subscale 2 - Absence of attention-getting behaviors.

Subscale 3 - Responsibility regarding attendance.

Subscale 4 - Appropriateness of interpersonal skills.

In summary, factor analysis of the 27 items resulted in five single items with the remaining 22 items used to form four subscales. Table III contains a list of the subscale and single items and includes the factor loadings for all items used in forming subscales on both the 5- and 9-point formats. Each subscale is generally comprised of those items with high loadings on the factors identified through factor analysis. Both 5-point and 9-point versions of Subscales 1 through 4 were formed by averaging the $z$ scores for the items chosen for the scale. Item scores were standardized using means and standard deviations from the $\mathrm{N}=75$ sample employed in the factor analysis.

Hypothesis I. Hypothesis I states that the common factors underlying the Work Personality Scale items are: (1) motivation, (2) work habits, (3) work relationships, and (4) presence of maladaptive behavior. Regarding Hypothesis I, it appears that Subscale 1 reflects both motivation and work habits, Subscale 2 measures work relationships and presence of interfering behaviors, Subscale 3 measures work habits, and Subscale 4 measures both work relationships and presence of interfering behaviors. 


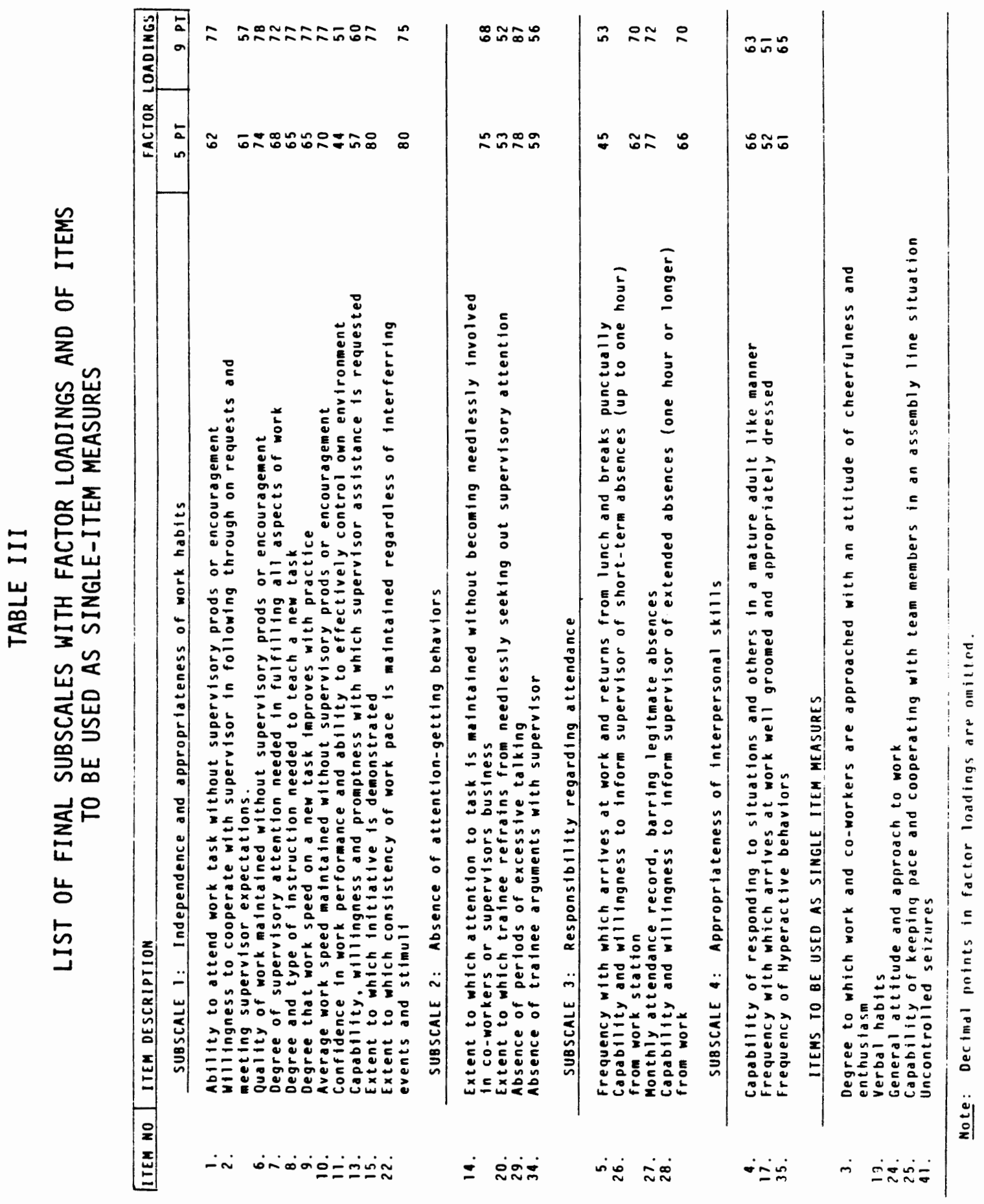


Rater, Test-Retest, and Internal Consistency Rel iability for the Work Personality Subscales

Table I presents the reliability results for all subscales and their component items and for all items to be used as single-item measures. All but two subscale reliabilities were significant at the .01 level, with those two being significant at the .05 level.

Scale Format. The decision of whether to utilize a 5-point or 9-point format in future research was determined on the basis of comparisons between the 5- and 9-point reliability coefficients. The first comparison was that between the item rater reliabilities for the 5- and 9-point versions. An examination of Table I indicates that the correlations for the 9-point items exceeded those of the 5point for 16 of the 27 items. The 5-point correlations were larger for ten of the items and the correlations were equal for one item. Next to be considered were the subscale rater reliabilities for the two formats. Here the decision is plit as the subscale reliabilities for the first two scales were higher on the 5-point format and the remaining two subscales have higher 9-point reliabilities.

A similar analysis was made for the test-retest reliabilities with the following results. Twenty of the 27 items had higher 9point correlations, six had higher 5-point correlations and one item had equal correlations. The subscale test-retest reliabilities reflected a similar outcome. This comparison revealed that three of the four subscales had higher 9-point reliabilities. A comparison of the two formats on internal consistency reliability indicated that three subscales had higher 9-point correlations and one subscale had a 
higher 5-point correlation.

Overall, the 9-point format appears to be somewhat more reliable than the 5-point format.

Frequency Distributions and Descriptive Statistics for the Work Personality Subscales

The frequency distributions in $z$ score form for Subscales 1 to 4 $(N=75)$ on both the 5 - and 9-point format are located in Tables III to $X$, Appendix IV. Additional statistical information, including the mean and the standard deviation for each subscale are also presented in these tables. Tables XI and XII contain the raw score means and standard deviations for items used in the factor analysis $(N=75)$ and Tables XIII and XIV contain the $27 \times 27$ item intercorrelation matrices for $N=75$. The final table in Appendix IV, Table XV, contains the complete correlation matrix for the comparison of the WAIS VIQ, PIQ, FSIQ, and the Purdue scores with the Work Personality Subscales.

Correlation of the Work Personality Scale with WAIS and Purdue

Pearson product-moment correlations were calculated to determine the degree of relationship between the Work Personality Scale, WAIS, and Purdue Pegboard. These correlations were computed for 44 subjects with the exception of the correlation using full scale IQ scores $(N=42)$. Hypothesis II. Hypothesis II states that the correlations between the total Work Personality scores and the two remaining aspects, WAIS full scale IQ and total Purdue scores, are low and positive. Because total Work Personality scores and total Purdue scores were not available, the correlations were computed using the Work Personality Subscale 
scores 1 to 4 and the Purdue subscores right hand, left hand, both hands, and assembly. Although it is common practice to consider the Purdue assemply score as the total score, the researcher contends that for the mentally retarded this practice is invalid. Because the skills involved in the assembly subtest scores reach beyond simple dexterity ability, a11 Purdue subtest scores were considered separately in the correlations with the WAIS and Work Personality Subscales.

Correlating the four Work Personality Subscales, both 5-point and 9-point versions, with the WAIS FSIQ and the four Purdue subtests resulted in 40 correlations. Of these 40 correlations, five were significant at $p^{<} \cdot 05$. Both the 5-point and 9-point versions of Subscale 1, "independence and appropriateness of work habits," were significantly correlated with WAIS FSIQ $(\underline{r}(40)=.33$ and $(\underline{r}(40)=.36)$ and with Purdue right hand scores $(\underline{r}(42)=.29$ and $\underline{r}(42=.40)$. The 9-point version of Subscale 3, "responsibility regarding attendance," had a significant negative correlation with the Purdue assembly score $(\underline{r}(42)=-.29)$. The remaining 35 correlations of Work Personality Subscales with the WAIS and Purdue were nonsignificant.

The eight correlations of the Work Personality Subscales with the WAIS ranged from -.22 to .36 with an average correlation of .18 . The 32 correlations of the Work Personality Subscales with the Purdue subtests ranged from -.29 to .40 with an average correlation of .06 .

The results generally support Hypothesis II. Only five of forty correlations were significant, and of those, four were positive with the highest $\underline{r}$ being .40 . The average correlations of the Work Personality Subscales with the WAIS and Purdue were low and positive. With 
a few exceptions, then, it appears that work personality is not highly correlated with measures of intelligence and dexterity.

Hypothesis III. Hypothesis III states that the correlations between total WAIS and total Purdue scores are positive and greater than the correlations of either total WAIS or total Purdue scores with work personality. Two t-tests to compare correlations for correlated data were used to test this hypothesis. In order to test this hypothesis in a general sense, average correlations were used in calculating the t-tests. The four correlations of the WAIS FSIQ with the Purdue right hand, left hand, both hands, and assembly subtests were, respectively, $\underline{r}(40)=.20, \underline{r}(40)=.33, \underline{r}(40)=.35$, and $\underline{r}(40)=.38$, with the latter three correlations significant at $p<.05$. The average of these four WAIS/Purdue correlations was .315. The average of the eight WAIS/Work Personality Subscales correlations was .182 and the average of the 32 Purdue/Work Personality Subscales correlations was .055 .

A comparison of the difference between the WAIS/Purdue correlation and the WAIS/Work Personality correlation was not significant $(\underline{t}(39)=.60)$. Similarly, a comparison of the difference between the WAIS/Purdue correlation and the Purdue/Work Personality correlation was not significant $(\underline{t}(39)=1.25)$. These results do not support Hypothesis III. It appears that although the average correlation between the WAIS and Purdue is positive, it is not significantly greater than the average correlations of either the WAIS or Purdue with the Work Personality Subscales. 


\section{CHAPTER $V$}

\section{DISCUSSION}

With the conclusion of this study, a scale devised for assessing work behavior takes its place among many other rating devices used with retarded persons. But its similarity to these other scales is limited only to their common purpose--the systematic evaluation of work behavior. Unlike many of the rating instruments presently in use with the mentally retarded, this scale was devised for the specific purpose of evaluating the work personality of the mentally retarded in a noninstitutional workshop environment. Secondly, it is one of few such devices that attempts to assess both adaptive and maladaptive behaviors. Finally, it is one of only a few scales developed with the intent to demonstrate that work personality is a separate component consisting of variables relatively unrelated to characteristics measured by common intelligence and dexterity tests. It should be noted that some individuals writing in the field of vocational training oppose the use of any assessment procedures (Larson \& Edwards, 1980). However, whether work potential can be determined through the use of assessment devices, such as the Work Personality Scale, remains to be examined in future research.

A comparison of the Work Personality Scale with a similar measure may help to clarify the distinctive characteristic of the current scale. In a study conducted by Malgady, Barcher, Davis, and Towner (1980) 
the predictive validity of a recently devised scale was examined. The development of this scale, called the Vocational Adaptation Rating Scale (VARS), interestingly enough parallels the development of the present scale in a variety of ways.

First, the lack of suitable rating devices for evaluating the work behavior of the mentally retarded served as the main incentive for both studies. In addition, both studies focused on including items which not only assessed work performance (i.e., work speed, work quality) but also adaptive and maladaptive behaviors (i.e., cooperation, temper tantrums) because of a similar belief that employability is not directly related to skill level.

A final and perhaps more pertinent similarity between two scales can be identified. The developers of both the VARS and the Work Personality Scale hoped to discover a device which would distinguish the component work personality from IQ. The preliminary analysis of the data indicates that the developers of each was successful in demonstrating the desired lack of relationship with IQ. As in the VARS study, IQ was significantly related with only one scale. In the present study, low to moderate correlations (.24 to .36) were found between IQ and Subscale 1 ("independence and appropriate work habits") and a similar moderate correlation was reported in the VARS study between IQ and one of their scales, "communication skills."

The similarities between these two independently developed scales clearly suggests that the previous dependence on IQ in evaluating the work potential of mentally retarded individuals has shifted to include a broader range of variables. In addition to the similarities between 
the two scales cited above, a number of differences are apparant. An examination of these discrepancies follows.

The most significant of these differences is in the role that rater reliability played in the development of each scale. In the development of the VARS, rater reliability was not considered in the selection of items. In fact, this psychometric property was deemphasized possibly because the reported correlations (.40 to .72$)$ were not very promising. However, rater reliability was a primary concern in the development of the present scale. Possibly, items similar to those which were deleted from the Work Personality Scale because of unacceptable rater reliability resulting from restricted range of scores were included in the VARS. The inclusion of such items may have contributed to the lower scale reliabilities reported in the VARS, al though it is difficult to determine with certainty because item correlations were not available.

Another difference which may be pertinent to the continuing development of the present scale is in the scoring format used by each. The developers of the VARS utilized a format which would allow the raters to distinguish between the frequency and the severity or "consequences of each maladaptive behavior" (Malgady et al., 1980, p. 634). It is the latter distinction which is of primary interest here. Eleven of the original sixteen interfering behaviors of the present scale were eliminated from the factor analys is because of unsatisfactory rater reliability. Consequently, the Work Personality Subscales did not include these items and were limited in their ability to assess such interfering behaviors which could negatively affect 
employability of the mentally retarded person. The low rater reliability of these interfering behavior items was due in part to their low frequency and consequent restricted range (e.g., item 37, "talks to self while working" and item 43, "sleeps on the job"). However, there were several interfering behavior items (e.g., item 31, "use of profanity" and item 42, "throws temper tantrums") for which restricted range was not the cause of the lower rater reliability. For these items, it may have been that the raters were simply unable to agree on the frequency of these behaviors. The failure of raters to agree on these items very likely was due to differing degrees of contact with each trainee, making the reliable determination of frequency over a one-month period difficult.

Because the researcher does not want to abandon these particular items, it is suggested that future research initially focus on the reassessment of these items using an alternative scale format. One alternative would be the previously described severity format used in the VARS. Assessment of interfering behavior in terms of their severity or consequences may actually be less subject to disagreement among raters than the determination of frequency proved to be.

The initial data for the Work Personality Scale are promising. Subscale rater reliabilities (.46 to .85$)$, test-retest reliabilities (.77 to .95), and internal consistency reliabilities (.61 to .94 ) generally range from satisfactory to high levels. The subscale scores are uncorrelated with WAIS, IQ, and Purdue dexterity scores with the exception that Scale 1 ("independence and appropriate work habits") is low to moderately correlated with both IQ (.24 to .34) and dexterity 
$(.12$ to .40$)$. The 9-point format resulted in generally higher reliabilities overall and, consequently, its use is recommended over the 5point format al though continued examination of this aspect should occur. Due to the lack of any validity information, the researcher cautions the use of this scale for the purpose of estimating vocational potential. However, with the available reliability data, the scale can fulfill a variety of functions. First, the mere existence of such a scale may serve to encourage those responsible for determining future work placement not to rely solely on IQ and dexterity tests but instead to consider, albeit cautiously, the actual work behaviors exhibited in a simulated work environment. Secondly, the scale may be utilized to identify training needs and allow for the subsequent remediation of work related problem behaviors and finally, supervisors, whose subjective judgments were previously ignored, can begin to play an important part in the evaluation of the mentally retarded in a workshop environment.

Development of the Work Personality Scale is only in its initial stage. Continued research and development is imperative if it should not become one of the many unnoteworthy scales presently in existence. Suggestions of only a few research possibilities will be presented.

A replication of the present study using larger sample sizes and with the suggested change in the scale format should be seriously considered. Such a study may result in increasing the length of the scale through the addition of items previously found to be unreliable which in turn may affect changes in items clustered through factor analysis. 
Continued research aimed at determining the relationship between work personality, IQ, and dexterity is expecially important. Analysis of this relationship could eventually lead to the determination of the degree to which each of these variables contributes to the prediction of vocational potential.

Finally, the convergent and discriminant validity of the scale should also be pursued. An interesting study would compare the Work Personality Scale with the VARS, the Adaptive Behavior Scale, the Vineland, The Stanford-Binet and a variety of dexterity tests. A study of this type would clarify the meaning of the components of work personality.

In summary, of the original 49 items, 27 were factor analyzed leading to the identification of four subscales and five single items which makeup the final version of the Work Personality Scale. The psychometric properties determined are promising and indicate that the scale is a reliable instrument when adequate training is provided. However, improved reliability, continued clarification of its relationship with $I Q$ and dexterity, and the determination of its predictive validity will depend on future research. 


\section{BIBLIOGRAPHY}

Anderson, M. L. Education of defectives in the public schools. Yonkers, New York: World Book Pub. Co., 1977.

Bitter, James $A_{.}$, and D. J. Bolanovich. WARF. A scale for measuring job-readiness behaviors. American Journal of Mental Deficiency, 74: 676-621, 1974.

Cohen, Julius M. An analys is of vocational failures of mental retardates placed in the community after a period of institutionalization. American Journal of Mental Deficiency, 65: $371-375,1960$.

Cohen, Julius M. Employer attitudes toward hiring mentally retarded individuals. American Journal of Mental Deficiency 67: 705$713,1963$.

Cowdery, K. M. Measures of general intelligenre as indices of success in trade learning. Journal of Applied Psychology 6: 311-330, 1922.

Cunningham, T., and D. Presnall. Relationship between dimensions of adaptive behavior and sheltered workshop productivity. American Journal of Mental Reficiency, 82: 386-393, 1978.

Elkin, Lorne. Predicting performance of the mentally retarded on shel tered workshop and non-institutional jobs. American Journal of Mental Deficiency, 72: 533-539, 1968.

Fogelman, Charles J. (Ed.). AAMD Adaptive behavior scale manual. Washington, D. C.: American Association of Mental Deficiency, 1975.

Gellman, W. The principles of vocational rehabilitation. Rehabilitation Literature, 29: 49-50, 1968.

Gold, M. Factors affecting productivity. Mental Retardation, 11 (6): $41-45,1973$.

Greenwood, D., and R. Perry. Use of the Adaptive Behavior Checklist as a means of determining unit placement in a facility for the retarded. A paper presented at the meeting of the P.ocky lountain Psychological Association, Denver, Colorado, May 1968.

Guarnaccia, Vincent J. Factor structure and correlates of adaptive behavior in non-institutionalized retarded adults. American Journal of Mental Deficiency, 80: 543-547, 1976. 
Hartzler, Ethel. A follow-up study of girls discharged from the Lauerton State Village. American Journal of Mental Deficiency, 55: $612-618,1951$.

Krantz, Gordon. Critical vocational behaviors. Journal of Rehabilitation, 37: 19-22, 1974.

Larson, Keith H., and J. P. Edwards. Community-based vocational training and placement for the severely handicapped. In C. Hansen (Ed.), Expanding opportunities: Vocational education for the handicapped. Seatt7e, WA: University of Washington Press, 1980 .

Leland, H., M. Shellhaas, K. Nihira, and R. Foster. Adaptive behavior: a new dimension in the classification of the mentally retarded. Mental Retardation Abstracts, 4: 359-387, 1967.

Malgady, R. G., P. R. Barcher, J. Davis, and G. Towner. Validity of the vocational adaptation rating scale: Prediction of mentally retarded worker's placement in sheltered workshops. American Journal of Mental Deficiency, 84: 633-640, 1980.

Michael-Smith, H. A study of the personal characteristics desirable for the vocational success ${ }^{\circ}$ of the mentally deficient. American Journal of Mental Deficiency, 55: 139-143, 1960.

Nie, N. H., C. H. Hall, J. G. Jenkins, K. Steinbrenner, and D. H. Brent. Statistical package for the social sciences, (2nd Ed.). New York: McGraw-Hil1 Book Company, 1975.

Nihira, K. Factorial dimensions of adaptive behavior in adult retardates. American Journal of Mental Deficiency, $\underline{73}$ : 868-878, 1969.

Nihira, K., R. Foster, M. Shellhaas, and H. Leland. AAMD Adaptive Behavior Scale. In Charles J. Fogelman (Ed.), AAMD Adaptive Behavior Scale Manual. Washington, D.C.: American Association of Mental Deficiency, 1975.

Ordahl, George. Industrial efficiency of the moron. Training School Bulletin, 15: 145-153, 1919.

Patterson, C.H. Methods of assessing the vocational adjustment potential of the mentally handicapped. Training School Bulletin. 6l: $129-152,1964$.

Rummel, R.J. Understanding factor analysis. Journal of Conflict Resolution, 11: 444-480, 1967.

Spreat, $S$. The adaptive behavior scale: a study of criterion validity. American Journal of Mental Deficiency, 85: 61-66, 1980. 
Sushan, Robert D. Work behavior rating scale. Los Angeles, California's Exceptional Children's Foundation, 1972.

Tate, Robert G. and George S. Baroff. Training the mentally retarded in the production of a complex product: A demonstration of work potential. Exceptional Children, 27: 405-408, 1967.

Thomas, C., D. Sprangler, and G. Izutsu. Some fundamental propositions in the construction of evaluation units in vocational rehabilitation. Personnel and Guidance Journal, 39: 584-590, 1961.

Tiffin, Joseph. Purdue pegboard examiner manual. Chicago, 111.: Science Research Associates Inc., 1968.

Tobias, J. and J. Gorelick. The effectiveness of the Purdue Pegboard in evaluating work potential of mentally retarded adults. Training School Bulletin, 57: 94-103, 1960.

Warren, F. G. Ratings of employed and unemployed mentally handicapped males on personality and work factors. American Journal of Mental Deficiency, 65: 629-633, 1961.

Wechsler, David. Wechsler adult intelligence scale manual. New York: The Psychological Corporation, 1955.

Windle, Charles. Prognosis of mental subnormals: A critical review of research. American Journal of Mental Deficiency, 66: 1-179, 1962. 
APPENDIX I

BEHAVIORAL SKETCH 
Chris is a 22 year old male whose IQ has been measured at 69. He has no identified physical problems and no physical limitations have been indicated. Chris has been in program for two months and is currently being trained in general assembly. On the first day of each week, he arrives at work 10-15 minutes late but is on time during the remainder of the week. He arrives properly attired for work with his hair combed but by the appearance of his hands and face, you would guess that he rarely showers. This is a consistent problem and he does not respond to daily supervisor reminders.

Upon arriving at work, he reports directly to his work station and waits for one of the supervisors to instruct him to begin work. You note that he waits for instruction even when he is to resume the same job task he was working on the day before. Chris always returns from breaks and lunch punctually but usually needs to be prompted to continue his work. He never leaves his work station without permission but only rarely remembers to inform his supervisor of an extended leave (i.e., vacation day, doctors appointment). Chris is rarely absent from work due to iliness; missing only one day this month.

Chris works below the average workshop productivity (25\%) when left unsupervised but rarely makes mistakes. You feel, however, that his productivity could be at least $15 \%$ higher because his work pace seems to be easily affected by what is going on around him. You note that on the majority of tasks, he needs occassional reminders to maintain his attention to the task 
at hand, as he will often discontinue work to offer his help to others. In general, Chris requires an average amount of supervision to maintain maximum work speed and work quality; requiring additional supervision and support to insure that he doesn't become discouraged and minds his own business.

When learning a new task, you observe that he needs the instructions repeated 2-3 times and often requires that the task be demonstrated before he can successfully complete the movements. Once he seems to have a grasp on the new task, improvement is slow, usually taking 3-4 more hours before he can execute the operation smoothly. Finally, you note that when Chris is first informed that he will be learning a new job, his response is one of self-doubt and uncertainty. He initially refuses to try but with a few supportive comments from his supervisor, he always agrees to make an attempt and without fail finds that he can easily perform the new task. At this point his attitude changes and he now expresses great enthusiasm and a re-newed confidence in himself. This same pattern of behavior is observed each time a new task is introduced.

With regards to his interactions with staff and co-workers, you have made a number of observations; Observation 1.: You find that Chris is generally a very happy person; only rarely having an off-day when he seems to withdraw and become unresponsive to all. You usually find him pleasant to work with and very willing to cooperate with staff members and he will often go out of his way to please others. His willingness to please seems to be his greatest asset al though he occassionally goes overboard; seeking 
supervisor approval more often than is necessary. You estimate that he asks for approval 4-5 times a day.

Observation 2.: Chris has some difficulty dealing with criticism but only because he seems to interpret any criticism as an indication that you are displeased with him personally. You find that unless you are very careful in how you present the criticism, he will withdraw and you will consequently have to convince him that you are not unhappy with him. If this reassurance is not provided, he will remain withdrawn and unresponsive until the next work day, seemingly forgetting the incident overnight.

Observation 3.: A.1 though Chris can verbally make himself understood, he does seem to have some difficulty in asking for assistance. You have observed that when he runs into a problem, he will discontinue work and wait until you notice him rather than seek you out at the time the problem arises.

Observation 4.: You find that when Chris is having persistent problems with a job task or when under pressure to work faster, he responds by either discontinuing work or withdrawing. He rarely gets angry or looses his temper however, and if he is dealt with before he completely withdraws, the problem is easily resolved.

Observation 5.: Chris' interaction skills with his co-workers are good to excellent. In assembly line situations, he cooperates well with the other team members although he at times falls behind, slowing down the group productivity. He socializes appropriately with his co-workers and in fact seems to be accepted by even the 
higher functioning trainees.

In summary, Chris appears to be a responsible and mature individual. Although he does have occasional off days when he may withdraw, he is usually polite, enthusiastic and easy to work with. His strong points include a willingness and desire to please and perform well and a generally positive attitude towards work. His main weakness is his lack of confidence, the effect of which is observed in his inability to accept constructive criticism and his inability to adapt to changes in work tasks. Finally, Chris seems to have a slight problem in minding his own business and attending to his work task. 
APPENDIX II

INSTRUCTIONS PROVIDED TO RATERS FOR

SCORING SCALE ITEMS 
ITEM

(3) Enthusiasm, cheerfuiness

(4) Maturity

(6) Work quality

(8) Ability to follow instructions

(10) Work speed

(12) Reaction to frustration

(13) Ability to ask for assistance

(14) Minds own business

\section{INSTRUCTIONS}

Focus on overall or general attitude. Consider manners, emotional characteristics reaction to stress etc., then rate overall level of maturity. Assume that a rejection rate of $10-$ $15 \%$ is average and rate accordingly. Assume instructions are understood. Do not consider willingness to follow instructions.

Rate work speed when unsupervised.

Stress: IInusual or conflicting situations.

Frustration: Discouraging or disappointing situations.

Focus primarily on willingness and promptness. Do not devaluated the trainee who attempts to communicate but has difficulty in getting message across. "D" descriptor criterion: 5-10X daily. "C" descriptor criterion: 1-2 X daily. "B" descriptor criterion: 1-2 X weekly. 
ITEM

(19) Vocal habits

(21) Response to criticism

(22) Consistency of work pace

(25) Ability to work as team member

(27) Attendance
INSTRUCTIONS

Focus on ability to verbalize. A deaf person who has no speech should not be rated on this item. Please indicate on the rating form when this occurs. Criticism-negative feedback. Focus on frequency with which trainee responds negatively to criticism. Stress frequency of fluctuations rither than the degree that work is affected as a result of inconsistencies.

Focus on ability to keep pace with team members.

Include all days absent from work except days for which prior permission has been obtained. 
APPENDIX III

OPERATIONAL DEFINITIONS OF INTERFERING BEHAVIORS 
1. Excessive Talking: Frequency with which trainee: (1) talks unecessarily with co-workers duing work periods, or (2) talks beyond what is necessary when communicating with supervisors (i.e., trainee takes 10 minutes to explain why he/she made a particular mistake).

2. Excessive Need for Supervisory Attention: Frequency with which trainee: (1) verbally requests help or approval from supervisor beyond what is necessary to insure quality work, (i.e.. trainee repeatedly asks supervisor how he/she is doing on a job), or (2) trainee continually contacts superior to discuss unecessary or inappropriate topics (i.e., trainee tells supervisor about his/her latest sexual adventure).

3. Use of Profanity: Frequency with which trainee uses profanity unecessaily-at the slightest provocation- or in a loud, obnoxious manner.

4. Excessive Concern over Illnesses and/or Problems: Frequency with which trainee: (1) verbalizes his/her concerns repeatediy to same person or to as many people who will listen, or (2) begins each new day or week with a new illness or problem which will need to be resolved by a supervisor or counselor.

5. Withdraws or Isolates Self: Frequency with which trainee becomes unresponsive or physically isolates self from others.

6. Arques with Supervisor: Frequency with which trainee openly disputes a supervisors authority. 
7. Hyperactivity: Frequency with which trainee displays: (1) excessive motor activity (i.e., continual change of work positions or movement around work area) or (2) impulsiveness as demonstrated by sudden spontaneous bursts of movements or verbalizations.

8. Engages in Attention-Getting Behaviors: Frequency with which trainee engages in behaviors, such as making loud noises, sticking out tongue or teasing co-workers, solely for purpose of gaining supervisor or co-work attention. Attention received is usually negative.

9. Rocks or Exhibits Stereotyped Movements: Frequency with which trainee rocks (moves rhythmically back and forth or side to side) or exhibits stereotyped movements such as rubbing beard, touching nose or moving hand in front of face. Four or more successive repetitions of any of these stereotyped movements would constitute a single (1) occurrence.

10. Talks to Self while Working: Frequency with which this behavior is observed.

11a. Inappropriate Expression of Affection: Frequency with which trainee hugs, kisses or repeatedly touches a supervisor or a co-worker. Exclude those occurrences which you feel were justified by the nature of the circumstances (i.e., kissing a co-worker good-bye on his/her last day).

11b. Unacceptable Sexual Behaviors: Frequency with which trainee masturbates, makes a sexual advance toward a supervisor or co-worker 
or exhibits him/herself sexually in a public place.

12. Uncontrolled seizures: Frequency with which trainee has an observable seizure as evidenced by convulsions, shaking or quivering, loss of consciousness or absent spells which unexpectediy interrupts speech or motor movements.

13. Temper Tantrums: Frequency with which trainee looses control emotionally and/or physically: shouting, screaming, throwing objects or physically attacking another person.

14. Sleeping on the Job: Frequency with which trainee falls asleep while performing a job task.

15. Self Abuse: Frequency with which trainee hits, bites or mutilates a part of his/her own body. 
APPENDIX IV

TABLES 


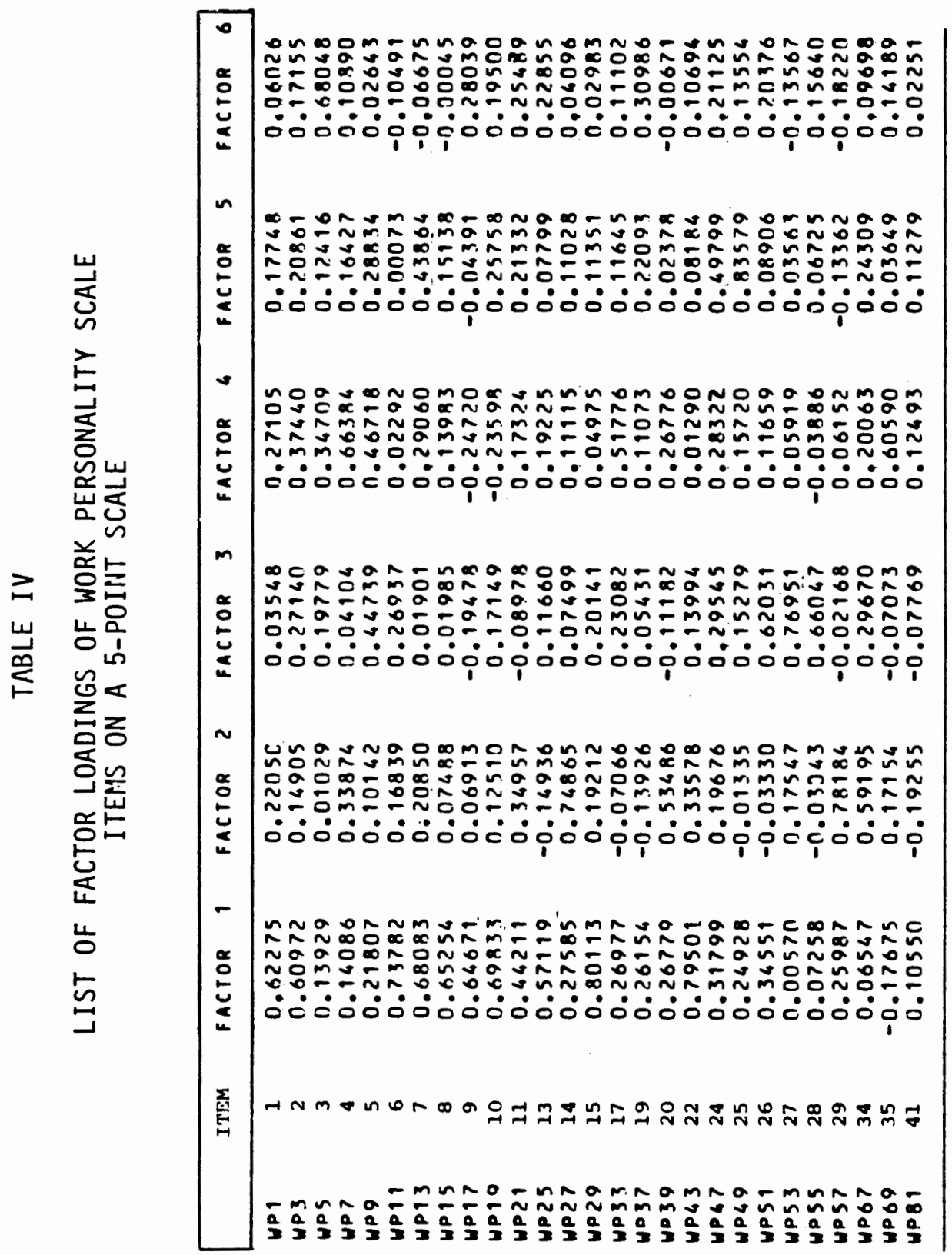




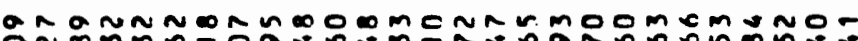

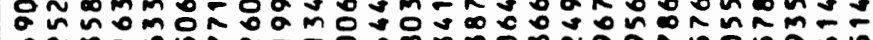

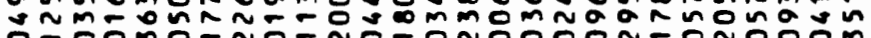

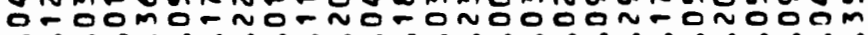
- ópó00

nooknogaxnocnN n N Nmm. ñm⿻C-mas

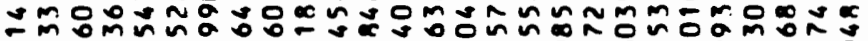

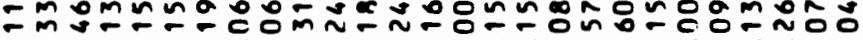

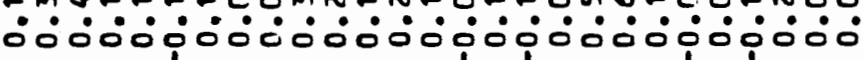

ㄷmon-5ーニ

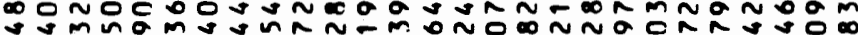

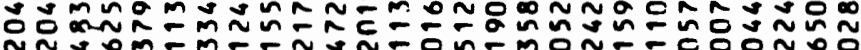
nN $\therefore 00000000000000000000000$

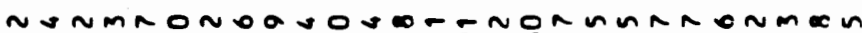

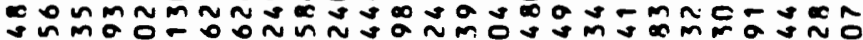

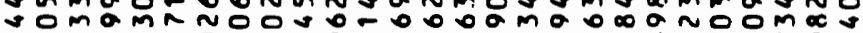

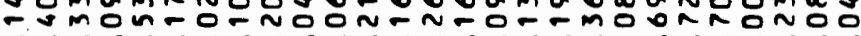

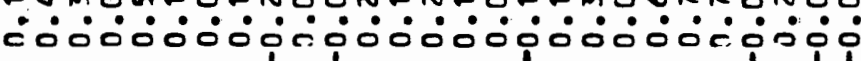
任

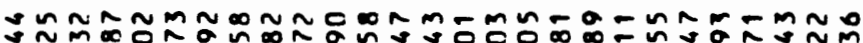

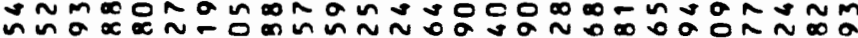

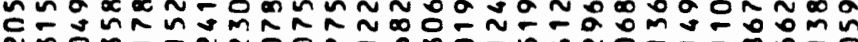

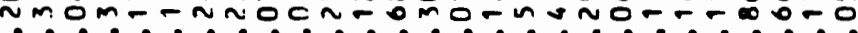
○ं

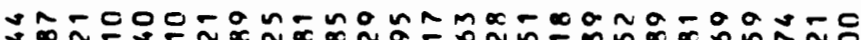

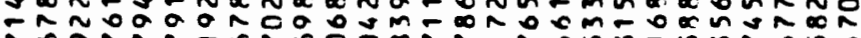

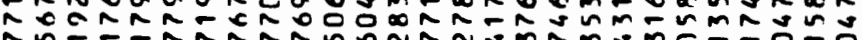

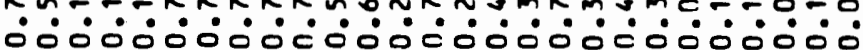
年,

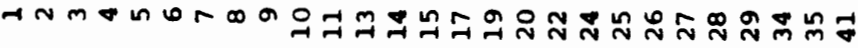

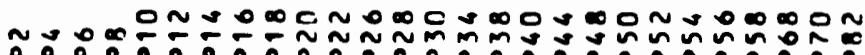

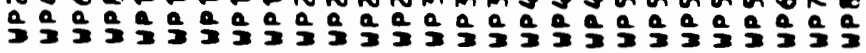


TABLE VI

FREQUENCY DISTRIBUTION AND DESCRIPTIVE STATISTICS OF SUBSCALE 1 ITEMS ON THE 5-POINT FORMAT

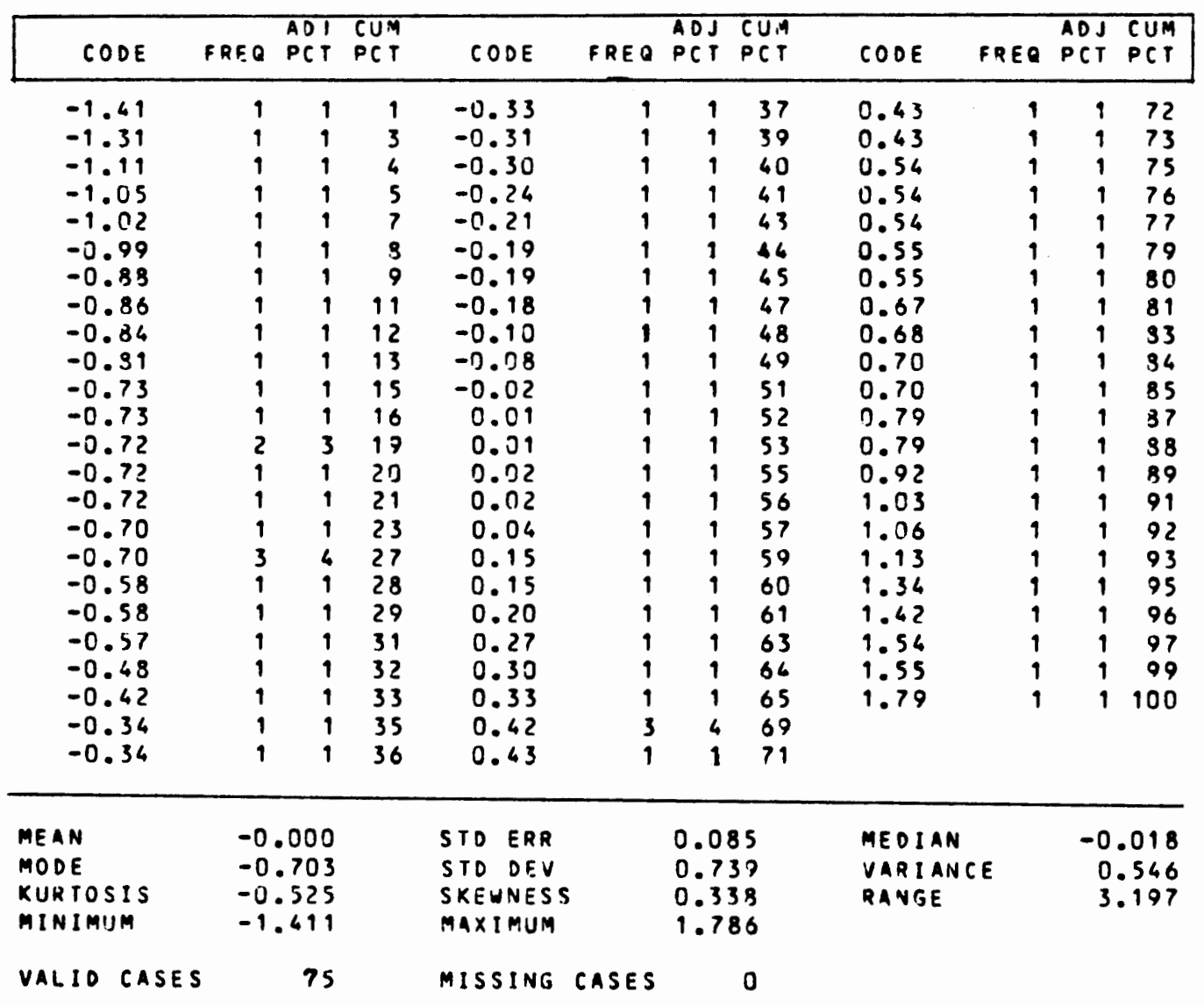




\section{TABLE VII}

FREQUENCY DISTRIBUTION AND DESCRIPTIVE STATISTICS OF SUBSCALE 1 ITEMS ON THE 9-POINT FORMAT

\begin{tabular}{|c|c|c|c|c|c|c|c|c|c|c|c|}
\hline COOE & FREO & $\begin{array}{l}A D J \\
P C T\end{array}$ & $\begin{array}{l}\text { CUM } \\
\text { PCT }\end{array}$ & CODE & FREO & $\begin{array}{l}A D J \\
P C T\end{array}$ & $\begin{array}{l}C U M \\
P C T\end{array}$ & COOE & F REO & $\begin{array}{l}A D J \\
P C T\end{array}$ & $\begin{array}{l}\text { CUM } \\
\text { PCT }\end{array}$ \\
\hline $\begin{array}{l}-1.71 \\
-1.66 \\
-1.59 \\
-1.58 \\
-1.57 \\
-1.40 \\
-1.32 \\
-1.31 \\
-1.09 \\
-1.02 \\
-1.02 \\
-0.91 \\
-0.77 \\
-0.72 \\
-0.68 \\
-0.67 \\
-0.67 \\
-0.55 \\
-0.51 \\
-0.51 \\
-0.50 \\
-0.47 \\
-0.42 \\
-0.41 \\
-0.40\end{array}$ & $\begin{array}{l}1 \\
1 \\
1 \\
1 \\
1 \\
1 \\
1 \\
1 \\
1 \\
1 \\
1 \\
1 \\
1 \\
1 \\
1 \\
1 \\
1 \\
1 \\
1 \\
1 \\
1 \\
1 \\
1 \\
1 \\
1\end{array}$ & $\begin{array}{l}1 \\
1 \\
1 \\
1 \\
1 \\
1 \\
1 \\
1 \\
1 \\
1 \\
1 \\
1 \\
1 \\
1 \\
1 \\
1 \\
1 \\
1 \\
1 \\
1 \\
1 \\
1 \\
1 \\
1 \\
1\end{array}$ & $\begin{array}{l}1 \\
3 \\
4 \\
5 \\
7 \\
3 \\
9 \\
11 \\
12 \\
13 \\
15 \\
16 \\
17 \\
19 \\
20 \\
21 \\
23 \\
24 \\
25 \\
27 \\
28 \\
29 \\
31 \\
32 \\
33\end{array}$ & $\begin{array}{l}-0.29 \\
-0.13 \\
-0.07 \\
-0.04 \\
-0.04 \\
-0.03 \\
-0.03 \\
-0.01 \\
0.08 \\
0.03 \\
0.03 \\
0.14 \\
0.14 \\
0.16 \\
0.16 \\
0.17 \\
0.19 \\
0.20 \\
0.23 \\
0.30 \\
0.38 \\
0.41 \\
0.43 \\
0.44 \\
0.47\end{array}$ & $\begin{array}{l}1 \\
1 \\
1 \\
1 \\
1 \\
1 \\
1 \\
1 \\
1 \\
1 \\
1 \\
1 \\
1 \\
1 \\
1 \\
1 \\
1 \\
1 \\
1 \\
1 \\
1 \\
1 \\
1 \\
1 \\
1\end{array}$ & $\begin{array}{l}1 \\
1 \\
1 \\
1 \\
1 \\
1 \\
1 \\
1 \\
1 \\
1 \\
1 \\
1 \\
1 \\
1 \\
1 \\
1 \\
1 \\
1 \\
1 \\
1 \\
1 \\
1 \\
1 \\
1 \\
1\end{array}$ & $\begin{array}{l}35 \\
36 \\
37 \\
39 \\
40 \\
41 \\
43 \\
44 \\
45 \\
47 \\
48 \\
49 \\
51 \\
52 \\
53 \\
55 \\
56 \\
57 \\
59 \\
60 \\
61 \\
63 \\
64 \\
65 \\
67\end{array}$ & $\begin{array}{l}0.50 \\
0.52 \\
0.54 \\
0.55 \\
0.56 \\
0.50 \\
0.62 \\
0.64 \\
0.71 \\
0.71 \\
0.71 \\
0.72 \\
0.72 \\
0.77 \\
0.78 \\
0.82 \\
0.85 \\
0.87 \\
1.00 \\
1.05 \\
1.09 \\
1.10 \\
1.13 \\
1.19 \\
1.28\end{array}$ & $\begin{array}{l}1 \\
1 \\
1 \\
1 \\
1 \\
1 \\
1 \\
1 \\
1 \\
1 \\
1 \\
1 \\
1 \\
1 \\
1 \\
1 \\
1 \\
1 \\
1 \\
1 \\
1 \\
1 \\
1 \\
1 \\
1\end{array}$ & $\begin{array}{l}1 \\
1 \\
1 \\
1 \\
1 \\
1 \\
1 \\
1 \\
1 \\
1 \\
1 \\
1 \\
1 \\
1 \\
1 \\
1 \\
1 \\
1 \\
1 \\
1 \\
1 \\
1 \\
1 \\
1 \\
1\end{array}$ & $\begin{array}{r}68 \\
69 \\
71 \\
72 \\
73 \\
75 \\
76 \\
77 \\
79 \\
80 \\
81 \\
83 \\
84 \\
85 \\
87 \\
88 \\
89 \\
91 \\
92 \\
93 \\
95 \\
96 \\
97 \\
99 \\
100\end{array}$ \\
\hline $\begin{array}{l}\text { MEAN } \\
\text { MODE } \\
\text { KURTOS IS } \\
\text { MINIMUM }\end{array}$ & \multicolumn{3}{|c|}{$\begin{array}{l}-0.000 \\
-1.707 \\
-0.561 \\
-1.707\end{array}$} & $\begin{array}{l}\text { STD ERR } \\
\text { STD DEV } \\
\text { SKEWNESS } \\
\text { MAXIMIJM }\end{array}$ & \multicolumn{3}{|c|}{$\begin{array}{r}0.091 \\
0.786 \\
-0.54 .3 \\
1.280\end{array}$} & \multicolumn{2}{|l|}{$\begin{array}{l}\text { MEOIAN } \\
\text { VARIANCE } \\
\text { RANGE }\end{array}$} & \multicolumn{2}{|c|}{$\begin{array}{l}0.140 \\
0.617 \\
2.988\end{array}$} \\
\hline VALIO CASES & & 75 & & MISSING & CASES & & 0 & & & & \\
\hline
\end{tabular}


TABLE VIII

FREQUENCY DISTRIBUTION AND DESCRIPTIVE STATISTICS OF SUBSCALE 2 ITEMS ON THE 5-POINT FORMAT

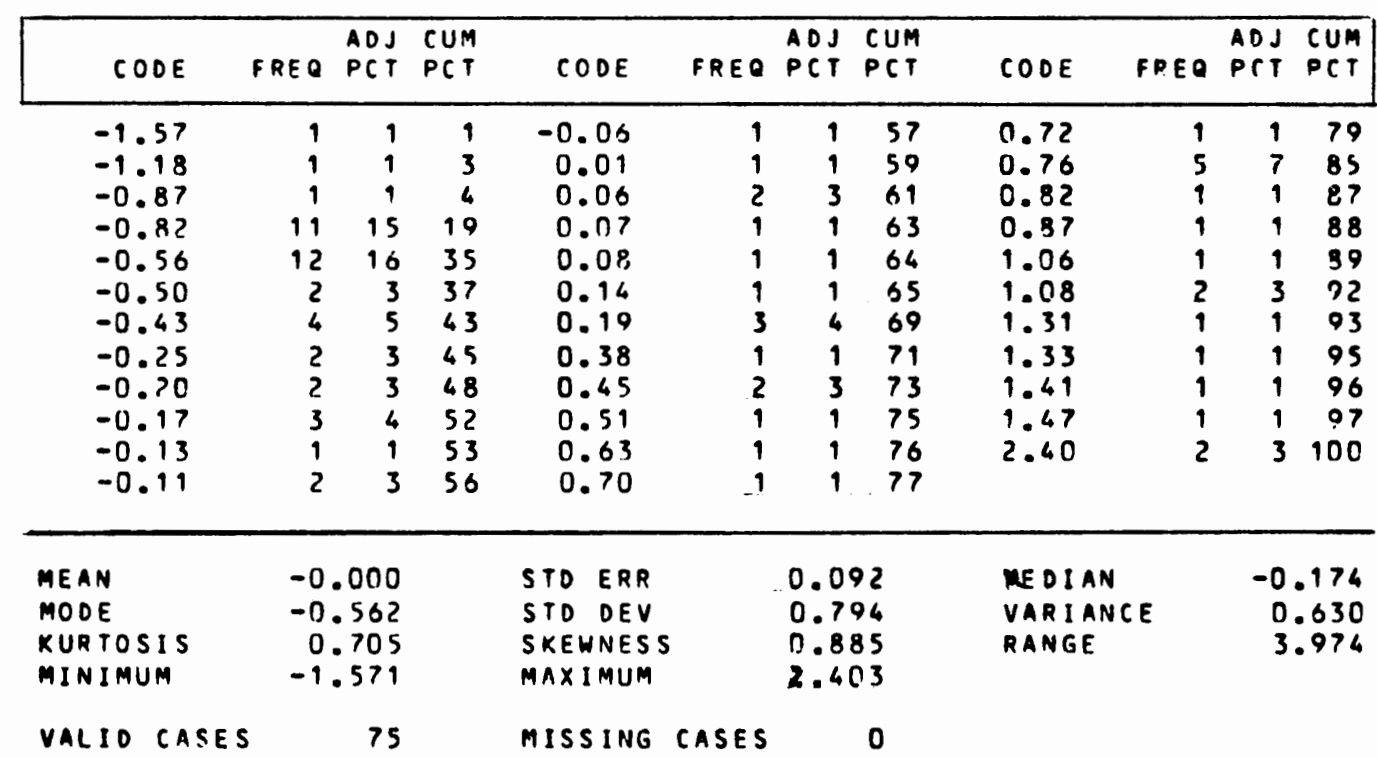


TABLE IX

FREQUENCY DISTRIBUTION AND DESCRIPTIVE STATISTICS OF SUBSCALE 2 ITEMS ON THE 9-POINT FORMAT

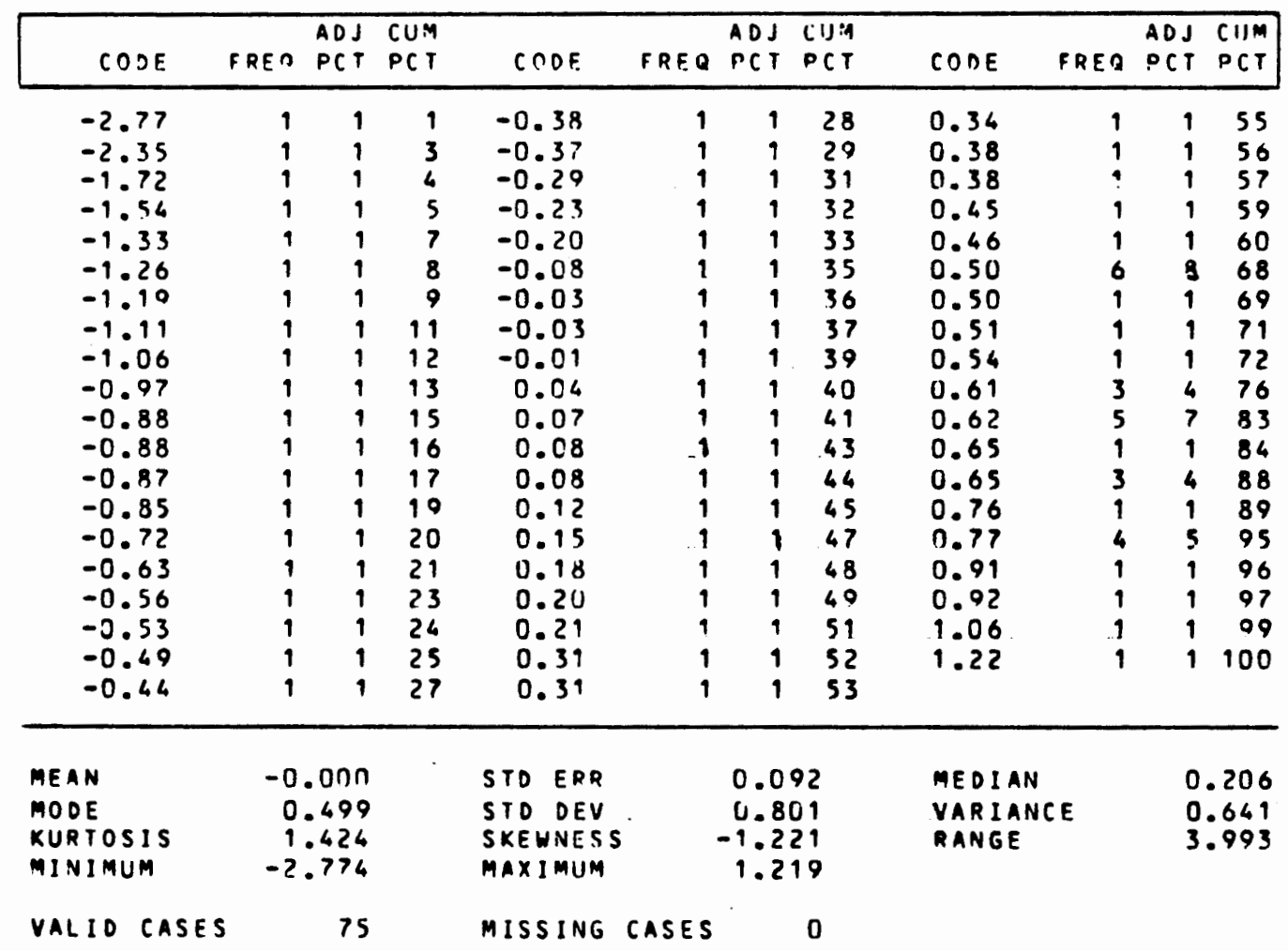


TABLE $X$

FREQUENCY DISTRIBUTION AND DESCRIPTIVE STATISTICS OF SUBSCALE 3 ITEMS ON THE 9-POINT FORMAT

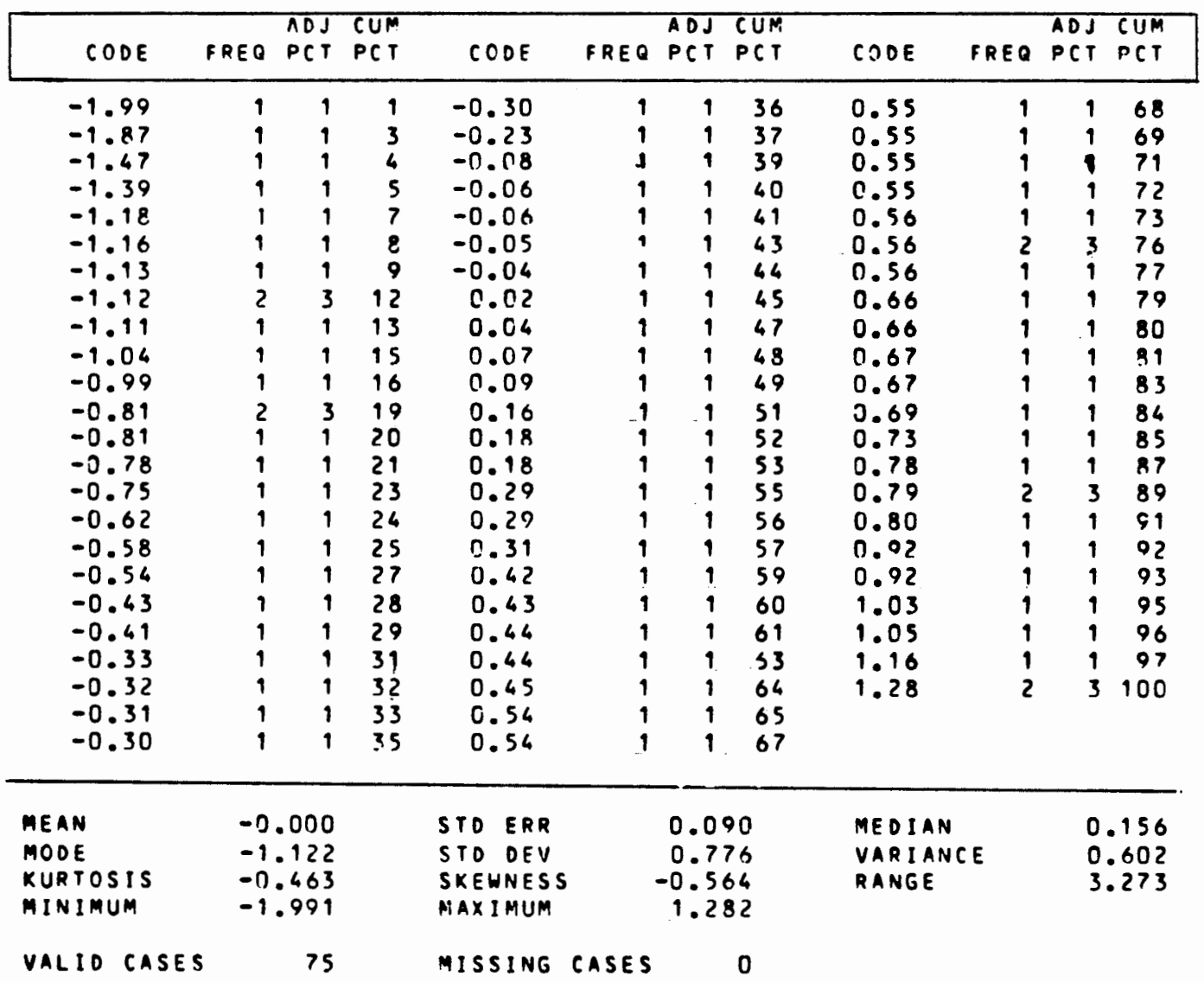


TABLE XI

FREQUENCY DISTRIBUTION AND DESCRIPTIVE STATISTICS OF SUBSCALE 3 ITEMS ON THE 5-POINT FORMAT

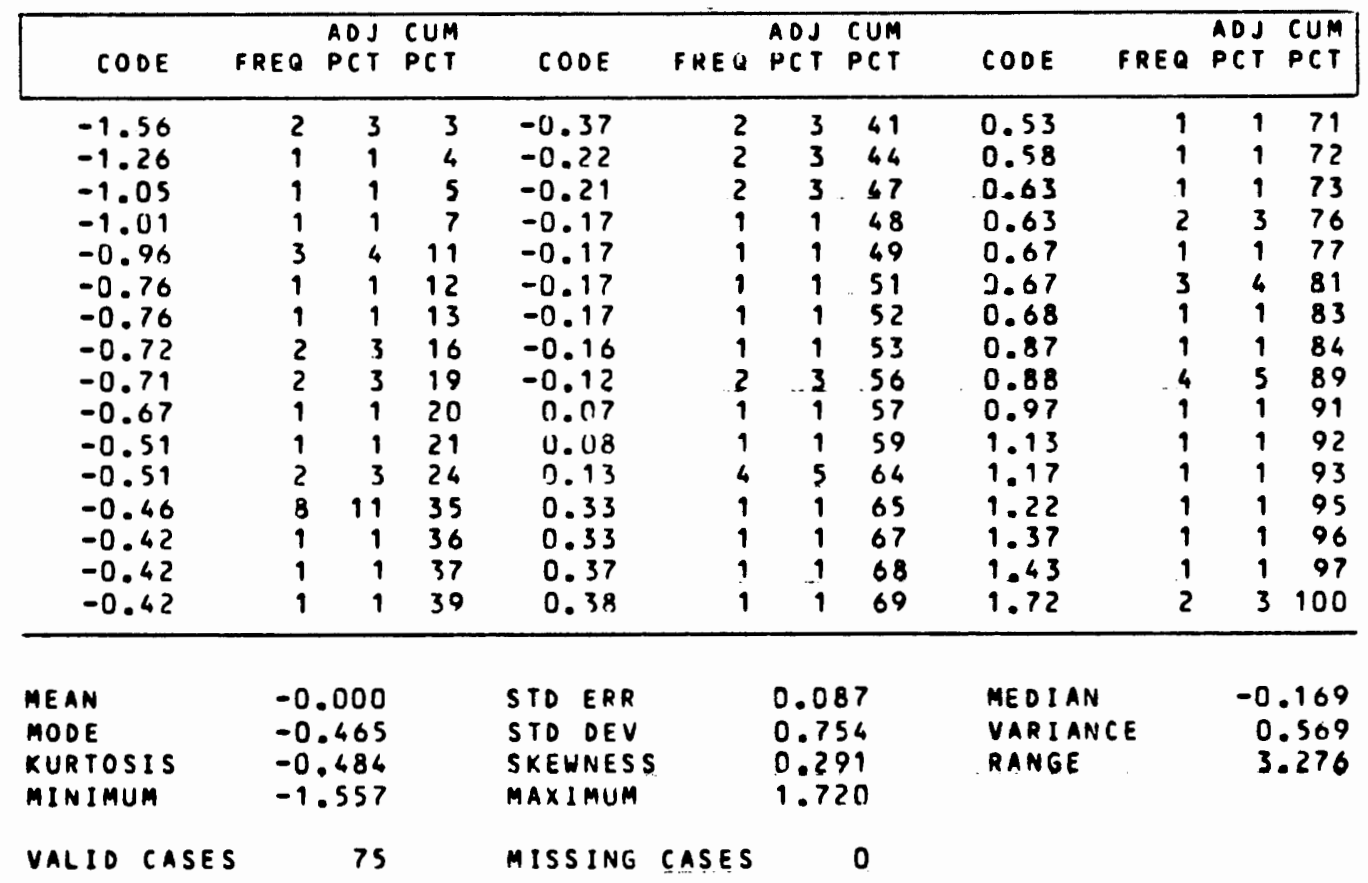


TABLE XII

FREQUENCY DISTRIBUTION AND DESCRIPTIVE STATISTICS OF SUBSCALE 4 ITEMS ON THE 5-POINT FORMAT

\begin{tabular}{|c|c|c|c|c|c|c|c|c|c|c|}
\hline CODE & F REQ & $\begin{array}{l}\text { ADJ } \\
\text { PCT }\end{array}$ & $\begin{array}{l}\text { CUM } \\
\text { PCT }\end{array}$ & CODE & FREO & $\begin{array}{l}A O J \\
P C T\end{array}$ & $\begin{array}{l}\text { CUM } \\
\text { PCT }\end{array}$ & CODE & FREQ & $\begin{array}{l}\text { AOJ CUM } \\
\text { PCT PCT }\end{array}$ \\
\hline $\begin{array}{l}-1.43 \\
-0.95 \\
-0.53 \\
-0.50 \\
-0.46 \\
-0.04 \\
-0.01\end{array}$ & $\begin{array}{r}2 \\
5 \\
2 \\
? 2 \\
2 \\
4 \\
2\end{array}$ & $\begin{array}{r}3 \\
7 \\
3 \\
29 \\
3 \\
5 \\
3\end{array}$ & $\begin{array}{r}3 \\
9 \\
12 \\
41 \\
44 \\
49 \\
52\end{array}$ & $\begin{array}{r}-0.01 \\
0.44 \\
0.47 \\
0.47 \\
0.48 \\
0.90 \\
0.92\end{array}$ & $\begin{array}{r}11 \\
9 \\
1 \\
3 \\
1 \\
2 \\
4\end{array}$ & $\begin{array}{r}15 \\
12 \\
1 \\
4 \\
1 \\
3 \\
5\end{array}$ & $\begin{array}{l}67 \\
79 \\
80 \\
84 \\
85 \\
88 \\
93\end{array}$ & $\begin{array}{l}0.95 \\
1.41 \\
1.44 \\
1.86 \\
3.31\end{array}$ & $\begin{array}{l}1 \\
1 \\
1 \\
1 \\
1\end{array}$ & $\begin{array}{rr}1 & 95 \\
1 & 96 \\
1 & 97 \\
1 & 99 \\
1 & 100\end{array}$ \\
\hline $\begin{array}{l}\text { MEAN } \\
\text { MODE } \\
\text { KURTOSIS } \\
\text { MINIMUM }\end{array}$ & $\begin{array}{r}0 \\
-0 \\
4 \\
-1\end{array}$ & $\begin{array}{l}.000 \\
496 \\
033 \\
434\end{array}$ & & $\begin{array}{l}\text { STD ERR } \\
\text { STD DEV } \\
\text { SKEWNESS } \\
\text { MAXIMUM }\end{array}$ & & $\begin{array}{l}0.0 \\
0.7 \\
1.3 \\
3.3\end{array}$ & & $\begin{array}{l}\text { MEDIAN } \\
\text { VARIANCE } \\
\text { RANGE }\end{array}$ & & $\begin{array}{r}-0.016 \\
0.571 \\
4.740\end{array}$ \\
\hline VAL ID CASES & & 75 & & MISSING & CASES & & 0 & & & \\
\hline
\end{tabular}

\section{TABLE XIII}

FREQUENCY DISTRIBUTION AND DESCRIPTIVE STATISTICS OF SUBSCALE 4 ITEMS ON THE 9-POINT FORMAT

\begin{tabular}{|c|c|c|c|c|c|c|c|c|c|c|c|}
\hline CODE & FRE ? & $\begin{array}{l}A D J \\
P C T\end{array}$ & $\begin{array}{l}\text { CUM } \\
\text { PCT }\end{array}$ & CODE & FREQ & $\begin{array}{l}\text { ADJ } \\
\text { PCT }\end{array}$ & $\begin{array}{l}\text { CUM } \\
\text { PCT }\end{array}$ & CODE & FREQ & $\begin{array}{l}\text { ADJ } \\
\text { PCT }\end{array}$ & $\begin{array}{l}\text { CUM } \\
\text { PCT }\end{array}$ \\
\hline $\begin{array}{l}-3.48 \\
-2.10 \\
-1.70 \\
-1.20 \\
-1.06 \\
-0.99 \\
-0.97 \\
-0.97 \\
-0.73 \\
-0.73 \\
-0.61 \\
-0.54 \\
-0.52\end{array}$ & $\begin{array}{l}1 \\
1 \\
1 \\
1 \\
1 \\
1 \\
1 \\
1 \\
2 \\
1 \\
1 \\
1 \\
1\end{array}$ & $\begin{array}{l}1 \\
1 \\
1 \\
1 \\
1 \\
1 \\
1 \\
1 \\
3 \\
1 \\
1 \\
1 \\
1\end{array}$ & $\begin{array}{l}1 \\
3 \\
4 \\
5 \\
7 \\
8 \\
9 \\
11 \\
13 \\
15 \\
16 \\
17 \\
19\end{array}$ & $\begin{array}{r}-0.51 \\
-0.35 \\
-0.33 \\
-0.33 \\
-0.30 \\
-0.30 \\
-0.30 \\
-0.14 \\
-0.09 \\
-0.09 \\
-0.09 \\
-0.09 \\
0.12\end{array}$ & $\begin{array}{l}1 \\
1 \\
1 \\
1 \\
1 \\
3 . \\
1 \\
1 \\
1 \\
4 \\
2 \\
2 \\
2\end{array}$ & $\begin{array}{l}1 \\
1 \\
1 \\
1 \\
1 \\
4 \\
1 \\
1 \\
1 \\
5 \\
3 \\
3 \\
3\end{array}$ & $\begin{array}{l}20 \\
21 \\
23 \\
24 \\
25 \\
29 \\
31 \\
32 \\
33 \\
39 \\
41 \\
44 \\
47\end{array}$ & $\begin{array}{l}0.12 \\
0.12 \\
0.34 \\
0.34 \\
0.34 \\
0.34 \\
0.53 \\
0.55 \\
0.55 \\
0.76 \\
0.76 \\
0.98 \\
1.19\end{array}$ & $\begin{array}{r}4 \\
1 \\
2 \\
10 \\
2 \\
1 \\
1 \\
1 \\
8 \\
3 \\
3 \\
2 \\
2\end{array}$ & $\begin{array}{r}5 \\
1 \\
3 \\
13 \\
3 \\
1 \\
1 \\
1 \\
11 \\
4 \\
4 \\
3 \\
3\end{array}$ & $\begin{array}{r}52 \\
53 \\
56 \\
59 \\
72 \\
73 \\
75 \\
76 \\
87 \\
91 \\
95 \\
97 \\
100\end{array}$ \\
\hline $\begin{array}{l}\text { MEAN } \\
\text { MODE } \\
\text { KURTOSIS } \\
\text { MINIMUM }\end{array}$ & \multicolumn{3}{|c|}{$\begin{array}{r}-0.000 \\
0.336 \\
5.733 \\
-3.476\end{array}$} & $\begin{array}{l}\text { STD ERR } \\
\text { STD DEV } \\
\text { SKEWNESS } \\
\text { MAXIMUM }\end{array}$ & 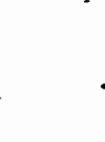 & \multicolumn{2}{|c|}{$\begin{array}{r}0.086 \\
0.749 \\
-1.781 \\
1.189\end{array}$} & \multirow{2}{*}{\multicolumn{2}{|c|}{$\begin{array}{l}\text { MEDIAN } \\
\text { VAR I ANCE } \\
\text { RANGE }\end{array}$}} & \multirow{2}{*}{\multicolumn{2}{|c|}{$\begin{array}{l}0.124 \\
0.561 \\
4.665\end{array}$}} \\
\hline VALID CASES & & 75 & & MISSING. & CASES & & 0 & & & & \\
\hline
\end{tabular}


TABLE XIV

MEANS AND STANDARD DEVIATIONS OF WORK PERSONALITY SCALE ITEMS ON THE 5-POINT FORMAT

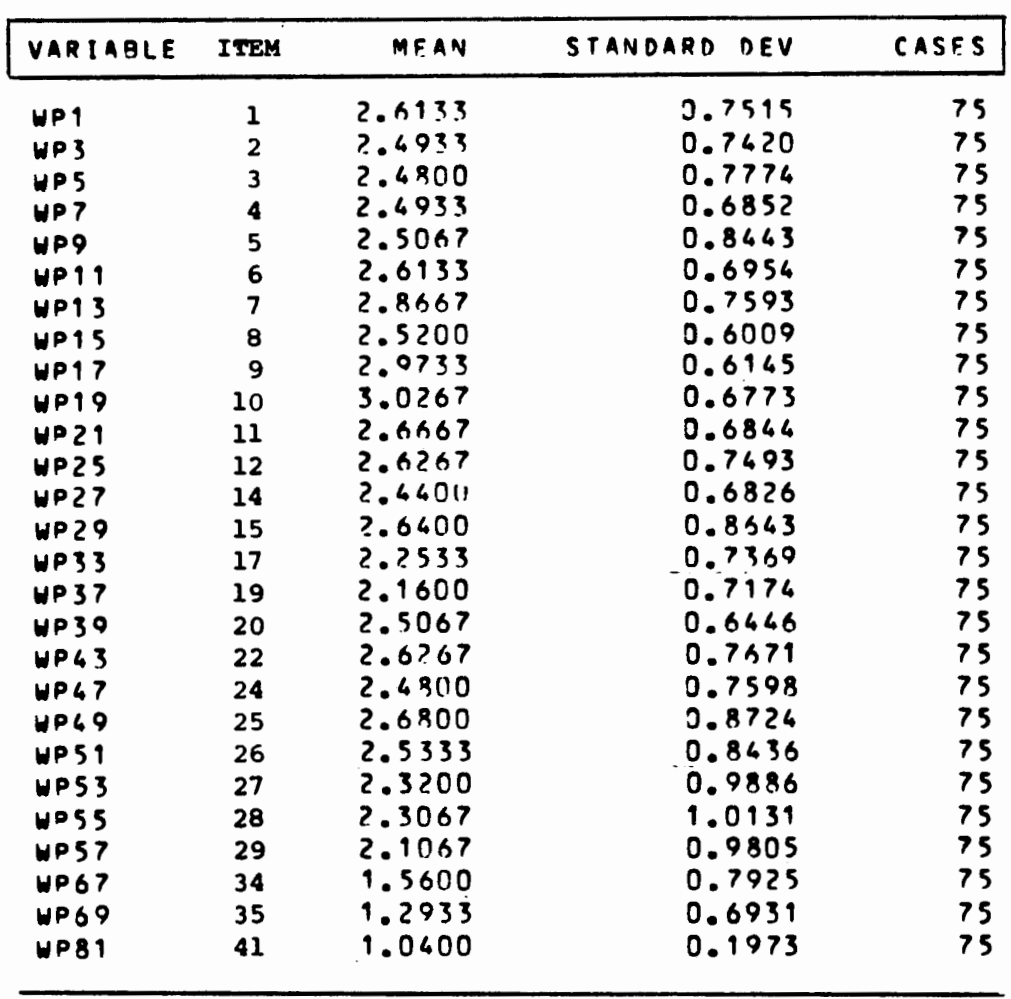


TABLE XV

MEANS AND STANDARD DEVIATIONS OF WORK PERSONALITY SCALE ITEMS ON THE 5-POINT FORMAT

\begin{tabular}{|c|c|c|c|c|}
\hline VARIABLE & ITEM & MEAN & STANDARD DEV & CASES \\
\hline$W P Z$ & 1 & 5.8933 & 1.8649 & 75 \\
\hline$W 04$ & 2 & $6.2 .4 n 0$ & 1.7386 & 75 \\
\hline WPG & 3 & 6.3467 & 1.6562 & 75 \\
\hline WP 8 & 4 & 6.1467 & 1.5656 & 75 \\
\hline WP1O & 5 & 6.1467 & 2.0381 & 75 \\
\hline WP12 & 6 & 6.1067 & 1.5646 & 75 \\
\hline WP14 & 7 & 5.5067 & 1.7658 & 75 \\
\hline WP16 & 8 & 6.2000 & 1.5067 & 75 \\
\hline WP18 & 9 & 5.0400 & 1.5373 & 75 \\
\hline WP 20 & 10 & 4.8267 & 1.6956 & 75 \\
\hline WP2Z & 11 & 5.9867 & 1.5891 & 75 \\
\hline WP 26 & 13 & 5.3800 & 1.8741 & 75 \\
\hline WP28 & 14 & 6.2133 & 1.7029 & 75 \\
\hline WP 30 & 15 & 5.9200 & 1.9155 & 75 \\
\hline WP34 & 17 & 6.8667 & 1.5625 & 75 \\
\hline WP38 & 19 & 6.9733 & 1.5332 & 75 \\
\hline WP 40 & 20 & 6.2667 & 1.61 .36 & 79 \\
\hline WP G 4 & 22 & 5.9733 & 1.6763 & 75 \\
\hline WPG 8 & 24 & $6 . ? 267$ & 1.6892 & 75 \\
\hline WPSO & 25 & 5.8533 & 9.9361 & 75 \\
\hline WP52 & 26 & 6.0133 & 1.9898 & 75 \\
\hline WP 54 & 27 & 6.6400 & 2.2580 & 7 \\
\hline WP56 & 28 & 6.6667 & 1.9759 & 79 \\
\hline WPSB & 29 & 6.9867 & 2.1592 & 75 \\
\hline WP68 & 34 & 8.0000 & 1.6357 & 75 \\
\hline WP>D & 35 & 8.4667 & 1.4078 & 79 \\
\hline WP 82 & 41 & 8.9467 & 0.2796 & 79 \\
\hline
\end{tabular}




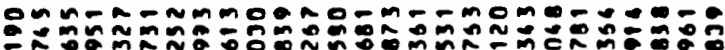

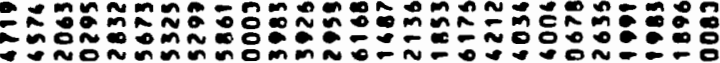
Non

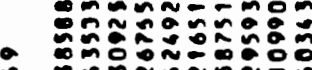

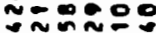

000 (1)

ะㅜำ

ผ

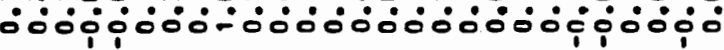

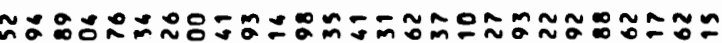

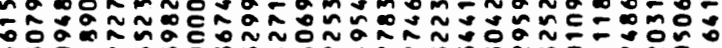

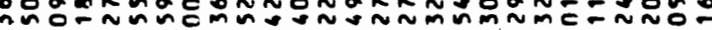

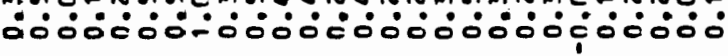

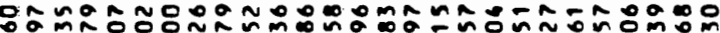

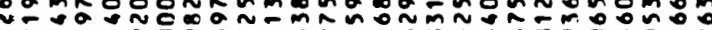

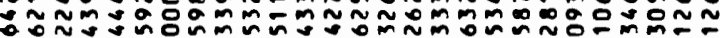

व0ं0்

年00000

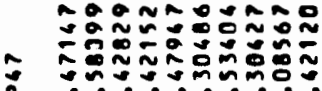

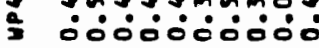

우우운

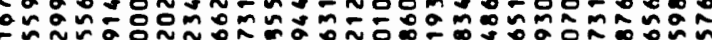

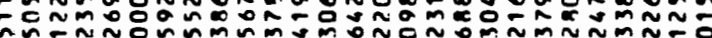

- $\dot{0} \dot{0} 0-\dot{0} 0 \dot{0} 00 \dot{0} \dot{0} 00000000000$

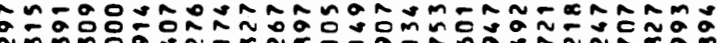

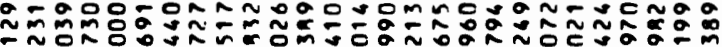

テ

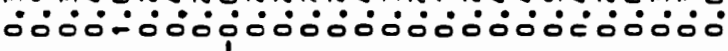

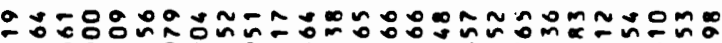

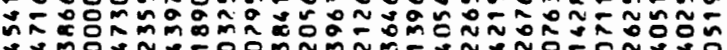

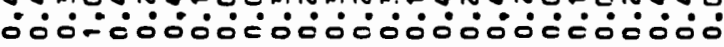

- ming

ก

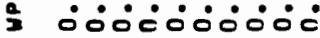

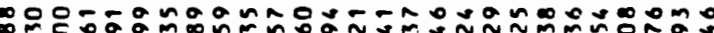

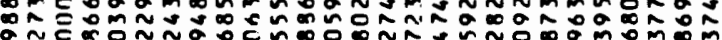

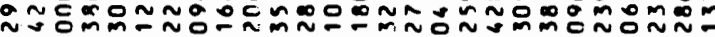

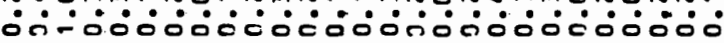

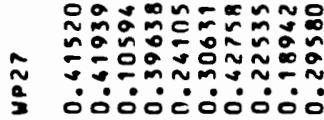

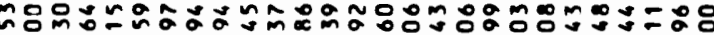

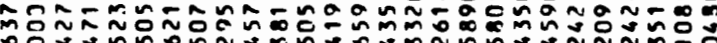

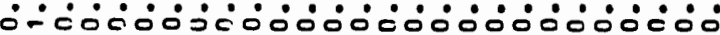

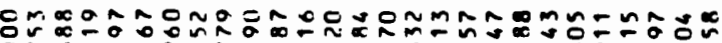

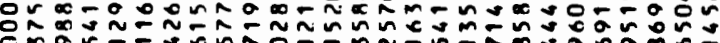

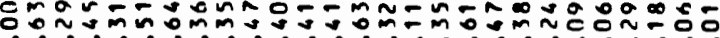

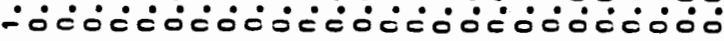

$\approx$ 出

a 0000000000

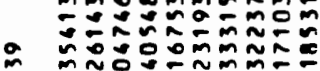

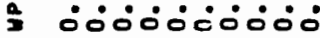

$\hat{m}$-Mñ

-

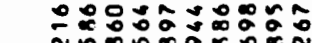

ก

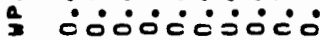

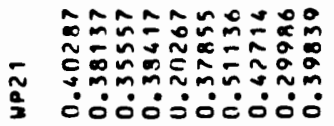




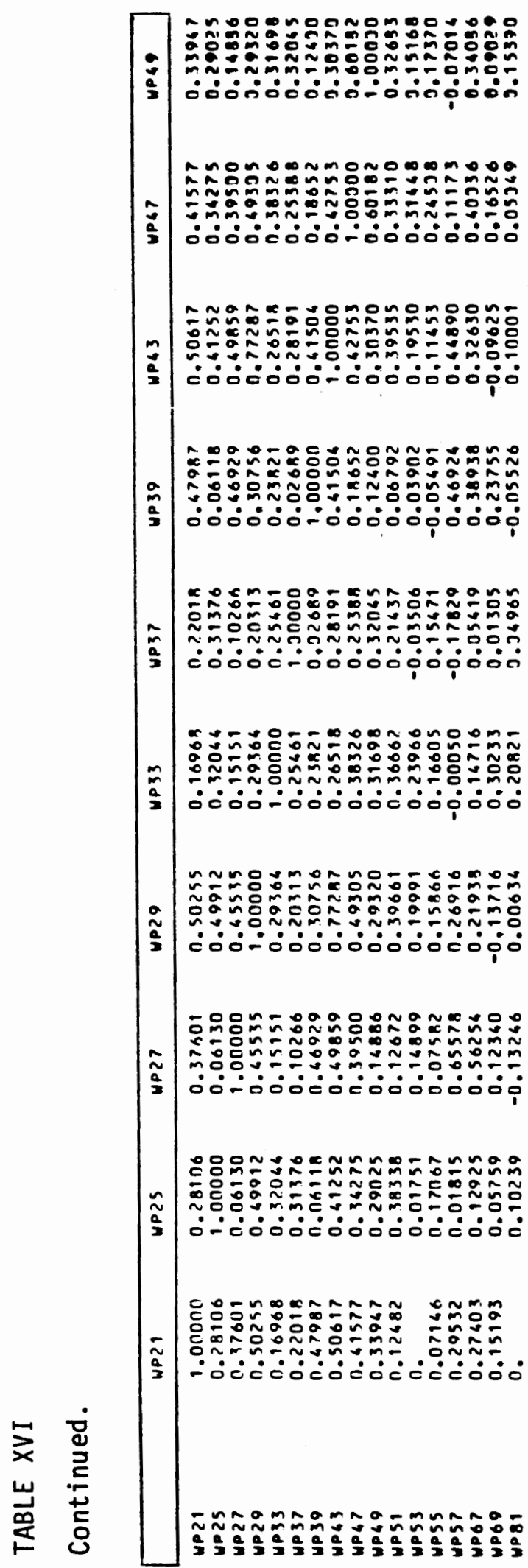

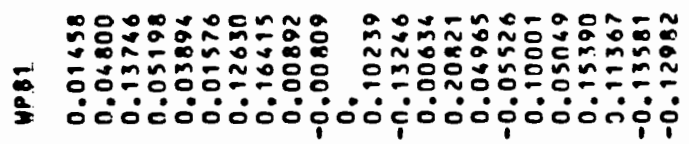

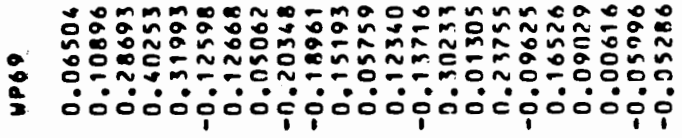

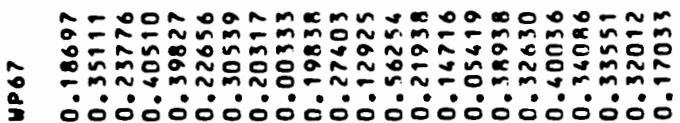

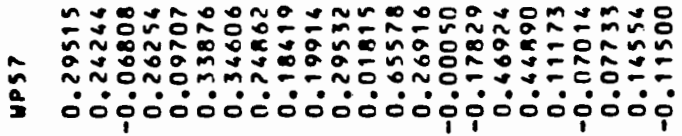

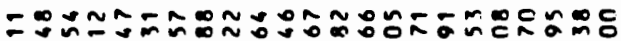

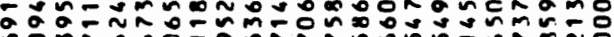

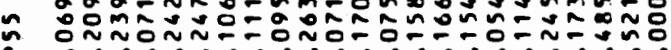

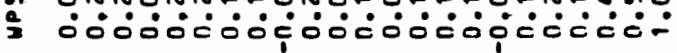

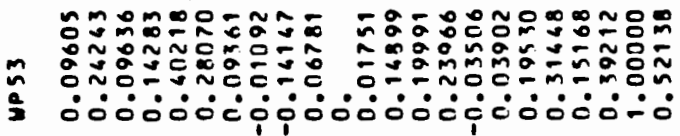

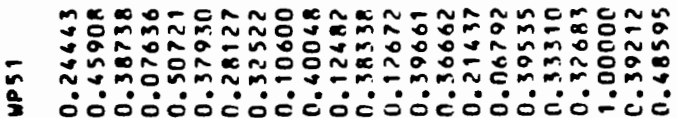

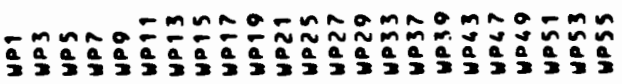




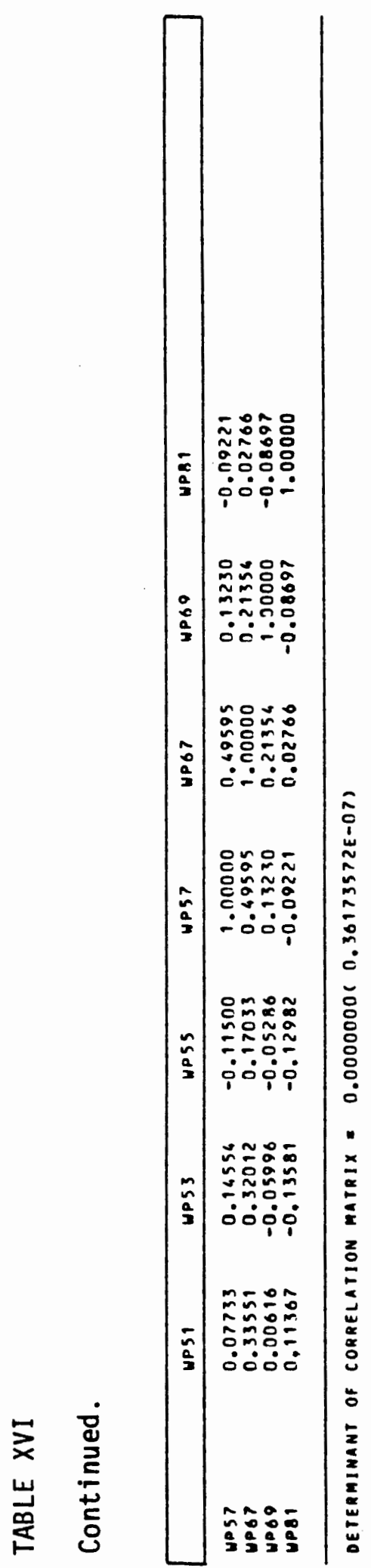




章

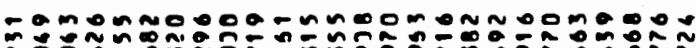

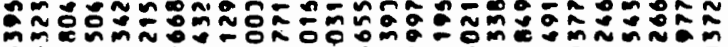

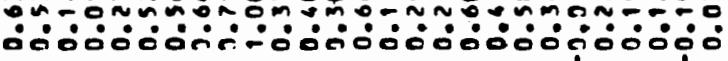

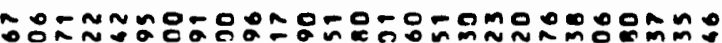

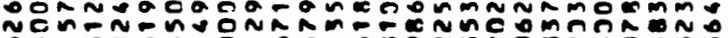

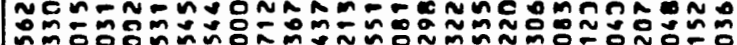

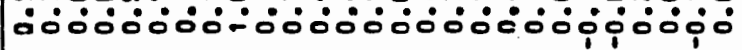

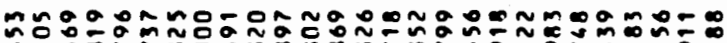

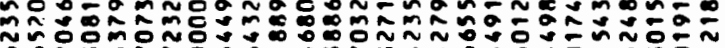
Gm.

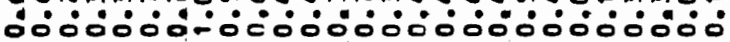

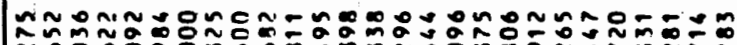

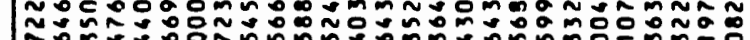

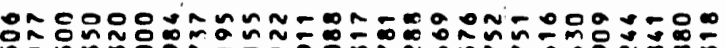

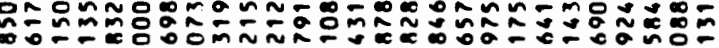

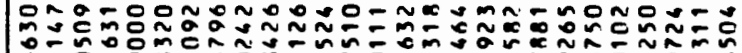

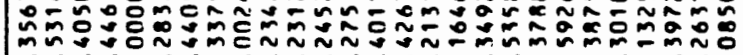

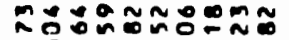

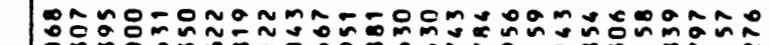

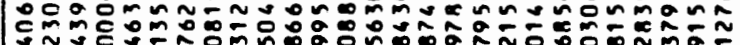
幺-ón

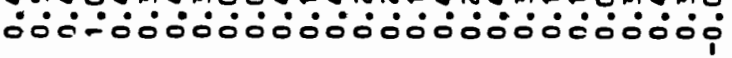

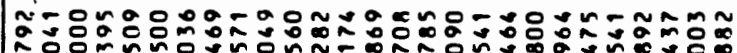

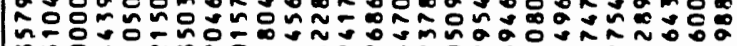

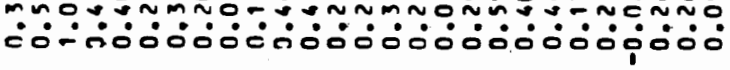

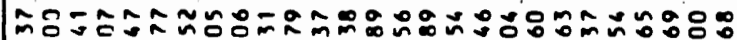

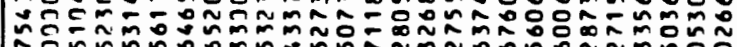
¿-00000ं00000000000000

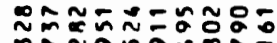

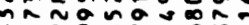

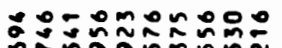

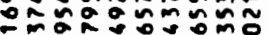

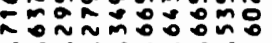

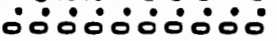

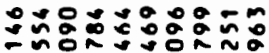

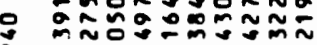

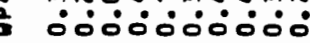

in

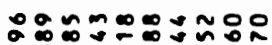

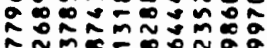
ก

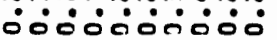

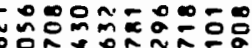

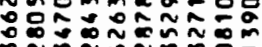

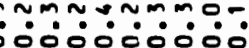

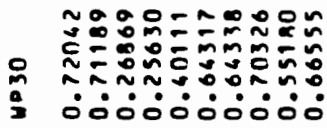

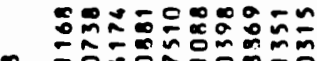

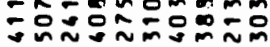

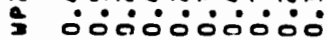

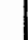

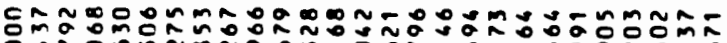

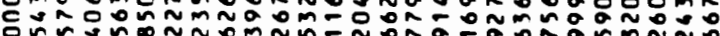




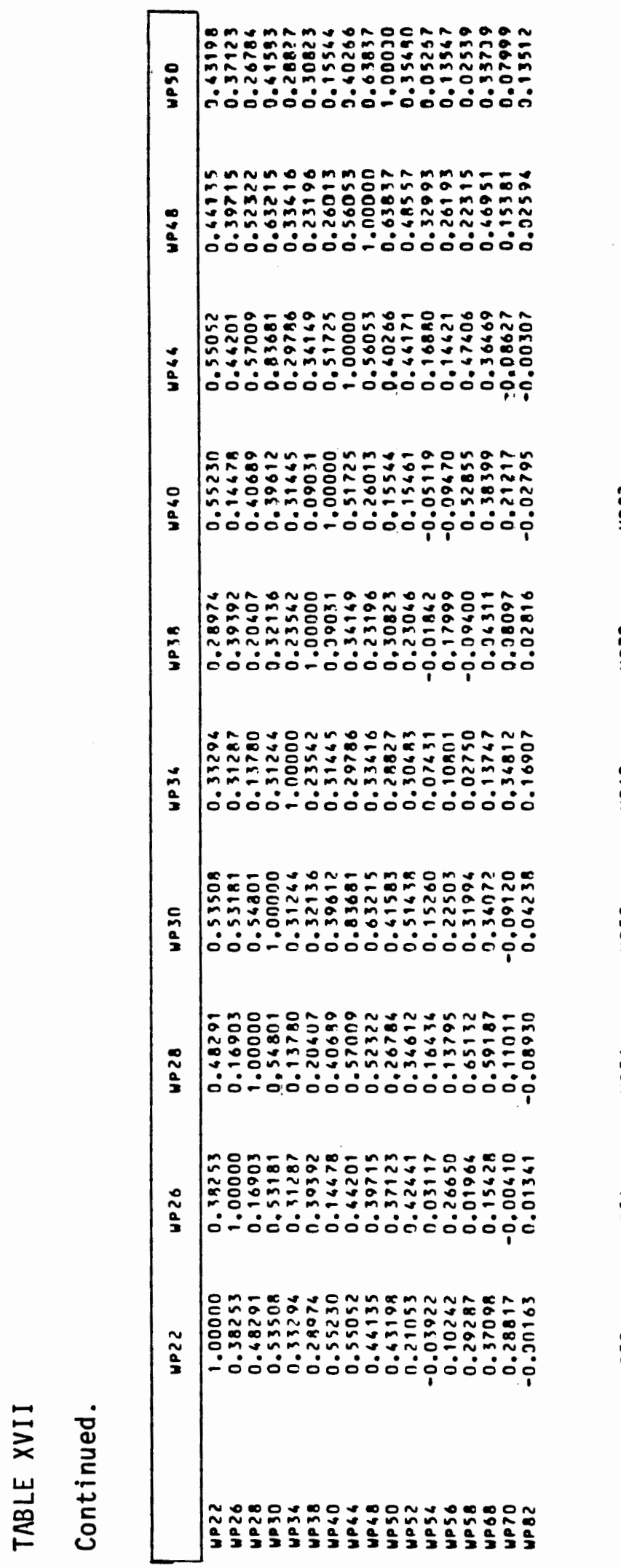

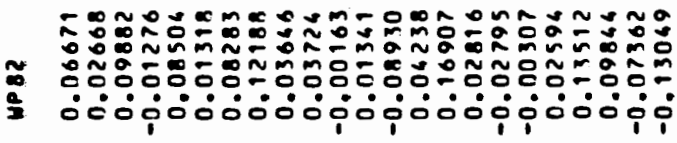

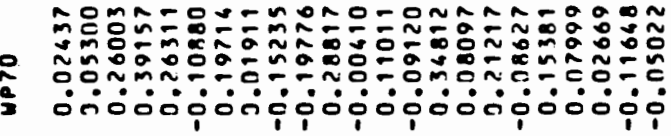

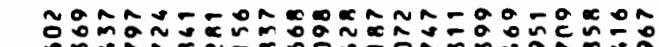

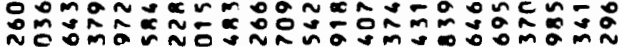
- nñ

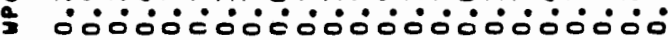

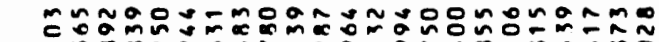

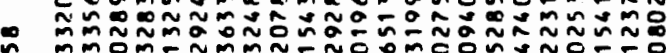

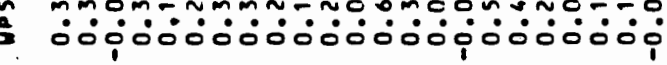

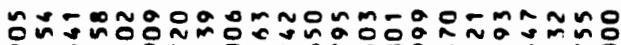

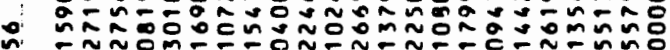
I O0000000000000000-

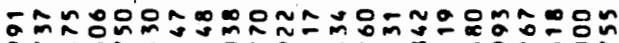

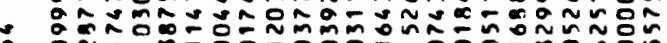

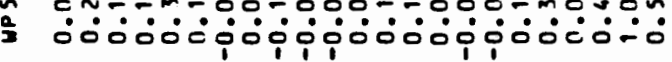

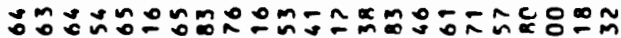

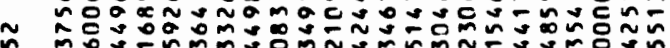

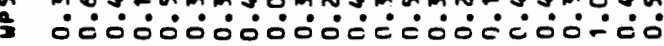




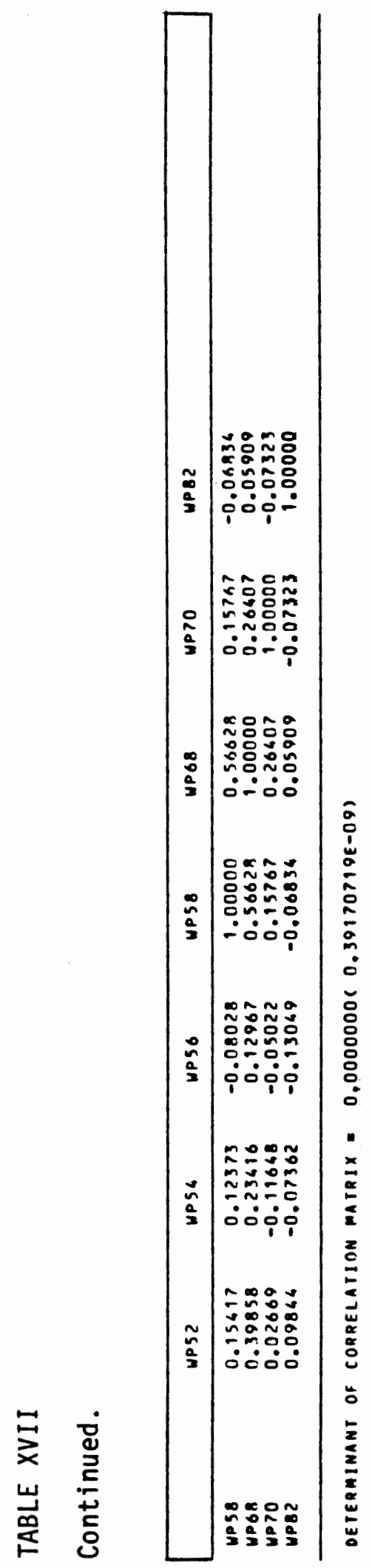




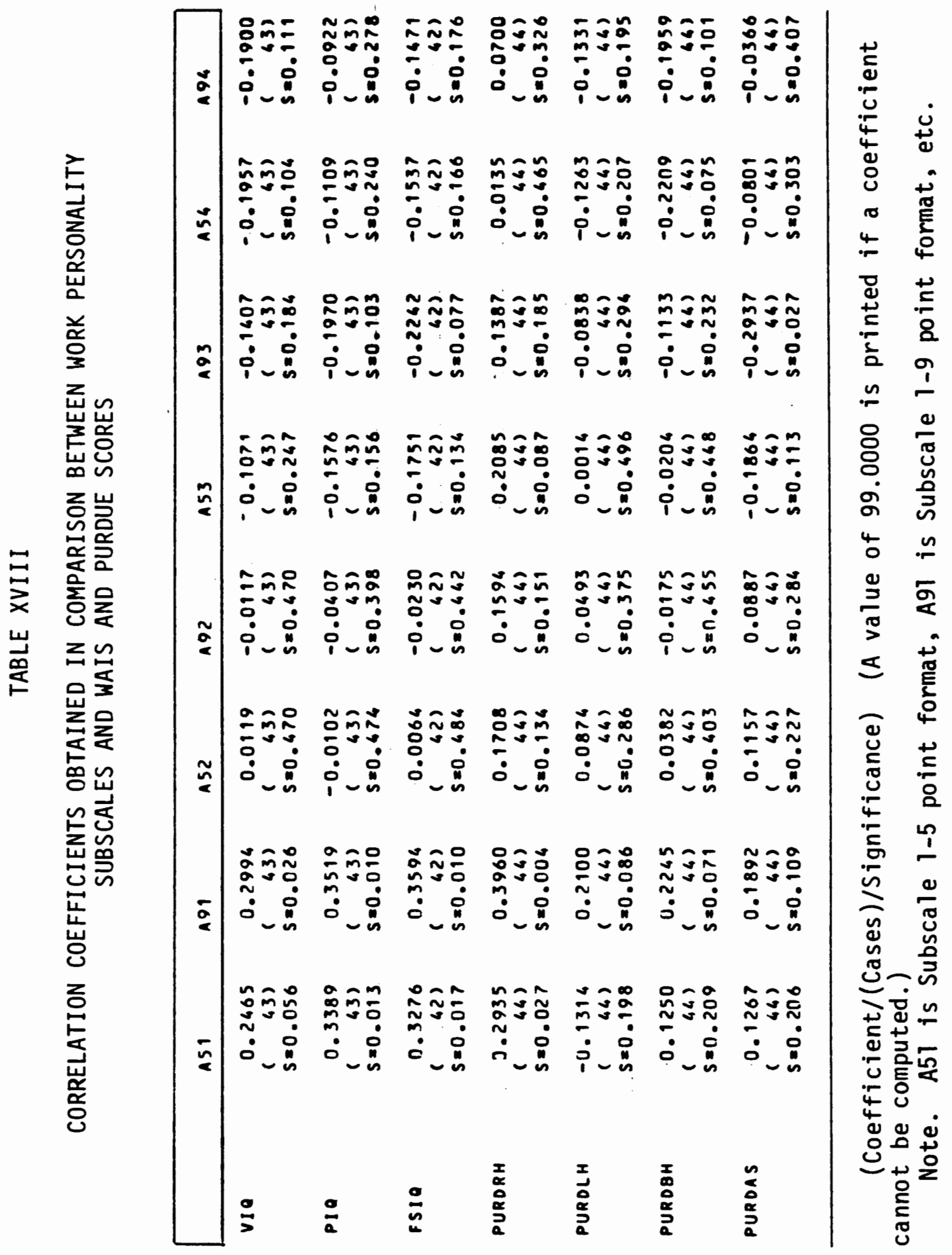

